\title{
A New Approach to Conservation: A Critical Analysis of DOC's Commercial Partnership Strategy
}

\author{
Ben Stantiall
}

A 120 point thesis submitted to Victoria University of Wellington in partial fulfilment of requirements for the degree of

Master of Environmental Studies

School of Geography, Environment and Earth Sciences

Victoria University of Wellington

March 2017 


\section{Abstract}

The complex range of challenges facing the environment has prompted the conservation movement to evolve and incorporate new concepts, attitudes and strategies. A prominent approach that has attracted scholarly attention is the appeal for broader societal involvement and an increased human-focus for the conservation movement. This new approach is particularly notable for the inclusion of private business in conservation strategies. Subsequently, these strategies have prompted criticism of their links to neoliberal ideology and the encouragement of consumption-based measures.

Conservation in Aotearoa New Zealand has followed this strategy of business involvement, represented by the Department of Conservation's (DOC) commercial partnerships. The deliberate use of large businesses is used to access external resources and expertise alongside exposure to their respective customer bases. However, the criticisms of neoliberal ideology, matched by the national significance of the conservation estate and its relationship with the New Zealand public has created numerous challenges and considerations for DOC to navigate.

To acknowledge the different attitudes and relationships that people have to the environment and conservation, a constructivist approach was used to examine the implementation of DOC's partnership strategy. A case study consisting of seven interviews with representatives from DOC, environmental NGOs and the businesses involved in the partnerships was carried out. The data revealed three central themes; initially, of the need for a wider approach to conservation, followed by the intrusion and influence of neoliberal ideology into the domain, and the presentation of win-win strategies. This research provides a critical analysis of DOC's recent shift in strategy and the implications of it on future strategies. 


\section{Acknowledgements}

This thesis was completed with the assistance of numerous people giving up their precious time, providing support, guidance, and a helping hand along the way.

I would first like to convey my thanks and gratitude to the School of Geography, Environment and Earth Sciences, the Professors, lecturers and staff members who helped make this thesis happen. I would also like to sincerely thank Dr. Marcela Palomino-Schalscha for the support in completing the requirements to undertake this thesis.

I would like to also thank those fellow Masters students with whom I shared the experience for creating a positive and supporting environment to work in for those undertaking similar research.

I am incredibly grateful to the people who willingly participated in the interviews and those that gave their time to help organise the interviews. In particular, Carole Lillico, Christine Officer, and Geoff Ensor who continued to give up their precious time along the way. Furthermore, the interview participant's dedication and enthusiasm to the topic area was an inspiration and provided ongoing motivation throughout the research process.

I must express my deep gratitude to my family and friends for providing me with continuous support and encouragement throughout my tertiary education, both for this thesis, as well as my previous years of study that led me here. In particular, I need to thank my parents and my partner, Alexandra, who has patiently put up with me throughout this thesis. This accomplishment would not have been possible without them.

I would finally like to thank my supervisor, Dr. Amanda Thomas, without whom, this thesis would not have been completed, let alone to the standard it is. I am very grateful for the continued guidance, support and patience, as well as, I'm sure, the seemingly endless hours of reading my work. Thank you. 


\section{Table of Contents}

Abstract

Acknowledgements

Table of Contents

v

Abbreviations

vii

Chapter One - Introduction

1.1 Introduction to the topic area

1.2 Research objective:

1.3 Research questions and overview:

1.3.1 Overview of the thesis structure

1.3.2 Summary of findings

Chapter Two - Introducing conservation

2.1 Conservation trends and historical influences

2.1.1 The origins of the conservation movement

2.2 Conservation trends

2.2.1 Protected areas

2.2.2 Community Based Conservation

2.2.3 Market oriented strategies

2.2.4 The outcomes of a changing focus for conservation 16

2.3 Chapter summary

Chapter Three - Methodology

$\begin{array}{ll}3.1 \text { Introduction } & 20\end{array}$

3.1.1 Constructivist epistemology 20

3.1.2 Poststructuralism 22

3.1.3 Discourse $\quad 23$

3.1.4 Positionality 25

3.2 Research Methods $\quad 28$

3.2.1 Grounded Theory 28

3.2.2 Case Study $\quad 29$

3.2.3 Interview Methods 30

3.2.4 Document Review $\quad 32$

3.2.5 Transcription and Coding 34

3.2.6 Analysis 35

3.2.7 Considered risks for interviewing 36

$\begin{array}{ll}3.3 \text { Chapter summary } & 37\end{array}$

vii 
4.1 Introduction 38

4.1.1 Conservation is failing 38

4.1.2 How failure is presented and the implications of it 40

4.2 Broadening conservation in Aotearoa New Zealand 42

4.2.1 Introducing partnerships in Aotearoa New Zealand conservation 44

4.2.2 Mirroring a wider approach $\quad 50$

4.3 The changing place of business involvement in conservation partnerships 51

4.3.1 The careful balancing act of conservation and business involvement 53

4.3.2 Additional challenges of pursuing business involvement in conservation 55

4.3.3 Changing power relationships within the conservation domain 56

$\begin{array}{ll}\text { 4.4 Chapter summary } & 57\end{array}$

Chapter Five - How conservation, neoliberalism and partnerships fit together in Aotearoa New Zealand $\quad 59$

5.1 Introduction $\quad 59$

5.1.1 Neoliberalism $\quad 59$

5.1.2 Neoliberalism as a process $\quad 62$

5.1.3 Neoliberal conservation $\quad 63$

5.1.4 Neoliberalism and the emergence of partnerships 65

5.2 Neoliberalism's link with partnerships and conservation in Aotearoa New Zealand 67

5.3 Commodification, commercialisation, marketisation and privatisation 69

5.3.1 Commodification 69

5.3.2 Commercialisation $\quad 72$

$\begin{array}{ll}\text { 5.3.3 Marketisation } & 75\end{array}$

$\begin{array}{ll}\text { 5.3.4 Privatisation } & 76\end{array}$

5.4 The future of neoliberal ideology and conservation 77

5.5 Contradictions of neoliberal conservation 78

5.6 Chapter summary 83

Chapter Six - Presentations and perceptions $\quad 84$

6.1 Introduction $\quad 84$

6.2 Win-win strategies $\quad 84$

6.2.1 Win-win strategies in the commercial partnerships 87

6.2.2 How success is found and promoted $\quad 89$

6.3 Selling conservation to business $\quad 91$

6.4 Contradictions of win-win and consumption-based strategies 92

$\begin{array}{ll}\text { 6.4.1 Perceptions of greenwashing } & 94\end{array}$ 
Chapter Seven - Conclusion, limitations and further research 97

7.1 Conclusion of Findings

7.2 Limitations of the research

7.3 Further Research

7.4 Summary

Reference List

102

Appendices

116

Appendix 1 - Ethic's Forms

116

Human Ethic's Approval Form

119

Appendix 2 - Question schedule

120 


\section{Abbreviations}

DOC - Department of Conservation

PA - Protected Areas

CBC - Community Based Conservation

NGO - Non-Governmental Organisation 


\section{Chapter One - Introduction}

\subsection{Introduction to the topic area}

This research has been inspired by the recent discussions and debate around the future of conservation in Aotearoa New Zealand. Most notably is the public presence of businesses working with the Department of Conservation (DOC) ${ }^{1}$ Referred to as 'partnerships', these relationships have grown out of DOC's ambition of increasing external collaboration. However, this strategy has produced strong criticisms, in part, based on perceptions that the commercial partnerships model represents an extension of neoliberalism. Neoliberal conservation has become an increasingly pervasive response to the perceived failure of both protected areas and community based decision making. This research demonstrates that the attributes of neoliberalism, specifically, the increase of competition, commercialisation and commodification, are becoming apparent in Aotearoa New Zealand conservation.

Despite a large range of literature that explores neoliberalism in Aotearoa New Zealand, there is little research into neoliberalism in relation to the country's conservation domain. Furthermore, there is also limited research into relationship directly between a government department and business for the restorative benefit of environmental conservation. To contribute to this gap in the literature, this research will explore the proposal of broadening the social priority of conservation through the involvement of business, which consequently, produces strong connections to neoliberalism. How neoliberalism is represented in Aotearoa New Zealand conservation is demonstrated through a case study of DOC's commercial partnerships, which highlights the use of a win-win strategy. The implications of this strategy are that it could have significant outcomes for how future conservation is carried out and how it is positioned in society.

The responsibility of environmental conservation is tasked to the Department of Conservation, formed in 1987 under the Conservation Act (1987). The

\footnotetext{
1 This thesis will also refer to the Department of Conservation as 'the Department'.
} 
Conservation Act requires DOC to protect natural and historic heritage, while providing the opportunity for recreation on land under its management (DOC, 2007). However, DOC recognise that the Department's role is much more than exclusively providing protection to environmental and historic sites. As summarised by their Outcome statement, DOC's vision is to ensure:

New Zealanders gain environmental, social and economic benefits from healthy functioning ecosystems, from recreational opportunities, and from living our history. (DOC, 2016a, p. 13)

The main form of conservation protection has come through the establishment of protected areas. While the country's 13 National Parks attract a significant amount of public attention, there is also over 10,000 other areas around New Zealand under different levels of protection. This enshrines over a third of the country's land mass under DOC's management. The establishment of such protected areas represents strong colonial legacies of the separation of nature and people (Coombes \& Hill, 2005). However, the perceived failure of this traditional approach has promoted DOC to find new ways to achieve conservation success and support its funding demands. This has seen DOC align with the dominant global conservation discourses of encouraging private business involvement. Recent approaches, such as Comanagement (Coombes \& Hill, 2005) and partnerships, have been employed to increase external collaboration sought by the Department.

With a focus on DOC's commercial partnerships, this strategy sees business contributing to funding and resources to conservation while enabling greater access to the public and to other businesses for the promotion of conservation. Correspondingly, the partnerships enable businesses to generate leverage by aligning with DOC's brand and conservation. It is important to differentiate here between business or commercial partnerships, and the relationships DOC has with iwi, hapū and community groups (DOC, 2017). DOC is often involved in Treaty of Waitangi settlement processes, which reflects, in part, the role that conservation discourses have played in colonisation in Aotearoa New Zealand (see for example Coombes \& Hill, 2006). Similarly, the relationships with community also represent a significant part of the DOC's work. However, 
examining the discourses and logics that underpin iwi, hapū and community relationships with DOC is beyond the scope of this thesis

\subsection{Research objective:}

The overarching research objective of this thesis is to understand how the involvement of private business is influencing conservation efforts in Aotearoa New Zealand.

A case study approach focused on how DOC's commercial partnerships are the production of, and subsequently influence, conservation policy and the implementation of new conservation initiatives in Aotearoa New Zealand. The following sub questions were used to guide the case study and analysis:

\subsection{Research questions and overview:}

- Why has DOC sought to increase private business involvement with conservation?

- How has DOC encouraged private business to become involved in conservation?

- How does the involvement of private business affect the public's relationship with conservation?

- What are the risks involved with increasing private business involvement in conservation?

\subsubsection{Overview of the thesis structure}

Chapter Two reviews literature examining the current trends and historical influences that have shaped the global conservation movement. The chapter highlights the promises and critiques of both protected areas and community based conservation, before discussing the alternatives that have emerged. Chapter Three discusses the methodology used and outlines the use of a case study that underpins this research. Chapter Four presents the first theme 
identified in the data which is the notion that conservation is failing, with the answer proposed to include more, and broader range, of people. The response to these narratives in Aotearoa New Zealand has been the development of partnerships with business. Chapter Five addresses the relationship between neoliberalism and the use of partnerships in Aotearoa New Zealand. In addition, the chapter will discuss neoliberalism and conservation in Aotearoa New Zealand more generally. Chapter Six examines win-win discourses, namely the idea that everyone benefits from increased business involvement in conservation. This thesis will draw on critical political ecology literature to explore some of the contradictions produced by the neoliberalisation of conservation.

\subsubsection{Summary of findings}

The premise for this thesis is established on the limited amount of literature focusing on neoliberal conservation in Aotearoa New Zealand. Furthermore, there is little scholarly attention on the relationships that government departments have with business for the specific intention of conservation benefits. However, contemporary conservation research shows a shift away from traditional approaches in the understanding that conservation is failing to fulfil its intention of environmental protection. This leads to the first theme revealed in the data: this failure has provided the justification for a broadening the appeal of conservation to society is in the form of business involvement, and specifically, in the form of DOC's commercial partnerships. Within these partnerships, DOC is expecting to realise restorative gains, moving past more common intentions of sustainability.

The second theme this research identifies is the process of neoliberalism within the commercial partnership strategy, and consequently, the wider conservation domain. Responses from the interview participants suggest this could produce significant consequences for other conservation organisations with an increase of competition with DOC for support from businesses. The neoliberal attribute of commercialisation is found through the language used in respect to 
conservation, as well as how DOC intend to cultivate stronger business acumen. The process of commodification is demonstrated by the use of representations to mediate human interaction with the environment. These representations are able to shift the position of humans and business in conservation. In doing so, these representations indicate that these strategies are able to transcend neoliberal contradictions.

Third, this research demonstrates that to navigate the undesirable parts of neoliberalism, the commercial partnerships are promoted as a win-win strategy. This presents the pursuit of conservation goals and economic development as being able to be simultaneously achieved. The deliberate use of success stories show that the two domains are compatible, while additionally incentivising involvement in the commercial partnerships. The main risk revealed in the case study is how the new approach is perceived by the public, specifically, concerns of greenwashing and through supplementing DOC's budget. However, the research will illustrate that these concerns are not held by all participants. 


\section{Chapter Two - Introducing conservation}

\subsection{Conservation trends and historical influences}

To identify what influences have helped shape environmental conservation, this chapter will outline prominent background contexts, actors and practices of how the movement has developed. This chapter will then address some of the main trends that have dominated the conservation movement, specifically stateled protected areas, and community based conservation which looked to replace people in conservation. Furthermore, this chapter examines where conservation is heading and some of the main contemporary pressures directing it.

\subsubsection{The origins of the conservation movement}

Conservation is often portrayed as a universal movement, united in strategy, values, attitudes and practices. However, as Brockington, Duffy and Igoe (2008) argue, the use of the term 'conservation' actually generalises and simplifies an incredibly vast range of individuals, groups and organisations involved and working in the discipline. Furthermore, the specific features and environmental outcomes that individuals and groups target are incredibly diverse (Brockington et al., 2008; Büscher, 2016; Stolton \& Dudley, 2010). However, the work of Adams (2015), Brockington et al. (2008) and Willems-Braun (1997) shows that despite generalising a wide range of participants, the term 'conservation' typically reflects a dominant Western paradigm retaining strong ties to colonial legacies and conservation's scientific foundations.

The Western paradigm is entrenched by persistent colonial power relations that work to subordinate both the environment and Indigenous people (WillemsBraun, 1997). Consequently, conservation initiatives have come at a huge cost for local Indigenous communities who have frequently been evicted from their lands and had their customary activities restricted (Colchester, 2004; Fletcher, 2012). Supporting this, Adams (2015) highlights that many colonial territories intensely extracted and exploited the local natural resources. Adams (2015) 
states that it wasn't until the scientific community called for increased environmental considerations that Western establishments were compelled to take action. As Willems-Braun (1997) states, this binary between early environmentalists attempting to resist the pressures from expanding industries still dominates conservation arguments today.

Building on the colonial foundations, early American conservation approaches in the late $19^{\text {th }}$ Century used collaborative and network building approaches to gain support. Brockington et al. (2008) illustrate that the American approaches were notable for employing social elites and corporate sponsorship to generate legitimacy and funding for their conservation projects. These strategies remained firmly entrenched in the movement and have carried through into contemporary global conservation institutions and practices (Brockington et al., 2008). Brockington et al. (2008) refer to this dominant Western paradigm towards conservation as 'mainstream conservation' where large international conservation organisations demonstrate central ideas, values and practices. This collaboration and networking model has also produced the enduring position of business involvement in conservation projects. This has led to the participation and engagement of philanthropists, political figures, private enterprises and investment (Brockington et al., 2008: Jones, 2012). As a result, the assistance of influential and authoritative actors has helped cement the foundation of this approach in society.

The scientific foundations of the conservation movement are still exceedingly prevalent in contemporary approaches (Western, 2000). However, the scientific approaches are now becoming supplemented or replaced by other discourses. For example, conservation is now regularly referred to as a humanitarian issue (see Adams, 2015) or a moral necessity for local communities (see Kirby, 2014). Other arguments focus on economic prospects as outlined by Brockington et al. (2008), the importance for personal well-being and ongoing human prosperity (see Adams, 2015; Stolton, 2010) or simply a fundamental requirement to stop species extinction and continued environmental degradation (see Likens \& Lindenmayer, 2012; Stolton \& Dudley, 2010). Despite the range of strategies and justifications used, scholars such as Brockington et al. (2008), Craig et al. (2000) 
and Freyfogle (2006) assert that modern conservation strategies have consistently failed to achieve targeted conservation outcomes and have also produced negative social consequences. Alongside the continued deterioration of the environment, there are concerns around the displacement and restriction of access for people to conservation areas and increased political/cultural division of urban and rural citizens (Brockington et al., 2008). Additionally, Fletcher (2012) states that projects attempting to simultaneously achieve conservation and development regularly fall short of their targets. This has required the conservation movement to regularly evolve its approaches and attitudes in an ongoing effort to balance environmental conservation with an increasing array of other considerations.

\subsection{Conservation trends}

The debate surrounding conservation models has historically focused on two dominant strategies: state-led protected areas, and community based conservation. However, the recent emergence of economically-based models signals another turn within conservation trends. To summarise the transitions of approaches, the following sections will provide an outline of the two dominant approaches and how they have stimulated new ways of carrying out conservation. From there, the new shifts in conservation attitudes and approaches will be examined.

\subsubsection{Protected areas}

When Western conservation emerged in the late 1800s, protected areas (PA) were the dominant method and discourse for protecting landscapes and biodiversity (Western, 2000). The leading motivation for this protection was the threat from human encroachments and interference (Brockington et al., 2008). Subsequently, as Dudley (2010) stresses, PAs were intended to establish a benchmark of how the environment or particular species would exist without human interference, providing an important standard for how exemplary environments should function. The pinnacle of the state-led protectionist 
strategy is the National Park structure implemented by states attempting to gain the highest level of environmental preservation (Brockington et al., 2008; McIntyre et al., 2001). The foundations of these protectionist approaches involve the restriction of access or activities in designated areas, the idea that humans are only temporarily allowed in the environment, and the humans and the environment need to be separated (Büscher, 2016; Büscher, Dressler, \& Fletcher, 2014; McIntyre et al., 2001). Contemporary developments with these approaches have seen boundaries of these areas controlled by legislation and force, leading to the term 'fortress conservation' used regularly by scholars (see Büscher, 2016; Hartter \& Goldman 2011; Brockington et al., 2008). However, as Brockington et al. (2008) and Dudley (2010) point out, not all PAs are expected to create pristine environmental scenarios void of human presence. Depending on the species and habitat, available land, resources or political willingness, the areas assigned vary remarkably in strategy, size and human interaction. Furthermore, areas established with particular guiding principles have regularly evolved to meet wider social, political and environmental demands (Brockington et al., 2008). These factors illustrate that PAs are regularly subjected to contextual influences and do not follow a uniform, one-size-fits-all model.

The proliferation of PAs around the world has been followed by associated academic research and critiques, focusing particularly on the broader impacts that have occurred (see Brockington et al., 2008; Colchester, 2004; Hartter \& Goldman 2011; Stolton \& Dudley, 2010). Literature about PAs has shown that this model has created a wide range of positive and negative impacts, which Hartter and Goldman (2011) attribute to the different types of PAs implemented and access to downstream benefits. Influencing factors include the reliance on agriculture or proximity to PAs (Hartter \& Goldman, 2011). As a consequence, individual and community attitudes are influenced according to the level and type of conservation experiences they have been exposed to. In addition, community attitudes are also influenced by the outcomes they have experienced when compared to what they perceived or were told would materialise from a particular project (Hartter \& Goldman 2011). As Butler and Richardson (2015) and Chaigneau and Brown (2016) explain, PAs are often proposed as win-win 
strategies, achieving both environment protection and generating economic benefits for local communities simultaneously. Chaigneau and Brown (2016) highlight that this win-win proposition has become the dominant discourse for PAs due to the relative simplicity of design and implementation demands. This is in addition to the underlying, and frequently promoted, assumptions that can appeal to large parts of the community. For example, a project's implementers will promote that the benefits generated by a PA will be equally distributed throughout the community in an attempt to gain the widest support (Chaigneau \& Brown, 2016). Although these win-win strategies retain strong marketability, Chaigneau and Brown (2016) challenge whether the expected outcomes eventuate in reality. Büscher (2014) supports this question by stating the benefits that occur are often loudly promoted to conceal the negative consequences, which distorts the true impacts of protected areas.

Other prominent criticisms of PAs are centered on the marginalisation, eviction and ongoing exclusion of local communities who live within the designated area or on land surrounding it. Justified by the need for environmental protection and to reduce human interference, many of the affected communities have regularly been expelled from ancestral lands or been subject to heavy restrictions as to what activities they are allowed to carry out (Agrawal \& Gibson, 1999; Colchester, 2004; Humavindu \& Stage, 2015). Exclusionary tactics are typically validated through the discourse that conservation and communities are mutually exclusive (Coombes \& Hill, 2005). Neomalthusians and those who subscribe to the "tragedy of the commons" have argued that with increasing populations, the harvesting of local resources will evolve into overuse and exploitation, therefore requiring strict controls around resource access and use in order to maintain the resource (Hodgson \& Watkins, 1997). As Agrawal and Gibson (1999) explain, communities require resources for heating, eating and drinking, maintaining their homes and other daily necessities. This argument is strengthened by persuasive research (see Meffe, Ehrlich, \& Ehrenfeld, 1993; Myers, 1990) showing rural populations in some areas around PAs have grown drastically, raising the fear of elevated and widespread resource exploitation within PAs - legally or otherwise - as communities try to support themselves (Agrawal \& Gibson, 1999). Despite the significant costs 
experienced by local communities excluded from lands and resources, the spread of PAs and National Parks have propagated around the world with widespread support (Agrawal \& Gibson, 1999).

There is a growing acknowledgement from academics, NGOs, donors and conservation organisations that human-free environments are not historically representative, accurate or achievable (Berkes, 2004; Coombes \& Hill, 2005; Western, 2000). Furthermore, the human-free conservation strategy is based on a Western worldview that is underpinned by a separation of nature and society. These conservation strategies actively exclude those societies that don't have a binaried view of the world (Agrawal \& Gibson, 1999; Berkes, 2004). This recognition is part of a holistic change shifting the position of communities towards becoming a main contributor for achieving conservation outcomes (Agrawal \& Gibson, 1999). There are also further criticisms that PAs have actually led to unintended negative impacts for local ecosystems and environments in many instances (Brechin, Murray, \& Mogelgaard, 2010; Brockington et al., 2008). For example, Brechin et al. (2010) highlight that in some instances, environmental degradation has increased in the surrounding area following the creation of PA. This ironically undermines the original purpose of such efforts and creates further incentive to try different approaches (Hartter \& Goldman, 2011; Mulrennan, Mark, \& Scott, 2012). In the late 1980s in particular, this dissatisfaction led to the rise of more participatory, inclusive conservation initiatives that promoted local knowledge and claimed to be more responsive to nature/society challenges (Brockington et al., 2008).

\subsubsection{Community Based Conservation}

Responding to the growing pressure from NGOs and social movements for more socially-just and participatory systems, the community based conservation (CBC) model became a popular alternative to the state-led protectionist approach (Robinson \& Makupa, 2015; Mulrennan et al., 2012). As previously highlighted by Agrawal and Gibson, (1999), Colchester (2004), and Humavindu and Stage (2015), local communities can often experience the biggest cost from 
the implementation of protected areas. As a replacement, CBC models were promoted as a democratic way of simultaneously generating conservation outcomes and social assistance for local communities (Mulrennan et al., 2012). For instance, global initiatives referred to as "indigenous and community conserved areas" are intended to provide conservation and recreation activities aimed at managing conservation areas for the direct benefit of local communities and the wider society (Robinson \& Makupa, 2015, p. 1215). Importantly, proponents of CBC claim the approach leads to a stronger input and decision making from the community alongside more appropriate resource use management structures that fit the local community needs (Mulrennan et al., 2012). These characteristics were seen as essential attributes to move away from the exclusionary model with frequently associated with protected areas.

Complementing the perceived democratic attributes, CBC projects were also promoted as breaking down wide-spread negative attitudes held by communities towards wildlife resulting from clashes with farming livestock and confrontations with communities themselves. In an attempt to change these attitudes, CBC projects have sought to generate social and economic benefits from tourism and encouraging the preservation and importance of local wildlife populations (Berkes, 2004). Berkes (2004) argues that this supports the narrative that the relationship between humans and the environment should no longer be seen as separate or unconnected. Furthermore, CBC moves past positioning humans as environmental controllers or managers, or even as the main source of environment degradation (Berkes, 2004). Rather, CBC attempts to re-established the diminished connections between humans and the environment. This is matched by the need for larger areas that wildlife could use, specifically in the land surrounding PAs to account for the natural species movements (Büscher, 2014; 2016). Berkes (2004) adds that this was envisioned through the use of networks of communities surrounding PAs to create larger conservancies to create biodiversity corridors and enhanced species resiliency in the face of fragmented habitats. The strengthening of community connections with local wildlife is intended to then, it is hoped, lead to economic development opportunities, which will provide added motivation for further protection and conservation (Berkes, 2004; Humavindu \& Stage, 2015). 
Despite the positive social and environmental outcomes CBC projects aim to produce, four weaknesses have been identified (see Humavindu \& Stage, 2015; Mulrennan et al., 2012; Agrawal \& Gibson, 1999). First, the idea of a homogenous 'community' with shared norms and predictable structure is challenged. Romanticised assumptions about homogenous, bounded communities ignores the diversity of people, their needs and desires, as well the often-fluid nature of community and belonging (Agrawal \& Gibson, 1999; Mulrennan et al., 2012). The second weakness identified is the broad use of the term 'community based conservation'. Contradictory to the term, $\mathrm{CBC}$ projects are often created, implemented and assessed by external experts, which can undermine the originally anticipated principles of community empowerment and social justice (Mulrennan et al., 2012). This is compounded by the third critique of $\mathrm{CBC}$ whereby projects are outcome rather than process driven. This reduces the importance of the process involving communities in conservation decisions and ongoing management which can relegate the 'community' element to a secondary consideration in favour of conservation priorities (Mulrennan et al., 2012). The fourth weakness of CBC, highlighted by Humavindu and Stage (2015) and Mulrennan et al. (2012), shows that despite the importance given to the participation of local communities, little involvement is actually realised. Mulrennan et al. (2012) argues that many projects fail to involve local communities in decision making processes, which consequently has done little to challenge the power inequalities between donors, experts, conservation proponents, and communities that plague protected area approaches.

The consequences of the shortcomings of CBC projects and lack of success has resulted in appeals by conservation biologists for a shift back to top-down protectionist approaches (Fletcher, 2012; Mulrennan et al., 2012). However, what the mixed fortunes of both PAs and CBC demonstrate is that conservation is characterised by a wide range of challenges and contexts. An important aspect of this is the position of local communities and resources available which consequently means there can be no one-size-fits-all approach to conservation. Into this increasingly complex picture, market oriented conservation strategies have emerged as a third mainstream conservation paradigm. 


\subsubsection{Market oriented strategies}

The after-effect from the critiques of $\mathrm{CBC}$ and PAs is the strengthening of calls from networks of politicians, corporate and conservation leaders for a more capitalist, market-based approaches (Craig, Moller, Norton, Saunders, \& Williams, 2013; Fletcher, 2014; Igoe, Neves, and Brockington, 2010). This is reinforced by the reduction of global conservation funding (Büscher et al., 2014) and the demand for conservation projects with a more devolved structure, as seen in CBC (Fletcher, 2014; Igoe et al., 2010). As a response, conservation has seen the increasing involvement from parts of society that are often considered to be antagonists of, or incompatible with, environmental protection. The involvement of such parts of society has led a selection of scholars to define the new approach as 'new conservation', or 'new conservation science' (Doak, Bakker, Goldstein, \& Hale, 2014: Marvier, 2014; Soulé, 2013). New conservation promotes the inclusion of social development targets and claims that poverty alleviation can be obtained through investment from corporate businesses (Doak et al., 2014). A fundamental argument made by new conservationists is that broadening the numbers of people in different parts of society that can benefit from conservation will help secure the movement's importance in society (Doak et al., 2014). Enabling new actors to become involved with conservation will help enhance the importance of conservation and to extend the priority of it in society.

To increase the importance of conservation in society, the new conservation approach calls for the movement to take a more obvious human-centered focus. This is rationalised by the claim that improving the livelihoods of people, specifically impoverished communities, will see a reduction of their direct impact on the environment and change their attitudes towards conservation (Soulé, 2013). Doak et al. (2014) and Marvier (2014) add that conservation should move past exclusively trying to protect wilderness environments traditionally associated with protected area approaches to conservation and expand away from species diversity objectives. Rather, conservation should also target urban areas and landscapes with more potential to benefit human 
welfare, and thus, more potential for conservation to become a mainstream social consideration (Czech, 2007; Marvier \& Kareiva, 2014).

New conservationists are quick to point out that this approach is not exclusively about replacing traditional value types associated with PAs and $\mathrm{CBC}$, such as intrinsic with economic value, although a stronger emphasis is placed on economic value when appraising conservation. Rather, to broaden its appeal, new conservationists claim that the conservation movement can gain much more traction with public opinion if it positions the advantages for human welfare as a greater incentive (Kirby, 2014; Marvier, 2014; Marvier \& Kareiva, 2014). Lalasz, Kareiva and Marvier (2011) add that conservation will be able to increase its priority in society if people think it's in their own personal best interest. Western (2000) states that this wider appeal and prospective participation would see conservation be able to transcend established attitudes and management approaches towards conservation creating a more holistic conservation paradigm.

As established by Doak et al. (2014) and Marvier and Kareiva (2014), a main tactic of new conservation strategies is to encourage partnerships between traditional conservation approaches and private business. This is reinforced by literature calling for similar relationships in conservation without making specific reference, or identifying it as 'new conservation' (see Western, 2000; Craig et al., 2013). The underpinning assumption of these strategies is that increased economic growth will produce more resources that can be invested in maintaining key biological resources, which then provide the environmental platform for further economic growth (Doak et al., 2014). This allows conservation objectives to be pursued in parallel to social issues. For instance, the inclusion of human rights and poverty alleviation goals alongside recognising the "right of people to develop resources (sustainably) to support their livelihoods" (Miller, Minteer, \& Malan, 2011, p 952). However, Doak et al. (2014) criticises these expectations by stating that proponents of new conservation fail to fully acknowledge the damage to the environment that corporate business has historically has. In addition, contemporary efforts to link business with 'green' outcomes have also been largely unsuccessful (Doak et al., 
2014, p. 79). This raises question around the actual ability to realise conservation goals alongside other economic-based goals.

Marvier and Kareiva (2014) acknowledge that while there are concerns on increasing profit-driven business involvement with conservation, many private companies are already aligning with more sustainable practices on their own accord. Marvier and Kareiva provide the caveat that this is largely driven by the potential of brand recognition and reputation improvements rather than altruistic concerns for the environment. However, this approach is argued to have distinct advantages as new conservation's priority of incorporating businesses can distance itself from being swayed by short term political shifts or impulses (Czech, 2007). It may also access a wider range of customer bases through marketing strategies and normalising the presence of environmental conservation in everyday life (Büscher, 2010).

\subsubsection{The outcomes of a changing focus for conservation}

Discussions and arguments found in conservation literature shows that there are conflicting opinions around the pursuit of this new approach. While proponents confidently claim that a stronger human-centric focus will lead to more conservation gains, there is strong criticism directed toward this approach, encapsulated sharply by Soulé (2013) who states "it does not deserve to be labelled conservation" (p. 895). A key component of this criticism is the general context within 'new conservation' literature, which is based on a global perspective, rather than its application to specific contexts. This approach is the able to work in generalities and highlight examples that support the argument (Soulé, 2013). As highlighted by Tallis and Lubchenco (2014), this broad perspective fails to capture areas of the world where conservation and development have often, or still do, faced-off in opposition to each other. This has also been reproduced in heated exchanges within literature highlighting the stakes that this debate represents (Tallis \& Lubchenco, 2014; see also Kirby, 2014; Marvier \& Kareiva, 2014; Soulé, 2013). 
Demonstrating the conflicts within conservation literature is the foundations for the appeal of conservation taking a more human-focused is that protecting the environment for its own sake is not working. As Soulé (2013) notes, proponents of this new approach to conservation maintain the attitude that traditional biological-focused conservation is "dysfunctional", "antihuman" (p. 895) and out of touch with the realities of everyday people. Marvier and Kareiva (2014) support this sentiment by stating; "intrinsic value is not the only, and may not be the most effective, rationale conservation can offer" (p. 131), and that for conservation to succeed it must broaden its appeal. However, Soulé (2013) contends that many of these assertions are unsubstantiated or inaccurate. Minteer and Miller (2011) add that the many of the claims of the advantages new conservation will provide have not received as much research attention and are often left "unexamined" (p. 946). Doak et al. (2014) goes further by stating that there is very little research that indicates enhancing conservation's emphasis of a human focus will deliver the expected benefits. In reality, the current way in which we, as a global population, manage the natural resources gives the authors little optimism that increasing the human focus of protecting the environment will generate actual conservation gains (Doak et al., 2014).

Doak et al. (2014) and Western (2000) state that new conservation promotes future strategies should measure success on its breadth of society it can reach. To do this, Lalasz et al. (2011) argue that successful new conservation strategies will be relevant to people's welfare, specifically to urban dwellers and the poor. This provokes questions of whether new conservation will ultimately shift the values in which conservation is measured, reducing or removing intrinsic values for those that can appeal to a wider audience (Doak et al., 2014; Soulé, 2013). This supports Doak et al.'s (2014) argument that taking on this new approach towards conservation could mean that the discipline would have to change the ultimate goal of contemporary conservation. This would require an adjustment from protecting ecosystems and halting species loss to saving features of the environment that would benefit humans the most. Kareiva and Marvier (2012) argue that in traditional conservation practices and ideology, the general public are positioned as the threat to the environment, with scientists playing the role 
of the saviour (Kareiva \& Marvier, 2012). This situation, in many areas, has severely restricted human interaction with the environment. Taking this new approach may lead to better access for some groups of society, however, it restricts conservation's objective to narrow human-focus while relegating other motivations to the side lines (Doak et al., 2014). Soulé (2013) questions further what the outcomes would be for current strategies if new conservation approaches become widely implemented. For instance, how would parts of the global environment fit into new conservation strategies which don't provide any immediate benefit for society or individuals?

The other side of the debate argues that conservation already commands a strong human-focus (Doak et al., 2014). For instance, Hawksworth (2008) states that environmental conservation has developed from recognising the importance of maintaining species diversity in order to maintain biological resiliency, variety and natural patterns. It is through this holistic preservation of the environment that conservation provides benefits to human life and welfare (Stolton, 2010). As Buckley (2009) argues, this deliberate production of benefits to human welfare illustrates that conservation is a social construction (see also Miller et al., 2011). This is evident in the ways that conservation is executed, for example; the creation of protected areas, initiatives for mitigating and offset schemes, tax and trade interventions, which all need human involvement to exist (Büscher et al., 2012). These arguments demonstrate the complex goals, considerations, and outcomes that conservation strategies face.

\subsection{Chapter summary}

Environmental conservation originated from concerns about the condition of the environment and its prospects for future generations. Subsequently, this has produced a range of strategies and levels of human involvement. Within these strategies, the original Western scientific foundation remains a dominant influence for what conservation should represent and how it should be carried out. Increasingly, environmental conservation is positioned alongside the pursuit of other objectives, for instance, social development goal. These 
objectives have stimulated debate around increasing the human-focus and of business participation in conservation projects. Conjecture is also apparent on whether 'new conservation' is able to generate net conservation gains at all. Additionally, these strategies have sparked robust debate about what this would mean for conservation and if in fact, such strategies can be considered to be 'conservation' all at. This raises questions that generating a more humanfocused approach to conservation may change the ultimate goal of conservation. Given that new conservation is emerging as an important and influential approach to conservation, and given the context specific nature of conservation success and failure, this thesis examines new conservation in Aotearoa New Zealand. The methodology for examining this case study is discussed in the following chapter. 


\section{Chapter Three - Methodology}

\subsection{Introduction}

This chapter introduces the research methods used in this thesis. A constructivist epistemology is supported by the application of a poststructuralist methodology. According to this epistemological approach, knowledge is situated and the researcher is an important factor is shaping knowledge production. Therefore, as the researcher I locate myself within the research before discussing the research methods used. A case study consisting of a series of semi-structured interviews was employed. Finally, this chapter explains the process I engaged with to analyse the information gathered.

\subsubsection{Constructivist epistemology}

A constructivist ${ }^{2}$ perspective provided the epistemological foundation for this research. As Hershberg (2014) and Jones (2002) define, constructivism is built on the idea that people construct, interpret and create knowledge of their surroundings (Hershberg, 2014; Jones, 2002). Constructivist epistemology determines that knowledge is a product of people's beliefs, historical contexts, individual mental processes and social experiences (Charmaz, 2014; Gogus, 2012; Hershberg, 2014; Jones, 2002). Gogus (2012) states that there is also a level of subjective selection involved. For instance, as new ideas and information are exposed, individuals are able to choose to accept or blend them into their established views and beliefs. In addition, constructivists argue that truth is relative and dependent on an individual's perspective, leading to the assertion that there is no single objective reality for humans to access (Hershberg, 2014; Jones, 2002). Equally, the recognition of one truth or reality is just as valid as another's - even if the two positions contradict each other (Macnaghten \& Urry,

\footnotetext{
2 Constructivism vs social constructivism; Some scholars and literature provide distinction between constructivism and social constructivism (see Charmaz, 2014), while others do not. This research follows the second body of work and uses the term 'constructivism' to encompass both terms.
} 
1998). While constructivism has different variations of how it's applied among disciplines, the underlying principles highlight the relationship between social processes and knowledge production is fundamental to the constructivist position. This relationship allows power hierarchies and social norms to be challenged and critiqued in the understanding that they rely on contextual, historical and cultural practices (Hershberg, 2014).

This research follows the work of Willems-Braun (1997) and Macnaghten and Urry (1998) to explore the constructions of the environment, or 'nature', and ideas associated with it, specifically conservation. In doing so, this research accepts that there is no single definition of nature, but rather a diverse range of contested variations of the concept. Recognising that nature is constructed shifts away from an objective position. which often portrays the natural environment as an independent entity waiting to be discovered and recognised by modern scientific methods (Jones, 2002; Macnaghten \& Urry, 1998). Furthermore, Macnaghten and Urry (1998) and Jones (2002, p. 248) identify that 'multiple natures' exist, acknowledging that there are different perspectives, judgements and definitions of nature. These multiple natures are the result of different social and cultural contexts and practices that have shaped the knowledge created by a respective group. Macnaghten and Urry (1998) and Waitt (2010) argue that within these different interpretations of nature there are dominant positions, which hide and ignore environmental change and can misrepresent society's nuanced relationship with the environment. For example; Macnaghten and Urry (1998) highlight that Western views seen to be scientifically-based often overshadow Indigenous interpretations of a particular phenomenon.

Some scholars have claimed that constructivism and environmental conservation are not compatible. Woodgate and Redclift (1998) argue that constructivism fails to recognise the destruction and degradation of the environment, rather stating that such action is only symbolic. The authors argue that research must remedy the binary stance that nature is either a physical material which humans require for existence, or alternatively as a symbolic representation of cultural and social interpretations (Redclift \& 
Woodgate, 1998). In response to this argument, Jones (2002) states that there is a middle ground within constructivism. This is referred to "contextual" or "moderate constructivism" (Jones 2002, p. 248). This position acknowledges the physical attributes of the natural world while accepting multiple interpretations of it. This research engaged this concept of moderate constructivism.

\subsubsection{Poststructuralism}

This research used a poststructuralist methodology to identify, challenge and disrupt dominant ideas, narratives and discourses associated with environmental conservation in Aotearoa New Zealand (Harris, 2001). Young (1981) states that poststructuralism is more appropriately applied as an umbrella term rather than a definition representing a compact and unified body of theory. However, Braun and Wainwright (2001) and Khoja-Moolji (2014) identify that the central idea of poststructuralism is to deconstruct transcending ideas around social realities that are perceived as common sense and 'facts'. As well as disrupting and deconstructing, poststructuralism challenges established sets of common sense by attempting to highlight alternative discourses and ways of understanding the world (Harris, 2001; Merlingen, 2013). A poststructuralist approach endorsed this research to investigate and acknowledge alternative meanings of 'conservation' and 'nature' and what power relations underpin changing approaches to conservation.

Poststructuralism is built on the acceptance that the establishment of social realities and facts, or 'truths', are power building apparatuses situated within specific sets of knowledges (Harris, 2001; Khoja-Moolji, 2014; Young, 1981). The relationship between the power and knowledge is represented by discursive structures - which will be covered more comprehensively in the next section (Waitt, 2010). Michel Foucault's seminal work on poststructuralism linked the use of discursive structures to institutions such as schools, hospitals, and prisons. Due to their ability to produce knowledge sets, these institutions are able to reinforce their power by regulating what types of discourse and knowledge are deemed acceptable (Harris, 2001; Khoja-Moolji, 2014; Young, 
1981). The institutions establish limitations on what meaning can be applied to ideas, objects, relationships and places, which influence and control dominant common sense and understandings of the feature while also silencing other meanings (Mansvelt \& Berg, 2010).

Poststructuralism asserts that discourses and knowledges are only fixed or stabilised temporarily. Additionally, poststructuralism addresses the way in which language is not only a reflection of reality, but an essential part of it too (Escobar, 1996). As Harris (2001) describes, the importance of poststructuralism is that it can break down larger narratives and knowledge sets, or what is considered to be 'reality'. In doing so, this type of inquiry can uncover and disrupt actions and discursive practices that supress or exploit social groups and the ways in which they see the world.

Poststructuralism's relevance for this thesis is that it enables the researcher to apply critique to the area of study instead of to trying to establish and navigate an apparently objective, value-free position. This permits the researcher to "deconstruct, suggest alternatives, relativise, question and refuse" (Harris, 2001 , p. 346). Information that the research uncovered perceived to be a fixed reality is allowed to be re-evaluated and re-analysed, moving past outcomes or consequences that are seen as unavoidable (Harris, 2001; Merlingen, 2013). A poststructuralist approach enabled me as the researcher to scrutinise 'truths' and common-sense understandings around conservation and associated concepts, the power relations that underpin these truths, and the discourses that are obscured by them,

\subsubsection{Discourse}

Foucauldian notions of discourse are a core component of poststructuralism (Parker, 1992; Young, 1981). Using Cheek (2008) and Ellermann's (1998) description, discourses are defined as ways of thinking and speaking about reality. Discourse can be understood as the formation and structuring of texts that construct an object (Parker, 1992). These texts take the form of written documents, speech, images and other arrangements that are accessible to 
others (Young, 1981; Phillips, Lawrence, \& Hardy, 2004). Discourses not only describe and categorise, but bring phenomena into existence. They also provide a framework for valuing a certain way of talking about one reality over another. The importance of discourse is they authorise and enable - while simultaneously imposing control and restrictions - on what is said, who can say it and when it can be talked about (Parker, 1992). However, Phillips et al. (2004) notes that these manipulations of what can be said are also able to be reformed as power shifts and knowledge develops.

Phillips et al. (2004) assert that discourses cannot be studied directly. Rather, they are studied through the examination of the texts that comprise them (for example; written, spoken or images). The study of discourse examines how texts are produced, circulated and consumed to locate and identify their impact on social reality. Parker (1992) states that discourse analysts regularly use poststructural positions to break down what has been 'said' in a reflexive manner (continually asking questions about it) to produce a better understanding of the discourse. This process does not have to be restricted to a singular or a small number of texts, but can address a wide variety of them and can draw on the influence from other discourses that the texts take on (Phillips et al., 2004). By grounding in poststructuralism, discourse and reflexivity can be hugely beneficial to the research as a way identifying the nuances and influences within the research scope (Parker, 1992).

Discourses, as Parker (1992) states, do not necessarily produce power, but are able to challenge and resist it. As Ellermann (1998) highlights, Foucault argues that power is changeable, plural and diverse. Where there are dominant discourses, counter or resistant discourse, will transpire to challenge dominance which may then lead to wider changes within the discourse or as a whole (Ellermann, 1998). Phillips et al. (2004) supports this by asserting that discourses can be seen as in a constant state of struggle. This reinforces the Foucauldian argument that discourses are only in existence at a certain point in time (see also Phillips, 2004). This also represents the opportunity of change for actors who are able to direct and manipulate the discursive formations (Phillips et al., 2004). 


\subsubsection{Positionality}

A constructivist perspective rejects the idea that theory is developed independently from the data (Vanner, 2005). Instead, constructivism establishes the researcher as an important influence in the research process. This influence comes from the researcher's epistemology, experiences and beliefs, motivations for carrying out the research and interpretations of the data (Vanner, 2005). Outlining a researcher's positionality supports the idea that researchers cannot detach themselves from the process of collecting, analysing and discussing data - particularly if they have strong personal links or attitudes towards the topic (Milner, 2007). Hershberg (2014) adds that constructivists place importance on the relationship between the researcher and research participants and how this may influence the information that is shared by participants and the knowledge that is produced. As Charmaz (2014) states, it is important to recognise the researcher's approach to the research, how it is carried out and the interpretation of the data is a construction itself.

When applying constructivism into practice, Charmaz (2006) encourages researchers to be reflexive in their work. By reflecting on their own positionality, researchers acknowledge that the research process is not intended to be objective or neutral (Charmaz, 2014; Mauthner \& Doucet, 2003). Instead, researchers are able to account for their own personal values and characteristics (for instance, their ideology, race and gender) that make their way into the research (Atkins, 2004). As prompted by Vanner (2015), by summarising my positionality before data collection, then expanding on it postcollection helped locate my social and power position. By using a reflexive approach, the validity of the research is enhanced through the increased transparency of how the data and interpretation was generated and why. The process of the researcher working in a reflexive manner to locate their position within the research helps to produce a more ethical, transparent and robust process (Milner, 2007; Sultana, 2007). 
Bradshaw and Stratford (2010) state the researcher's positionality is crucial when generating robust research by establishing its "trustworthiness" (p. 77). Connelly (2016) defines trustworthiness as the level of rigor within the research method, data collected, and interpretation of it. The importance of trustworthiness is that is it establishes credibility, or confidence, in the findings of the research (Cope, 2014; Connelly, 2016). Cope (2014) argues that credibility is enhanced when positionality is detailed as a part of demonstrating the research process taken. It also allows readers to gain more insight how the researcher produced discussion and conclusion points (Cope, 2014). In doing so, positionality creates "confirmability", which Connelly (2016, p. 435) states allows the research to be reproduced and repeated.

Salient characteristics of my positionality are that I'm currently a postgraduate tertiary student studying Environmental Studies. My decisions to pursue this area of study follows my personal attitudes towards the role and position the environment has in society. This developed from my pre-university employment in the mountain environment that gave me an insight into how certain industries that rely on a particular resource do not always act in ways that can guarantee environmental sustainability. Specifically, I became interested in long term consequences for the resources and broader environmental health when positioned as a central focus for economic gain. I believe that this also has parallel links to the way the New Zealand economy is positioned with its strong focus on primary industries, such as agricultural, forestry, aquaculture. This shaped my interest towards the concepts of sustainable economic development and considering economic approaches to environmental conservation.

The specific impetus for this research came through personal exposure to international examples of alternatives to traditional state-led conservation. A notable component of these examples was the active involvement of private businesses. This provided the inspiration to assess what is happening in Aotearoa New Zealand's conservation domain in respect to private business involvement. Significantly, my previous introduction to business intrusion into state-led domains led my initial attitude of such compatibility with Aotearoa 
New Zealand conservation efforts to have a degree of scepticism. However, my introduction to business involvement in state-led domains was not directly in the conservation arena, which also added to the personal interest in the area of study. I also recognised that the circumstances and context that had led to such international conservation projects are considerably different to Aotearoa New Zealand's. Nevertheless, the cautious attitude I held was matched by the intrigue of seeing similar approaches generate apparent conservation successes here in Aotearoa New Zealand. I employed these differing viewpoints to try to help balance the research throughout the process and to remain openminded about the discoveries.

While acknowledging positionality is important, Sultana (2007) states that a researcher should not become paralysed in pursuit of a trying to erase their subjective influences within research process. A researcher's presence, personal characteristics, beliefs and values will all inevitably have an impact on the data collected and how it is interpreted and analysed (Sultana, 2007). With this in mind, as a postgraduate Environmental Studies student, I was conscious about receiving some guardedness from participants who may stereotype me as having strong, possibly idealistic views, on environmental protection. In this context, I was attentive to explain my own background and inspiration for the research to the participants. I was also mindful to explain that the objective of the research process I had selected was to enable the data to be the principal source of direction for the subsequent theory.

When carrying out the interviews, I received an enthusiastic reception from the participants who were willing to engage in the research. This potentially may have been a result of my physical appearance as a Caucasian male which, as Laker (2016) states could portray a level of privileged knowledge or perspective. However, the phone interviews would have negated this particular feature of my positionality. However, Chiswell and Wheeler (2016) state that other personal characteristics, such as researcher gender, can have a significant role in research and knowledge production. While this thesis did not specifically focus on these influences, there remains the opportunity for future research to assess this area. 


\subsection{Research Methods}

The following sections will outline the case study that was used as a primary method of data collection. It will outline interview methods, document review and process following the interviews used for analysis.

\subsubsection{Grounded Theory}

In keeping with a constructivist epistemology that acknowledges the position of the researcher, this research employed grounded theory. Grounded theory is a form of qualitative research in which data collection and analysis unfold to develop each other through a continuative process. Methods of grounded theory include interviews and document analysis - both of which were utilised in this research (Charmaz, 2011; Glaser, Strauss, \& Strutzel, 1968). The process of grounded theory, as described by Vanner (2015), attempts to unlock the dominant themes and theory through data. The selection of grounded theory as a building block for this qualitative research is reinforced by Charmaz (2011) who argues that grounded theory is an appropriate tool for advancing the issues of social justice. Social justice inquiry, as defined by Charmaz, is the study and research of issues around topics such as; inequality, access and constraints, privilege and poverty, as well as the collective good and individual rights. This research fits within social justice inquiry because it examines uneven power relations within the conservation domain (see also Roberts, 2003).

Martínez Pérez et al. (2015) state in grounded theory, data and theory are primarily developed through an "interactive, inductive, and contemporaneous process" (p. 4) between the research and participant. As a result, the data and theory are considered to be constructed (Martínez Pérez et al., 2015). While not neutralising the effect of the researcher, grounded theory negotiates the researcher's influence through the continual comparison of between multiple data sources and simultaneous analysis of the data (Martínez Pérez et al., 2015). This aims at producing theory that is empirically based as opposed to a predetermined theory being placed on the data (Clarke, 2007, as cited in Vanner, 2005). 


\subsubsection{Case Study}

The use of a case study was selected as an appropriate way of exploring complex social and environmental processes (Perry, 2011; Yin, 2003). Rather than being viewed as a specific technique, Punch (2014) contends that case studies are a way of processing and organising social data while maintaining the integrity of the particular phenomena being researched. Baxter (2010) adds that the use of case study is valuable when attempting to provide a more comprehensive understanding of a specific topic. The use of a specific case is used to represent a broader, or collection, of issues (Elman, Gerring, \& Mahoney, 2016).

Case studies are a practical way to provide a holistic view of the research setting to acknowledge and account for wider factors that play a part in the phenomenon. Specifically, when context may be particularly important to the research, or it is not clear where the context and phenomenon boundaries are (Cousins, 2005; Punch, 2014). For instance, a study examining how or why particular decisions are made may not be able to be detached from the contexts from which they originate (Baxter \& Jack, 2008). Punch (2014) adds that the strengths of implementing a case study is that it enables the researcher to study the selected area in more comprehensive way through accessing different data sources and perspectives. The use of case studies also allows a number of different types of evidence to be involved in the analysis (Punch, 2014; Yin, 2003).

Perry (2011) establishes that case studies provide a way of accessing the perceptions, definitions and meanings of the interview participants and how personal experiences, beliefs and influences construct their realities (Perry, 2011). As highlighted by Perry (2011), case studies are specifically valuable when confronting contested knowledges or understandings about specific events and processes. These different perspectives also reveal the different discourses and counter discourses which are then able to be analysed (Perry, 2011).

This case study focused the DOC's relationship with the businesses formally involved with the Department's commercial partnerships. This relationship 
provides definition of what explicitly is the 'case' and where the surrounding context begins and ends as there are a finite number of businesses involved (Punch, 2014). At the center of the research was the interviews with DOC supported by data collected from their publicly released documents. The commercial partners involved with the research included Toyota New Zealand, Genesis Energy and Fulton Hogan. In order to examine multiple discourses at work and how they can be contested, prominent environmental conservation NGOs were also interviewed. The participant NGOs were Forest and Bird Protection Society of New Zealand (Forest and Bird) and the Environmental Defence Society.

\subsubsection{Interview Methods}

Semi-structured interviews were carried out to explore the case study selected. As described by Barriball (1994), semi-structured interviews are well suited for analysing values, attitudes and beliefs in what can be complex, layered topics. Semi-structured interviews allow the researcher to make further enquires seek clarification when needed. This helps the create depth to the data and expand on complexities that simplified or open-ended questioning may create. In contrast to structured interviews, which employ a standardised question set and presumes a common vocabulary is used between participants, semistructured interviews acknowledge that words can have different meanings among individuals and groups (Barriball, 1994; Segal et al., 2006). This also supports the constructivist foundation this thesis employs.

Open ended questions were used to elicit a wide range of responses and create the opportunity for unanticipated data (Yin, 1994). This was encouraged by a deliberate conversational manner allowed by the semi-structured method, which as Valentine (2005) states, further enables the interviewer to pursue a particular query through a range of different questions. Semi-structured interviews also allow the interviewer to modify and create new questions to fit the participants (Segal et al., 2006). This is aimed at allowing the participants to become involved in the research by providing their own dialogue of how their 
realities, views and ideas are constructed (Galletta, 2013; Punch, 2014). This, as Punch states enables "greater openness and insight, a greater range of responses, and therefore richer data" (2005, p. 173).

A total of seven semi-structured interviews were carried out, with four face to face and three over the phone as a consequence of time and location restraints for the participants. Those interviews which were carried out in person where either located in café or a meeting room of convenience. The interviews lasted between 25-50mins with all interviews getting through the intended questions schedule. The participants for these interviews were representatives from three categories. The first was the Department of Conservation (DOC). The second group were representatives from DOC's commercial partners, with NGOs involved with conservation advocacy making up the third category. Between the three categories, two interviews were carried out with DOC, three with DOC's commercial partners, and two with independent NGOs. This number of interviews was appropriate considering the time period and scale of this research to produce a rich body of information.

Below is the table outlining the participant's number allocation:

\begin{tabular}{|l|l|}
\hline Participant number & Organisation represented \\
\hline Participant 1 & Department of Conservation representative \\
\hline Participant 2 & Department of Conservation representative \\
\hline Participant 3 & Forest and Bird representative \\
\hline Participant 4 & Environmental Defence Society representative \\
\hline Participant 5 & Genesis Energy representative \\
\hline Participant 6 & Toyota New Zealand representative \\
\hline Participant 7 & Fulton Hogan representative \\
\hline
\end{tabular}

The selection of commercial businesses was restricted to national level partners as of August 2016. Attempts to secure interviews from the commercial partners 
were also restricted due to an unwillingness from prospective participants to be involved. For instance, Air New Zealand's response was that their company policy is to not engage with research, and Meridian Energy believed that they had not been in their respective partnership long enough to be able to competently participate. Similarly, with the NGO category, the relationship with the topic deemed those chosen as the most qualified to participate.

As guided by Ayres (2008) and Dunn (2010), the assistance of an interview guide was used in the form of a set of questions (see Appendix 2). Despite three quite separate groups, the interview schedule was created to allow me to explore specific themes across all groups. This was targeted to provide data sets from each interview that would be comparable with other interviews (Barriball, 1994). For example, all participants were asked about what DOC, and conversely, what the partners get out of the partnership's model. Mirrored by Galletta (2013), the initial questions were intentionally formulated to produce the most open and expansive responses. Some of the central questions were complimented with pre-written follow up questions in the event they were needed during the interview. These were used as prompts when elaboration or examples were needed. Other questions came naturally in search of further explanation through points that participants made.

\subsubsection{Document Review}

A document review was used for the thesis year which was used primarily to reinforce and support the responses from the DOC participants. Examples and quotes were pulled out of the documents to expand or develop points when necessary. The documents review focused on government documents, reviews and annual reports. Specifically, the main documents used were the 2015 and 2016 DOC Annual Reports and Statement of Intents, the 2014 Briefing to the Incoming Minister, the State Services Commission's review of DOC published in 2014. In addition, a DOC Partnership business strategy document was given to me by one of the DOC participants for further assistance of the topics covered in the interview. While this document was used to support the participant's 
interview answers, care was taken to use parts that were immediately relevant to the responses given and topic in accordance to the discretionary use guaranteed by myself. Natural limitations for much of the literature was situated from around the start of DOC's commercial partnership strategy in 2013 (SSC et al., 2010).

The following table outlines the main secondary documents used to support the interview data.

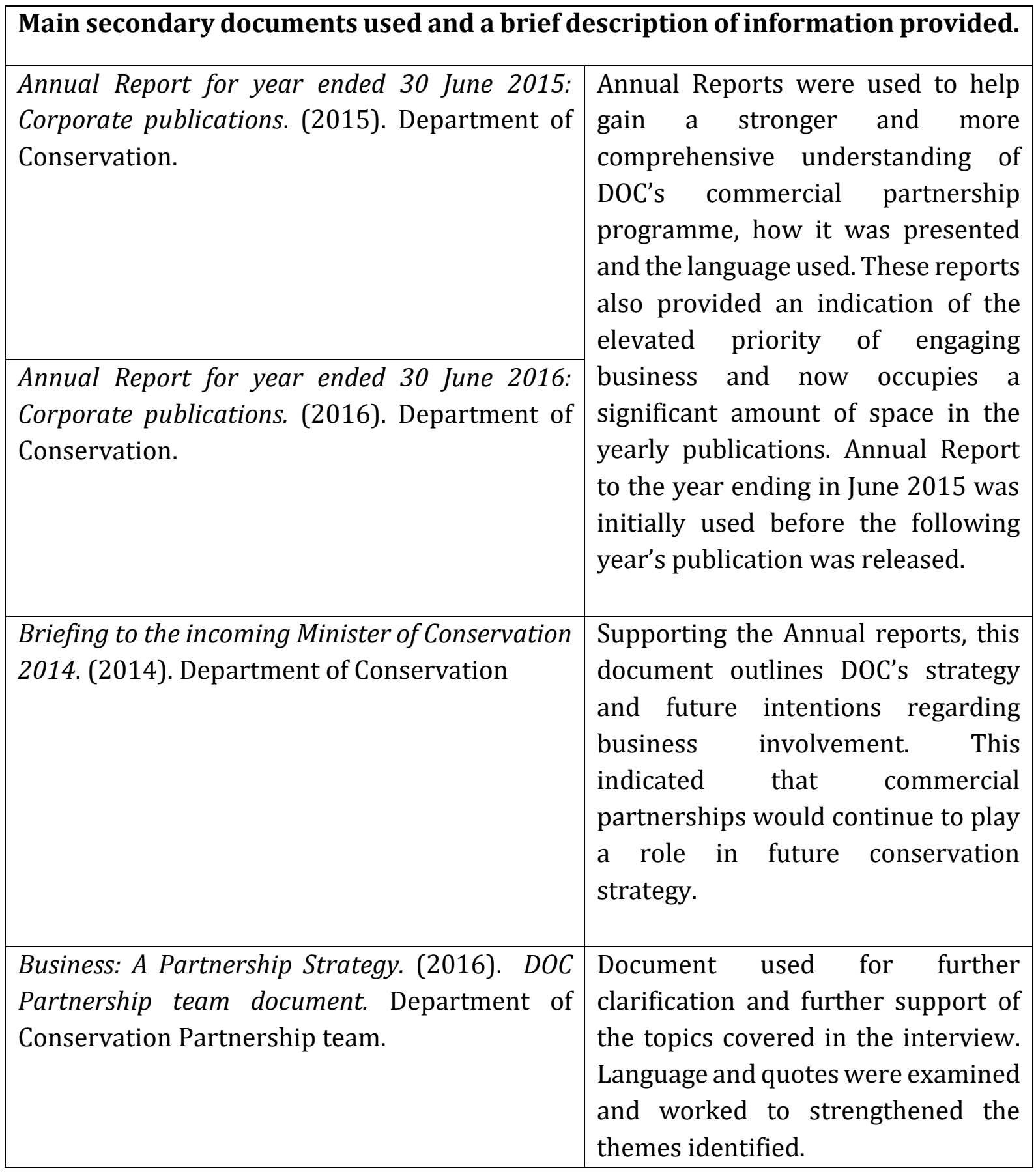




\begin{tabular}{|l|l|}
\hline $\begin{array}{l}\text { Business Growth Agenda: 2015. (2015). Ministry } \\
\text { of Business, Innovation and Employment. }\end{array}$ & $\begin{array}{l}\text { This document outlines the areas of } \\
\text { priority that the government intends } \\
\text { to deliver economic growth. The } \\
\text { Building Natural Resources Chapter } \\
\text { was predominantly referred to in } \\
\text { alignment with how the } \\
\text { conservation estate will be used. }\end{array}$ \\
\hline $\begin{array}{l}\text { The Business Growth Agenda: Future Direction: } \\
\text { and Employment. }\end{array}$ & $\begin{array}{l}\text { This document supports the Business } \\
\text { Growth Agenda: 2015 by giving } \\
\text { insight into the progress of policies } \\
\text { implemented. This progression } \\
\text { intended to identify new or changes } \\
\text { in discourse relating to how } \\
\text { conservation is expected to support } \\
\text { economic growth. }\end{array}$ \\
\hline $\begin{array}{l}\text { Review of the Department of Conservation (DOC). } \\
\text { Treasury, \& Department for the Prime Minister } \\
\text { and Cabinet. }\end{array}$ & $\begin{array}{l}\text { Document provided insight into } \\
\text { DoC's internal transition that led to a } \\
\text { stronger focus on commercial } \\
\text { partnerships. }\end{array}$ \\
\hline
\end{tabular}

Complete reference information for these documents can be found in the Reference List.

\subsubsection{Transcription and Coding}

Following each interview, a transcription of the interview was typed up with location, circumstances and other situational contexts also noted (Charmaz, 2014). As May (2011) argues, transcribing allows the researcher to become more familiar with the data, which helps in the analysis phase. Furthermore, transcribing full interviews can give a more in-depth understanding of the contents of the interview which prompt new ideas and questions (Charmaz, 2014).

Transcripts were then coded to identify reoccurring themes. Coding is the assignment of tags, names or labels to specific pieces of the data to organise the 
information into thematic groups (Punch, 2005). I employed this approach to the coding, targeting specific terms, sentences and larger sections of transcript showing distinct themes. The initial coding followed what Punch (2005) refers to as 'descriptive' coding aimed at preliminary analysis and allowing the researcher to get to know the data. With the application of a Foucauldian discourse analysis, I followed Waitt's (2010) proposal of 'analytical' codes following the exploratory descriptive coding. Analytical coding involves an amount of abstraction or reduction, which can be seen as interpreting themes. This is aimed at providing insight to why individuals or groups hold certain views and ideas about places and events, how different people relate to them (Waitt, 2010).

\subsubsection{Analysis}

The coded data was analysed inductively to produce understanding, grouping and subsequent theory (Fox, 2008). Punch (2014, p. 170) defines induction as "the systemic examination of similarities between cases to develop concepts or ideas". Guided by Hammersley and Atkinson (2007) and Baxter (2010) for elaboration, the inductive analysis produces common factors, which can be regarded as generalised conclusions from particular circumstances (Simon, 1996). An important consideration made by Fox (2008) is that these generalisations can be overturned or undermined by information that contradicts it. As a result, deduction was also employed to verify the theory created from the induction process (Baxter, 2010; Fox, 2008; Punch, 2014; Shank, 2008). As stated by Baxter (2010) and Fox (2008), deduction involves testing existing or new theories, data or case studies not included in the original research. The authors note that induction and deduction can work complimentary to each other in an iterative process to strengthen the applicability of the generalisations and overall analysis (Baxter, 2010; Fox, 2008).

A Foucauldian discourse analysis was used to examine what themes and ideas were found in the text. Although there is not a formal set of guidelines to conduct 
a Foucauldian discourse analysis, Punch (2014) and Waitt (2010) highlight a series of considerations to help researchers produce a thorough analysis. The authors specify that the researcher should consider the authorship of the text. This includes who the authored the text and, who the intended audience is, and why the text was produced (Punch, 2014; Waitt, 2010). Waitt (2010) continues by stating the researcher must also be aware of inconsistencies or contradictions within the data. As Punch (2014) states, a Foucauldian approach to discourse analysis is sensitive to how language is written and spoken, how it is used, and description constructed. This also includes things that were not said or ways in which questions were answered (Waitt, 2010). These guidelines were applied to the analysis of the data.

\subsubsection{Considered risks for interviewing}

Yanos and Hopper (2008) highlight a notable potential risk in the final data collected when undertaking interviews. The authors state that what participants say and how they act may not actually be the same as what they do (also see Charmaz, 2011). As a result, interviews can be seen as performances by people in order to present how they want to be seen. This may be particularly applicable for people representing businesses or organisations who have to balance their own values, their organisations positions and their roles within it. In the context of this research, participant responses were respected because accordingly to the constructivist methodology adopted, meaning is always being contrasted. Participants, therefore, were understood as actively constructing their realities.

Another important consideration noted by Valentine $(2005$, p. 116) is that of negotiating a "gatekeeper". As Valentine states, a gatekeeper is someone who holds the ability to grant or restrict access to potential research participants. In the context of this research, the gatekeeper position was occupied by DOC. During initial communication with DOC, it was proposed that contact with partners would be most appropriately achieved through DOC's formal contact with each respective business. This was suggested by DOC that it would enhance 
the perceived legitimacy of the research among the commercial partners (Participant 1, personal communication before interviews, 26/8/2016). As highlighted by Valentine (2005), researchers must be aware that gatekeepers hold significant power to direct the researcher towards selected participants which may provide favourable responses for the gatekeeper. Discussions with DOC about which partners were going to potentially participate in the research, the subsequent changes due to participant availability or willingness to engage with research, and the scope of final partner participants that ended up being involved did not indicate that this was an issue.

\subsection{Chapter summary}

The use of a constructivist epistemology, supported by a poststructuralist methodology, allowed the identification, investigation and analysis of prominent discourses associated with environmental conservation in Aotearoa New Zealand. My positionality was outlined to acknowledge the epistemological biases that myself as the researcher may have on the data collected. A case study using semi-structured interviews enabled the topic area to be investigated through the experiences and attitudes of the participants. The participants represented three different categories allowing the central transcending discourses to be highlighted. A process of transcription and coding enabled a Foucauldian discourse analysis to be applied to the data. 


\section{Chapter Four - A wider scope for conservation}

\subsection{Introduction}

This chapter concentres on the discourses underpinning the call for a new approach to conservation. The chapter will initially address the discourse focusing on the idea that environmental conservation is failing to achieve its goals. The proposed solutions that proponents of new conservation approaches argue for will then be outlined. A significant part of this is the role that society can play in achieving conservation goals. Following this, the theme of how business' role in contributing to increasing social involvement in conservation will be addressed with discussion on power and knowledge. The challenges and considerations of this approach are then examined, as well as how this approach is being applied to the New Zealand context.

\subsubsection{Conservation is failing}

The deterioration and degradation of the global environment is regularly cited at the beginning of literature used for the research. Outlining this situation enables the authors to provide their subsequent argument for remedial action. A common tactic of proponents calling for a new approach is to cite research showing continued loss of species and environmental degradation despite the considerable efforts of global conservation. For example, Lalasz et at. (2011) state in their opening sentence "by its own measures, conservation is failing. Biodiversity on Earth continues its rapid decline" (p. 1). Similarly, Craig et al. (2000) assert that "conservation in New Zealand is failing to halt an ongoing decline in biodiversity" (p. 61). These declarations are then supported by specific data illustrating the stated ongoing environmental degradation. The way in which these assertions are presented establish discursive structures for what the following action may be. Most notably, the outcome is that conservation needs to find a new approach if it is going to have future success (see Kareiva, 2012; Kareiva \& Marvier, 2012; Kirby, 2014; Lalasz et al. 2011). 
The failure of contemporary conservation efforts and subsequent calls for a new approach to conservation found in academic writing is reflected by the recent shift in DOC's strategy. Representing DOC, Participant 1 outlines that the Department's justification for a new approach stems from biodiversity indicators showing a declining national environment. As Participant 1 states, "probably back in about, 5-6 years ago, it became pretty clear that a lot of the [biological] indicators that we report against were down". Participant 1 adds that the sheer size of the conservation estate and the challenges facing it make the task of achieving the desired conservation gains incredibly difficult. "I think the reality was that when you manage over a third of New Zealand's land space, or landmass, and it's the stuff that people care about most, and a whole range of major challenges, that 2000 people [working for DOC] weren't going to turn that around" (Participant 1). Participant 1 emphasises that DOC already has a group of "really skilled people doing a lot work very passionately". However, the magnitude of the challenge that DOC faces is illustrated by an excerpt from the Department's 2016 Statement of Intent, "While biodiversity protection and recovery is being achieved in areas under intensive management, the overall trend outside these areas is that biodiversity is declining and ecosystem services are being reduced" (DOC, 2016a, p. 21). These assertions provide a representative example of how conservation efforts are portrayed as failing which then opens up the platform for new approaches to be proposed.

Compounding the challenges of the vast size of the conservation estate, a major consideration to navigate is the insufficient allocation of resources the Department receives. Due to the complex nature of the Department's other revenue streams, there is conjecture about the exact budget that DOC operates with. However, independent evaluations of the Department's government budget allocation put the reduction at around $\$ 40$ million between the 2015/16 and 2016/17 financial years (Gudsell, 2016). Representing the Environmental Defence Society, Participant 4 adds that "DOC's baseline budget has been reduced by about 100 million [dollars] in real terms over the last six years". This budget pressure is also acknowledged by Participant 1 representing the Department, "DOC is known to be under the pump a little bit, from a financial perspective". Furthermore, the Department has to also balance the management 
of tourism on the estate alongside its conservation duties (DOC, 2016a). As Participant 5 highlights:

Conservation funding is not getting any greater. And I think there are some real challenges for New Zealand in the sense that we're expecting our visitor numbers to double, and the majority of those people come here because of the great outdoors and what there is to offer, and somehow DOCs got to manage that.

With the Department's dual responsibility of the conservation estate while simultaneously negotiating the promotion of tourism activities, Participant 4 states "the problem that DOC has is its baseline budget is not right sized for the role that it has to play". However, the presentation of these challenges and failures can have significant implications for how previous strategies are seen and how future approaches take shape.

\subsubsection{How failure is presented and the implications of it}

The presentation of specific indicators showing ecological decline insinuates that the wider environment is following a similar trajectory. In doing so, this can create significant generalisations and simplifications about the environment's condition. Highlighting these generalities is not to dismiss the severity of the environmental challenges the global population faces. However, it does present the environmental challenges in a way that is based on particular understandings of how environment functions, specifically a Western scientific understanding (Hajer, 1997). Furthermore, the presentation of conservation as failing also generalises that all other attempts have failed, which as Doak et al. (2014) state, is quite misleading. In doing so, it discredits previous projects and approaches that have actually had success, for instance, individual PAs which provide important sanctuaries for biodiversity and ecosystem regeneration (Doak et al., 2014). However, as Doak et al. and West et al. (2006) note, the generalisations of failing efforts are largely established against the presentation that 'success' is represented by pristine, human-free conservation areas.

Further strengthening the use of the failing conservation discourse is the characteristics of the environmental crisis which allow it to fit different contexts, arguments and attitudes. Hajer (1997) and Waitt (2010) argue that 
particular features of the environment are selected to provide an understanding of specific challenges and the potential consequences to an audience. In reality, these examples can trivialise and underemphasise other important issues. For example, having a small or specific focus on a particular issue facing the environment is not representative of the wider environment's condition (Hajer, 1997). Alternatively, Hajer (1997) asserts that the presentation of a global environmental crisis can diminish localised, day-to-day environmental concerns creating the potential for marginalisation of these issues and the people it affects.

This hegemony of failing conservation has brought into existence a commonsense idea that is now taken as reality. Parker (1992) states that the dominance of this discourse sets the boundaries for the arguments and aligns the discussion with certain knowledges, views and political ideology. Hajer (1997) adds that the production and circulation of such discourses has been initiated by experts who have access to specific data collection skills and resources. This scientifically-based understanding about the state of the environment is then supported and reinforced by powerful actors to dominate the way in which we interpret the issues in focus (Hajer, 1997; Igoe, Neves, \& Brockington, 2010; Phillips et al., 2004). In this instance, the powerful, influential actors are represented by DOC, prominent conservation NGOs and large corporate businesses. Hajer (1997) describes these actors as "discourse coalitions" (p. 6) where organisations share a similar narrative or account of a particular issues. As Hajer (1997) demonstrates, these coalitions "develop and sustain a particular discourse" (p. 6) that allows the respective parties involved to generate leverage for their own needs. However, the parties involved have often not actually meet or agreed on a strategy and may interpret the outcome, meaning or significance of the issue differently.

The affirmation that conservation is failing sets the tone for what options can be presented for remedial action and who can present it (Waitt, 2010; Brockington et al., 2008). Hajer (1997) uses the example of the scale, spatial and temporal characteristics of environmental issues that retains, often remedial, discussions within specialised fields. As a result, this typically disqualifies or relegates the 
general public and alternative knowledge sets from the initial defining and discussions of such complex problems (Hajer, 1997). Subsequently, this discourse then requires approaches to remedy environmental challenges to be able to fit into a scientific paradigm. Waitt (2010) notes that with Foucauldian understandings, discourses are inherently unstable and open to challenge. However, the repetition of scientific understanding of an environmental crisis is a continues to constrain the discussion within certain boundaries and retain power within selective discourses (Hajer, 1997).

\subsection{Broadening conservation in Aotearoa New Zealand}

The discourses of failure and subsequent need for change are prominent in literature focusing on the context of Aotearoa New Zealand. This is demonstrated by Craig et al. (2013) who state "We believe New Zealanders need to have a vigorous dialogue about alternative ways to enhance social and ecological heritage and how this can sustain New Zealand society" (p. 256). The authors also state that citizen involvement in conservation needs to be increased around the country. This is to provide benefits to individuals and communities through providing more natural and social capital and encouraging additional sustainable economic opportunities (Craig et al., 2013). Russell et al. (2015) propose that increasing social involvement can be leveraged off the existing relationship that the New Zealand public has with the conservation estate. However, despite this relationship, Russell et al. (2015) state that meaningful efforts will need to be made to stimulate the public into supporting a new approach to nationally significant resource.

The sentiment calling for broader debate and participation in New Zealand conservation efforts follows the work of Doak et al. (2014) and Western (2000; see also section 2.2.3) on new conservation. The authors state that broadening the way in which benefits are derived from conservation will help secure the importance of the domain in society. By targeting influential parts of society to become involved, it is intended to improve the ability for conservation to expand its reach in society and extend the range of benefits derived from it 
(Doak et al., 2014; Western, 2000). A potential area where conservation is aiming to provide benefits to society is through enabling economic gains to be realised (Marvier, 2014; Russell et al., 2015). Russell et al. (2015) argues that increasing investment in conservation can return direct economic gains through reducing losses in the agricultural, forestry and horticultural sectors from the likes of invasive species. The authors also highlight the significant economic benefits that the country presently gains from tourism attractions located in the conservation estate (Russell et al., 2015). These examples are also indicative of the increased economic focus that arguments for investing in conservation have taken (Doak et al., 2014; Western, 2000).

Encouraging wider involvement and contribution from society has also become a priority for DOC. At its foundation, this wider involvement is the Department looking for ways to increase its ability to carry out conservation work. As Participant 2 states, "so how do we take the tax payers dollar, and make best use of that taxpayer's dollar to do what our job is, which is conservation for New Zealanders". The Department is approaching this undertaking from a range of directions, from a "hearts and minds approach" to using the position that conservation has in Aotearoa New Zealand for "business leverage" (Participant 1). However, Participant 1 asserts that these approaches must be undertaken while ensuring that conservation "has to be a clear winner". The ambition of widening the catchment of those involved is also reflected by Participants 3 and 4 who support the idea that conservation should be a priority for wider parts of society. Participant 3 elaborates by stating "I absolutely agree with them [DOC] that conservation is everybody's issue. Governments, trusts, businesses, people. You know, groups in the community. It's everybody's business and we all should be doing it". This alignment with DOC's intention has also created more options in terms of breadth and depth of conservation's place in society with similar attitudes shared by external organisations able to encourage it. 


\subsubsection{Introducing partnerships in Aotearoa New Zealand conservation}

Attempts to remedy the apparent failings of traditional conservation efforts have seen the implementation of new governance mechanisms. An increasingly popular example is the use of public-private sector relationships. Globally, the number of public-private sector relationships has seen significant growth, with many of these taking the form of 'partnerships' (Van Huijstee, Francken, \& Leroy, 2007; Visseren-Hamakers, Leroy, \& Glasbergen, 2012). VisserenHamakers et al. (2012) demonstrate that the appeal of these partnerships is they have improved governance structures, agenda setting and boosted participation in conservation projects. The authors demonstrate that partnerships have helped include communities in local conservation projects and enhanced the role of society in "global, regional, and national conservation politics" (Visseren-Hamakers et al., 2012, p. 274). This has enabled countries and local authorities to set and achieve environmental conservation commitments that might normally be out of their reach (Van Huijstee et al. 2007; Visseren-Hamakers et al., 2012).

The use of partnerships is also utilised within Aotearoa New Zealand conservation strategies. As defined in the 2016 Annual Report (DOC, 2016a):

A partnership represents the joint commitment by DOC and the partner to put time and resources towards a common conservation goal. Depending on the circumstances, a partnership may warrant a signed agreement, a shared Memorandum of Understanding (MOU), or a handshake between parties. (p. 76) DOC has employed partnerships as a central way of delivering more conservation. The range of partners is exemplified by the number of community groups, Iwi stakeholders and other external groups involved, which now sits at 887 individual partners (DOC, 2016a, p. 76). Peters, Hamilton and Eames' (2015) work demonstrates that DOC has increasingly relied on these relationships which now take up a wide range of tasks, from pest control, advocacy and education, to administration. This practical work benefits conservation approaches at both local and national levels which is supported by resources from councils, DOC, Iwi and businesses (Peters et al., 2015) 
Following an internal restructuring, 2013 onwards has seen the commercial partnerships become a significant focus for DOC (SSC et al., 2014). The rational for the commercial partnership is to "better enable all New Zealanders to engage in caring for biodiversity and to experience its benefits - environmental, social and economic" (SSC et al., 2014, p. 2). Participant 2 states, "what we identified was that the way that we could achieve that outcome, which was best bang for your buck, if you like, for conservation, was to work with others. And business is some of those others"' (Participant 2). As a result, the use of the commercial partnerships model has now become a core department strategy and is an important mechanism of DOC trying to achieve its broader goal of making "New Zealand the greatest living space on Earth" (DOC, 2016a, p. 13). The emphasis on commercial partnerships is demonstrated by the space allocated to them in the annual reports, as well as occupying prominent space on the DOC website (DOC, 2015; DOC, 2016a; DOC, 2016b). The importance of these partnerships is reinforced by playing a key role in DOC achieving their "Stretch Goals and Priorities". Specifically, the commercial partnerships will assist in the categories of pest control, improving freshwater ecosystems and enriching New Zealander's lives through conservation projects (DOC, 2016a, p. 72).

To facilitate more engagement, DOC has partnered with large, well-known businesses to enable conservation to become "mainstream" in New Zealand society (Participant 1). As Participant 1 states, the motivation for establishing commercial partnerships is to utilise their corporate networks and customer bases to target groups access a wide variety of people with messages about conservation. "In all cases, we [DOC] get access to a different audience, through different channels" (Participant 1). Participant 1 continues:

All of them have different audiences. Genesis has a very large base of customers. Meridian's just come on board, big range of customers. And they're pushing out that conservation matters that they're involved in it through those customer bases.

To demonstrate this, Participant 2 uses the example of Air New Zealand showcasing its involvement with conservation:

And another way in which we see that reach is, you open the magazine on an Air New Zealand flight, these days you open it and there will be at least one article 
connected with nature and conservation, because of course, they're making the most out of their partnership with us.

This marketing initiative demonstrates the exposure to large catchments of the public that DOC and the commercial partnerships can access.

It's important to note that DOC's commercial partners model is only one part of a wider strategy to increase participation with conservation from business. The range of external resource support for the Department is explained:

You have people that donate money with no expectation for how it will be directed. They give money to DOC to spend wisely. Then we have sponsors, who will sponsor a particular thing; bird or some replanting or whatever it is, but will likely direct the money but have no further involvement. Then we have a range of partners in conservation, so people who believe in our work, work either along us or independently, but we consider them partners. (Participant 1 )

The importance of this range of options for DOC to work with external groups and businesses is to cater to different circumstances and preferences (Participant 1). Participant 2 rationalises "so the traditional sponsorship model is part of the picture, but if you then think of the pie for business, then sponsorship will take you so far", also adding "so if we [DOC] shift [the] business [sector], so they are engaged with conservation in other ways, then we get more conservation". This final point made by Participant 2 indicates the fundamental objective of this wider approach the participants from DOC were at pains to point out. Reinforced by Participant 2, "it's always got to result in more conservation been done".

An appeal for businesses to take on a partnership, as oppose to a sponsorship, is the ability for engagement with the particular projects. Specifically, it allows the staff of the respective to be actively involved. As Participant 5 states:

For us [Genesis Energy] it's really important to be a partner as oppose to just a sponsor, it gives us a chance to get our staff engaged in what's the value of the partnership.

Complementary this, Participant 7 adds:

We've [Toyota New Zealand] also been able to get our dealer network involved with the program... it enables them to be involved in local community activities 
and relate to their customers and the local community as well. So, there's certainly lots of benefits that we get out of it.

These sentiments demonstrate that businesses are becoming willing to engage with conservation and work alongside DOC. This represents DOC's objectives that businesses will assist in the achievement of the Department's Stretch Goals and Priorities (DOC, 2016a).

To have significant and long-term success, DOC have identified that the approach needs to be broader than just trying to supplement the Department's budget. As Participant 1 states, "So the key value that we get out of that [the commercial partnerships] is not always money, but normally there is a funding component". This wider shift also involves a notable change in attitude from the Department. As revealed by Participant 1, "You could say that one of the big philosophical shifts has been saying that conservation is about people and therefore it has to be relevant to people". Participant 1 adds "and I guess tied to that was the fact that we also took a New Zealand lens, not a public conservation lens". DOC has taken a more holistic view to conservation's place in society and how it relates to people. As Participant 2 explains in respect to the commercial partnerships:

That then sits in a bigger context that we're working with Iwi, we're working with councils and central government agencies. We're working with community groups and national organisations etcetera etcetera. So, business is, if you like, like one wedge of the pie.

This extensive collaboration and change in philosophy is aimed at creating broad shift in how conservation relates to the New Zealand society.

While the bulk of invested time and resources from DOC is expected to return results that can be formally quantified and reported on, there are some outcomes that are not expected to be immediately apparent (Participant 1 and 2). Participant 1 (representing DOC), states this is part of a "multiplier effect" where the relationships that DOC builds with areas of society not typically associated with conservation can lead to conservation gains in the long term, specifically the private business sector. These gains may not be in the way of formal participation with the Department's conservation work, periphery projects or even using the recreational facilities DOC provide. However, it can 
be in the way of making conservation mainstream in society and something that is part of everyone's lives in some fashion. To illustrate this point, Participant 1 offers the example of businesses introducing environmentally conscious practices that are then carried on by employees into other work or parts of their lives. This positions the multiplier effect as a crucial component of the attempt of broadening conservation into wider society for the Department.

An example of the broader social engagement DOC is targeting can be illustrated by work focusing on "millennials" (DOC Partnership team, 2016, p. 6). The New Strategist (2012) defines millennials as the generation born between 1977 and 1994. As outlined in Business: A Partnership Strategy (DOC Partnership team, 2016), millennials are recognised to have a "strong belief that brands should stand for a cause, and that working for cause-driven businesses matters" (p. 6). With the millennial generation expected to make up half the New Zealand workforce 2020, DOC wants to be responsive to their attitudes and beliefs and create areas that millennials can contribute to (DOC Partnership team, 2016, p. 6). This focus is demonstrated by the Toyota New Zealand partnership project targeting children in an educational format. This partnership is aimed to increase "Kiwi kids' connection with the natural world" with the intention of establishing a lifelong relationship with the conservation estate and wider natural environment (Toyota New Zealand, 2016). The outcomes of changing opinions in younger generations towards conservation is demonstrated by Participant 7 who states their organisation, Fulton Hogan has observed that their graduates see contributing to social issues as an important aspect of their work. According to Participant 7, "the younger graduates and the like coming into the organisation do ask... about what do we give back?". From DOC's perspective, these attitudes will be indicative of the change that could benefit conservation.

It is important to recognise that there are motivations and incentives from the partnerships model that businesses are attracted to are not exclusively financially based. As Participant 7 states, a particular incentive for getting on board with this particular strategy was for Fulton Hogan's staff to get actively involved with a project that is seen to be a positive contribution to society: 
Whether it's more attractive or not, it's more, I think, you are seeing companies realising that it's just the right thing to do. We've got this... social responsibility, you know, the whole social license to operate etcetera. I don't think it's an attractiveness thing, I think it's more out of necessity. (Participant 7)

As Participant 5 adds, the partnership model allows the businesses involved to have a much more hands-on role, from sharing expertise and business knowledge with DOC to engaging with the project at-site. Participant 5 states, "we've (Genesis Energy) partnered with the Auckland Zoo as part of the Whio Forever program, so we run a whole lot of work there... and we give out staff a chance to be part of that". This, again, reflects Participant 1's projection that businesses are shifting to include more socially positive actions. It is these apparent genuine intentions from business owners and employees that the Department is trying to tap into to generate more conservation actions.

By using businesses to tell the Department's story, DOC is also aiming to create a higher social profile for conservation in the business sector (Participant 1 and 2). As Participant 2 explains, a real benefit of this is that the current partners involved are large and leading players in their respective industries. By getting these partners to showcase that conservation is something that they have been willing to get involved with, it will potentially help shift other, more reluctant business owners to follow suit. For instance, the partners are conveying to other businesses that "we are involved in conservation because conservation is good for business. And if you're not involved with conservation, you're missing the boat" (Participant 2). Speaking from DOC's position, Participant 2 adds that the use of an industry leader demonstrating and giving specific first-hand examples to other New Zealand business owners is much more powerful than a representative from DOC. "When the CEO of Air New Zealand says it, they, listen" (Participant 2). Through this leadership taken by Air New Zealand, DOC aims to see other businesses participating with conservation in some way as a result with a longer-term goal of having every business involved with conservation in New Zealand. This use of commercial businesses is summarised by Participant 2, who states "So how do we [DOC] use their influence to get into hearts and minds and ultimately to lead to more conservation being done?". This is a clear 
representation of the scope that DOC is trying to get to support their intention of wider public involvement in conservation.

\subsubsection{Mirroring a wider approach}

The New Zealand government has made explicit moves to increase the economic contribution from conservation (MBIE, 2014). This pursuit of increased contributions is to be fulfilled in a variety of ways, for instance; through making changes around the contributions that businesses concessions provide (Craig et al., 2013; Dinica, 2016). Alternatively, this can also come through the leverage that the New Zealand national image and brand has which attracts tourism and global consumers (McIntyre et al., 2001). As stated by Dinica (2016), this has seen terms such as "greening growth" and "conservation economy" used by political actors and Departments, specifically by those that either directly manage, or manage economic sectors that rely on, natural resources. This represents a changing discourse on conservation's place in the New Zealand society and economy (Craig et al., 2013; Dinica, 2016). It also demonstrates the importance of conservation, which now widely recognised to be "underpinning our economy" (MBIE, 2015, p. 1). Examples of this is represented through the delivery of life-supporting services (Russell et al., 2015) and the provision of natural environment's condition for tourism (Dinica, 2016). These connections provide explicit incentive to achieve conservation targets alongside social and economic goals.

Dinica (2016) stipulates that there doesn't appear to be any new government policies pursuing improved environmental or climate change initiatives that would indicate a true greening of the economy. Rather, the government is relying on businesses gaining access and benefit from aligning with the conservation estate who will then contribute back to the wider movement (Dinica, 2016). However, Participant 1 (representing DOC) proposes that one of the advantages of using commercial partnerships is their political influence. "So, one of the really important things here is I think, businesses, and particularly our large businesses, to a very large degree influence policy settings and 
direction for the country". Participant 1 continues by stating "rather than constantly banging away a government level, then the government changes. businesses could play a really strong role as champions, and advocates for a different future for New Zealand. A different premise really". Participant 1 adds that this can help create a new area of value to New Zealand. As participant 1 adds, there are already a lot of businesses around New Zealand contributing in some way to conservation. However, by aiming to get "every business in New Zealand to be restoring our nature" (Participant 1), New Zealand can reinforce its point of difference in world. This can also reaffirm our influence globally to be of value by leading the way in this approach (Participant 1). This uniqueness, DOC claims, can simultaneously strengthen New Zealand's cultural identity that is enshrined in the natural environment and conservation work (DOC, 2016a).

\subsection{The changing place of business involvement in conservation partnerships}

The presence of business involvement with conservation is significant as the relationship between private business and economic functions has been traditionally seen as incompatible with environmental conservation (Craig et al., 2013; Tallis \& Lubchenco, 2014). As Rajvanshi (2015) states, unsustainable economic development and industrialisation has generated an extensive impact on the environment. However, there has been as notable shift in the links between conservation and business. Here, a caveat is needed as the inclusion of 'business' is more specific than just opening up the conservation estate to direct influence of capitalist markets (Büscher, 2014; Büscher et al., 2012; Fletcher, 2010). Rather, by engaging with specific parts of the business sector and redefining its place in society, a more human-centric approach to conservation.

The inclusion of the business sector in conservation is notable for a number of reasons. Primarily, the pursuit and inclusion of business is now seen by many an inevitable, if not necessary, for conservation to be successful (Kareiva, 2012; Marvier \& Kareiva, 2014). This is together with a wider cohesion between business and the environment. As Participant 1 states, "Businesses and nature 
have to live in harmony. There has to be a balance, and there is a potential imbalance in some places, but there has to be a meshing together". As Kareiva (2012) explains, recognition that human impacts on the environment are unavoidable is becoming a dominant view. Rajvanshi (2015) adds that halting economic development will not provide the long-term conservation outcomes sought, nor is it likely to be achievable. Similarly, the pursuit of social development goals is increasingly seen to be compatible with conservation goals. This is a move away from the traditional binary of economic growth versus environmental conservation, or as Lalasz et al. (2011) declare, the choice between prosperity or biodiversity.

The involvement of the business sector in efforts to provide benefits for the environment is not a new concept. As Marvier and Kareiva (2014) point out, businesses are already starting to implement schemes and practices in attempt to become more sustainable. The authors add that many of these businesses are implementing the changes to generate competitive advantages rather than out of altruistic motivations (Marvier \& Kareiva, 2014). However, the Business: $A$ Partnership Strategy (DOC Partnership team, 2016) illustrates that New Zealand businesses have been tardy in their implementation of sustainable practices, with even less providing any restorative biodiversity contributions. In many circumstances, implementing these actions are primarily about businesses managing their social license to operate - which is particularly important to those who are using natural resources (Participant 7; DOC Partnership team, 2016). Supporting this point, Participant 7 from Fulton Hogan states that the partnership project with DOC they are carrying out is not actually intended to provide any commercial advantage for them. Rather, it is part of an attitude from the organisation that such a collaboration is "the right thing to do" (Participant 7). This reflects DOC's attitudes that many New Zealand businesses "want to be part of something bigger" (Participant 1) than just continuing a business as usual approach. 


\subsubsection{The careful balancing act of conservation and business involvement}

Proponents of conservation actors and private business argue that working together has the potential to generate significant benefits for the conservation movement (Marvier \& Kareiva, 2014). However, as outlined by representatives from the NGO participants (Participants 3 and 4), there are potential hazards around the government further reducing DOC's budget if the commercial partnerships program is deemed to be a success. As previously outlined in section 4.1.1, DOC is already perceived to be facing some significant budget pressures (Participants 1 and 7). With these pressures and the potential of utilising the immense private business sector as a resource (DOC Partnership team, 2016), Participants 3 and 4 both emphasise that DOC will need to be very careful in balancing its pursuit and involvement of businesses as a funding source. As the representative from the environmental NGO, Environmental Defence Society (Participant 4), states, "I think generally speaking though, the idea of business stepping up to the plate and doing things for conservation, like predator control and so on, is a good thing and should be encouraged". However, Participant 4 also adds that there are certainly risks of including external organisations, specifically private companies, and their potential influence, intentional or otherwise, DOC strategy and policy. "There is a danger that you can get non-strategic sort of buy-in from DOC, for ill-conceived, business fashions" (Participant 4). Participant 4 adds "you [could] get business driving strategic, or driving non-strategic responses, that's the fury critter that they want to latch on, rather than looking at, say, habitat management more broadly". DOC's challenge is to further balance conservation outcomes against producing wider business involvement as consequence of such a wide range of commercial partners now part of the model,

To produce the best results from the relationship between business and conservation, Participants 3 and 4 see the commercial partnerships models as most appropriately used as an added benefit. This would be in addition to sufficient budget support from government, rather than being used as key funding source (Participants 3 and 4). Subsequently, how the commercial partnerships are used by DOC are an important component of gaining support 
from other conservation organisations. "So, views on the partnership model, need to say that we've [Forest and Bird] never been opposed to, you-know, corporates getting engaged with conservation, that's fine... it's the icing on the cake" (Participant 3). However, Participant 3 elaborates that is unlikely to be restricted to just being the 'icing on the cake', rather, it may increasingly displace state funding of the Department. Participant 4 argues that "the other problem, of course is that in-part, [the partnerships] can let government off the hook, so there's a delicate balance that needs to be struck here between getting additional resources and keeping the pressure on government to right-size the budget". Finding the balance of trying access new resources can also have repercussions for other actors in the conservation domain if not implemented carefully.

Further complicating the situation is that DOC's pursuit for resource support from the private sector has created tension within the New Zealand conservation domain. As participant 3 explains, DOC is now encroaching into areas where many NGOs and community groups acquire their funding from. "You're [DOC] also taking away from their potential sources of their own sponsorship and money. You're competing, you're now competing with the Forest and Birds, the Fish and Games, the WWFs" (Participant 3). Participant 3 continues, "and again, they are actively competing with the conservation groups in the community for philanthropic money". With DOC's strong brand recognition within New Zealand, it is incredibly hard for smaller groups to compete with businesses looking to gain some leverage back of their support of conservation (Participant 3 and 4). This frustration is illustrated by Participant 3, "there's this real naivety in there [within DOC], they don't see that they are the big elephant, therefore that when they move around, all sorts of things get trampled, they don't see it". This can have significant wider implications regarding DOC's intention of enabling wider involvement with the movement and may lead to the unintentional consequences of a reduced NGO, non-profit and community sector capacity for conservation work. 


\subsubsection{Additional challenges of pursuing business involvement in conservation}

Increasing reliance on commercial partnerships and business could lead to significant challenges in relation to fluctuations of the economy and within individual businesses. While it is not always revealed why businesses pull out of sponsorship programs, or in this case partnerships, the recent movements and acquisitions within DOC's commercial partners is evident of such challenges. Where companies do pull out of a funding scheme, it can create real tests for the continuation of a project or, indeed the survival of species (Participant 3 and 5). As demonstrated by Participant 5:

One of the biggest risks for us is if we no longer fund whio, if we withdraw after five years, we've never said it's a given it's going to continue, we've managed to support it for 10 years so far, so what does it look like if we pull out. Do you leave a species high and dry? So, there's a real element of, if we withdraw from it, and don't continue the partnership, does it fall over. (Participant 5)

Participant 3 highlights the example of lack of a current partner associated with the kiwi. "BNZ pulled out in 2011, I think, maybe 2012, it's been a while now, they pulled out and they have not been able to find a sponsor... its speaks volumes". Participant 3 adds, "it's our national icon... it's the species with the most community groups associated with its conservation, direct conservation, so it's superb for a sponsor". This example demonstrates the precarious nature the conservation estate has when relying on business partnerships.

DOC's inclusion of business partnerships has been approved by some of its critics providing it is done "right" (Participant 3 and 4). Understandably, what is deemed to be the 'right' way of doing it is up for debate, however, there are objectives that are agreed on. For example; conservation has to be is a "clear winner" (Participants 1 and 2). To what extent is conservation the clear winner is also a question that needs to be raised. Soulé (2013) similarly presents trepidation with new parts of society becoming involved with conservation with the understanding that it can benefit them in some way. For example, the focus on the certain species has been demonstrated by Genesis Energy supporting the whio (blue duck) and Fulton Hogan aligning itself with the takahe. Reinforcing 
Participant 3's statement, business involvement is great for the individual species whom the partners involved are providing resources for. However, while this species focus provides an easy marketing tool, it may not be the most effective tool for ecosystem protection (Brockington et al., 2008, Participant 3). For instance, this may restrict the decisions around conservation resource allocation to monetary-based value judgements (Miller, Soulé and Terborgh, 2014).

\subsubsection{Changing power relationships within the conservation domain}

With DOC utilising large businesses to tell their conservation story, this presents a number of questions on where power is situated. Following Foucault's work, the Department is an important source of power and knowledge. Reinforced by the Department having its own cabinet minister and policy making ability, DOC has established its political authority alongside other government departments. (Craig et al., 2013). Through this authority, DOC is able to influence dominant conservation discourse and practices (Young, 1981; Phillips et al., 2004). However, increasing the business sector involvement and influence may lead a shift in power relationships. Linking to Participant 3 and 4's concerns relating to the increased involvement of large businesses (see section 4.3.1), other actors in the New Zealand conservation domain may see their involvement, access or influence change.

An added consideration is that DOC is also aiming to establish itself as a facilitator between community groups and businesses (Participants 1 and 2, both representing DOC). In this position, DOC uses its networks to link community groups who are seeking funding and resources to businesses willing to step in. Participant 2 uses the example of Kiwibank where DOC was able to get them on board as a partner supporting a particular project as part of their commercial partnerships strategy. In addition, they also were able to link Kiwibank and a community group for conservation projects. This position of DOC as a facilitator is aimed at producing conservation gains through community collaboration where the Department is used in a background 
supporting role. As Brockington et al. (2008) state, if such collaborative efforts are done well, it can produce positive outcomes such as increasing social democracy. However, the authors note that the use of these networks does not automatically lead to the realisation of biodiversity goals, but as Participants 1 and 2 acknowledge, they can help generate more social interest and business involvement. "We've got to find ways to connect and make it easy for businesses at a local level to get involved with conservation. That will build community support for business and business support for community groups" (Participant 1). This follows the intention of getting more conservation achieved from expanding society's involvement.

Through enhancing its role as a facilitator, DOC is able to remain as a key player and help to preserve its influence in the conservation domain. Equally, DOC may also be reducing its own importance and position within the conservation domain to the perception of others. As highlighted by Participant 7, "they have moved from this authoritative almost dictatorial position to more consultative". This is in reference to DOC's historically authoritative approach to its work which consequently allowed people to rely and entrust on DOC to carry out conservation work. As summarised by Participant 1, “we've probably being guilty in creating a department that's seen to do the work. Oh conservation, Department of Conservation will look after that". Hardie-Boys (2010) reinforces Participant 7's previous statement that the Department is now using collaboration and engagement with external groups as main strategy in its attempt to encourage wider involvement with conservation.

\subsection{Chapter summary}

The premise that conservation is failing to achieve its goals has proved to be a powerful discourse. Specifically, it has enabled new approaches to conservation to become established. The failure discourse rests on the Western scientific values and measurements which subsequently restricts proposed alternative approaches and strategies for conservation action. Proponents of new conservation appeal for a wider scope of society to become involved in 
conservation efforts, with the main premise of this is an increased business presence in the domain. This research has shown that the use of commercial partnerships is the main mechanism for achieving this. The commercial partnerships are intended to provide DOC with access to additional funding and resources, access to new areas of society to make conservation mainstream for all New Zealanders.

While there is support of broader public involvement from the interview participants, the presence of large, well-known business in conservation has been met with caution. Questions remain around whether the increase of resource support from partners will change the budget allocations from central government remain. Similarly, there are fears that with DOC attracting private business support it will increase competition between external groups and environmental NGO's for access to funding. This, consequently, may result in change in power locations as DOC shifts away from its historical authoritative approach to conservation. The following chapter will explore the role of neoliberalism in producing and shaping new conservation initiatives in Aotearoa New Zealand. 


\section{Chapter Five - How conservation, neoliberalism and partnerships fit together in Aotearoa New}

\section{Zealand}

\subsection{Introduction}

This chapter examines the ideology of neoliberalism and how it is found within conservation in Aotearoa New Zealand. Initially, neoliberal ideology and how the ideology represents a process will be outlined. Following the definition of neoliberal conservation, distinctions will be made between neoliberal conservation and new conservation before discussing how neoliberalism has influenced the use of partnerships. The chapter will then examine the four main components of neoliberalism found in conservation; commodification, commercialisation, marketisation and privatisation. Examples of how these components are evident in the case study are provided. This chapter then examines how neoliberalism can influence future strategies and the contradictions produced through neoliberalising conservation.

\subsubsection{Neoliberalism}

The term neoliberalism is commonly used to cover a wide range of market oriented policies and related practices. This, consequently, makes it difficult to identify a single definition of neoliberalism (see Auerbach, 2006; Harvey, 2005; Springer, Birch, \& MacLeavy, 2016; Steger \& Roy, 2010). Furthermore, it has increasingly become a collective label for a broad range of social, economic, environmental and political problems (Springer et al., 2016). Indeed, neoliberalism as an ideology has been enacted in very different ways in a variety of contexts. Using Brenner and Theodore's (2002) and Cachelin, Rose and Paisley's (2015) definitions as a foundation, this thesis defines neoliberalism as the replacement of social and political decision making processes for "market discipline, competition and commodification" (Brenner \& Theodore, 2002, p. $350)$. This is characterised by an emphasis on greater individual responsibility, 
the protection of property rights, encouraging free trade and open markets (Brenner \& Theodore, 2002; Harvey, 2005). In essence, it's the process of shifting the responsibility of resource allocation from states to the market, giving way to increased economic competition which is allowed to reach into all aspects of society, politics and the economy (Cachelin et al., 2015; Springer et al., 2016).

Neoliberal ideology rationalises that increasing market based approaches in replacement of state intervention is the best avenue for continued economic growth. Furthermore, neoliberalism is based on an assumed link between wealth creation and the development of social well-being for a population as the benefits of increased economic action will be dispersed throughout society (Büscher et al., 2012; Fletcher, 2014; Springer et al., 2016). As stated by Büscher et al. (2012, p. 13), "economic growth becomes the prerequisite for positive social... outcomes". Additionally, neoliberalism contends that social benefits can be amplified by extending the range, reach and frequency of market transactions and allowing the market to allocate resources efficiently and effectively (Springer et al., 2016). As a result, with different economic contexts and varying types of mechanisms used around the world, neoliberalism may produce significantly different situations to previous economic models, as well as variations between countries (Büscher et al., 2012; Fletcher, 2014; Springer et al., 2016).

To enable the market to extend its reach, neoliberalism requires the decentralisation of power and responsibility away from the state (Harvey, 2005; Springer et al., 2016). This is commonly matched by the privatisation of state owned assets and a consequential reduction of social services and state funding (Büscher et al., 2014; Harvey, 2005). A product of shifting responsibility to the market is the increased priority given to economic competition and commodification in society (Cachelin et al., 2015; Springer et al., 2016). The versatility and variety of neoliberalism makes it problematic to define a singular role of the state. A transcending theme is that the state's role is reassigned to foster individual responsibility and encouraging entrepreneurial skills through creating institutional framework of strong property rights, allowing free trade 
and open markets (Harvey, 2005; Springer et al., 2016). However, the state is not banned or disqualified from becoming involved in the market once it is operating. Instead, Fletcher (2014) and Harvey (2005) assert that the state must create the terms of market interactions, encourage favourable market conditions, but seek to minimise regulatory obstacles to market intervention and control.

The processes and conditions that neoliberal ideology demands and legitimises has led Foucault to call it a new form of a governing, or 'governmentality' (Foucault, 2008, as cited in Fletcher, 2010). Foucault contrasts governmentality, ways of thinking and acting, with disciplinary government where individuals conform to social norms and ethics. Rather, Fletcher (2010) argues that neoliberal governmentality seeks to create incentives that, combined with internalised regulation, a rational, self-interested individual will follow to carry out acceptable behaviours. In addition, neoliberalism is not strictly a platform for economic interactions, but as a model for society itself (Fletcher, 2010). This neoliberal governmentality prescribes that wider social and environmental arenas should be governed according to the notion that rational, self-interested individuals maximise scarce resources (Adams, 2015; Fletcher, 2010). Consequently, the influence of neoliberalism has seen the creation of markets involving environmental characteristics, notably in conservation and the tourism sector.

A major concern highlighted by Brenner and Theodore (2002) is that there is considerable separation between the theoretical ideology of neoliberalism and what is actually seen in practice. The authors highlight two main points of divergence; first, while neoliberal ideology asserts that free-market oriented systems that are free of state intervention, reality shows that this is quite the opposite. Instead, coercive and punitive state intervention in many areas has intensified with the intention of pushing the reach of markets into new areas of society (Brenner \& Theodore, 2002). The second point is that a neoliberal ideology promises that resources will be allocated most efficiently through the use of self-regulating markets. Brenner and Theodore (2002) contend this point by stating that in reality, neoliberalism has often generated extensive market 
failures, arrested economic growth, produced increasing rates of social inequality and a lowered social security through increased competition.

Against these criticisms, and for neoliberalism to become established, the ideology needed initial, and widespread, approval and consent from the population. Kurian and Munshi (2012) state that neoliberalism is regularly presented as a homogenised picture of selective experiences in ways that work to suppress and obscure the actual failings of the market led approach. Specific language of 'freedom', 'choice' and 'empowerment' are regularly recited (Cachelin et al., 2015, p. 1128; Phelan, 2014, p. 3). Through complex power relations and repeatedly obscured failures, neoliberal approaches have become established as common sense over time and seen as the only system that will work (Harvey, 2005).

\subsubsection{Neoliberalism as a process}

An important characteristic of neoliberal ideology is that it has been implemented in a variety of ways across spatial and temporal contexts (Brenner \& Theodore, 2007; Klooster, 2010). In this sense, neoliberalism should not be seen as a homogenous construct producing uniform outcomes. Büscher et al. (2014) state this led academic scholars and commentators to speak of 'neoliberalisation', rather than 'neoliberalism' or that something is 'neoliberal'. Brenner and Theodore (2007) propose that neoliberalism is not a fixed state or condition, but rather a "process" (p. 153) of transformation (see also Büscher et al., 2014; Harvey, 2005; Klooster, 2010). Prominent examples of this sort of transformation is the historical rise of Thatcherism in the United Kingdom, Reaganomics in the United States of America, and Rogernomics in Aotearoa New Zealand (Brenner \& Theodore, 2007; Larner, 2000; McIntyre et al., 2001). This process is also evident in conservation.

The shift of neoliberal processes into areas of society, specifically conservation, has not happened in one movement. Instead, it has developed progressively, but unevenly, over time, driven by dominant societal actors (Büscher \& Dressler, 2012). Klooster (2010) states that neoliberalism is seldom implemented in 
isolation and is regularly complemented by other policies of social and economic regulation. The variations of neoliberalism are predominately formulated through contextually specific interventions, relying on historical and geographical factors of the respective areas (Brenner \& Theodore, 2007). In addition, Harvey (2005) notes that it is not just a process of developing and rolling out attributes of neoliberalism, but historical examples also show that it can be reversed or certain aspects of it withdrawn when the outcomes are undesirable. This has enabled neoliberal conservation to restructure the relationship between society and the environment in order to achieve its objectives (Büscher \& Dressler, 2012).

The process of neoliberalism is illustrated within DOC's evolving commercial partnerships model (Büscher \& Dressler, 2012). Specifically, it is represented by the increasing presence of business involvement and the implementation of the commercial partnerships model from a historical setting of a state-run conservation estate. Simultaneously, the implementation of partnerships can also represent a new form of neoliberalism, adapting to fit the specific regulation and political currently in place in New Zealand (McIntyre et al., 2001). This characterises a much more socially inclusive neoliberal approach from the historically authoritative, top-down approach from the Department (DOC Partnership team, 2016; Participants 1 and 7). However, it retains direct links to the decentralisation, devolution and privatisation of government assets - key components of neoliberalism (Harvey, 2005; Larner, 2000).

\subsubsection{Neoliberal conservation}

Neoliberal ideology has become part of global conservation leading critics and scholars to employ the term 'neoliberal conservation' to describe these new approaches (see Brockington et al., 2008; Büscher, 2014; Igoe \& Brockington, 2007; Jones, 2012: Fletcher, 2010; 2012). The neoliberal influences in conservation are highlighted by a number of key features, most readily identified by the rolling back of state intervention and decentralisation of responsibility to regional authorities, NGOs and other non-state actors. In 
addition, the privatisation of resources and increased market influence has also led to the commodification of resources, which has facilitated new areas of consumption (Fletcher, 2012; see also Brockington et al., 2008; Büscher, 2014; Igoe \& Brockington, 2007; Fletcher, 2010). Neoliberal conservation promotes the expansion of market involvement and the extension of capitalism as the best potential to produce conservation outcomes (Büscher et al., 2012). Büscher et al. (2012) state that this new direction for conservation is becoming more common as states shift away from the more-traditional conservation-welfare approach.

In order to generate conservation outcomes, neoliberal conservation strategies require the potential for profit to incentivise consumers into desired behaviours. A fundamental component of neoliberal conservation is the endorsement that conservation and economic development are presented as win-win scenarios (Büscher et al., 2012; Fletcher, 2012). For instance, the protection placed on the environment and subsequent regeneration of resources can then support the increase of economic activity (Büscher et al., 2012). This cycle then positions the idea that continuous economic growth can be achieved simultaneously with conservation goals. Prominent and well documented examples of neoliberal conservation are ecotourism and payments for ecosystem services, as well as the less common bioprospecting (Büscher, 2014; Fletcher, 2012). Brockington et al. (2008) add that local communities and stakeholders are often pursued as participants in conservation-business relationships in attempts to win support for these approaches and to demonstrate associated positive economic development. However, Büscher et al. (2012) present an important caveat stating that payments to conserve the environment do not often go directly to the environment or communities, but rather to those that can capture them, for example, NGOs or business that have the ability to collect payments.

Conservation projects have the capacity to alternately or simultaneously restrict and create new areas for capitalism to access. For example, conservation projects can partially or completely fund themselves through tourism by presenting attractions in the conservation area. Alternatively, conservation 
areas can also provide a representation of the apparent absence of destructive market forces (Brockington et al., 2008; Collard, Dempsey \& Rowe, 2016). Jones (2012) refers to this as "staged authenticity" (p. 256) where simplified, idealistic representations of conservation are presented. These representations are commonly of socio-environmental relationships identified to be creating environmental issues, which are then frequently matched with ways to remedy them. These representations can also conceal and obstruct any contradictions found in reality (Brockington et al., 2008; Collard et al., 2016). These contradictions are a prominent feature of neoliberal literature, which will be expanded on in section 5.5 .

Whether intentional or not, the links between neoliberal conservation and new conservation are apparent. For example; prominent features of both neoliberal conservation and new conservation are the presence of actors previously seen to be incompatible with conservation - specifically the inclusion of the business sector. (Büscher, 2014; Fletcher, 2010; Kareiva, 2012). Kareiva (2014) is clear to point out that proponents of new conservation do not advocate for the replacement of more traditional conservation approaches, such as PAs, for ones based strictly on economic growth and corporate partnerships. However, Petriello and Wallen (2015) argue that the position, or diluted position, of intrinsic value in how conservation should be carried out is a prominent indicator that new conservation aligns convincingly with neoliberal approaches (Petriello \& Wallen, 2015). Subsequently, this thesis links the use of new conservation with neoliberal approaches in conservation. This establishes that advocates of new conservation are in reality advocating for stronger neoliberal approaches to conservation.

\subsubsection{Neoliberalism and the emergence of partnerships}

Neoliberal reforms have been implemented in many countries around the globe, including in Aotearoa New Zealand (McIntyre et al., 2001). The 1980s saw radical economic restructuring, which dramatically changed the New Zealand political and economic landscape (Curtis, 2015; Kurian and Munshi, 2012; 
McIntyre et al., 2001). The New Zealand model saw deregulation, the opening up of the economy to foreign investment alongside the sale of state owned assets, and the push for a more market oriented approach became the mainstay of the shift. As a result, New Zealand went from being one of the most regulated and economically interventionists countries in the world, to one of the most deregulated and market focused (McIntyre et al., 2001). Scholars have observed that the neoliberal approach has gone through three distinct phases in the New Zealand political landscape (see Aimers \& Walker, 2016; Craig \& Porter, 2006; Larner \& Craig, 2005). Initially, it was the withdrawal of state-led and managed economic production to an increase in marketisation of the nation's economy (Aimers \& Walker, 2016; Larner \& Craig, 2005). The second phase followed in the early 1990s, which saw a further increase in marketisation and subjected social policy to a more punitive, neo-conservative approach (Aimers \& Walker, 2016; Larner \& Craig, 2005). However, it was the third phase that opened up the opportunity for conservation partnerships as part of a broader emphasis on partnering business, communities and the governments together (Aimers \& Walker, 2016; Craig \& Porter, 2006; Larner \& Craig, 2005).

The implementation of such partnerships was presented as providing a range of benefits, including sustainable development, increased social inclusion and democracy in the provision of key services, building social capital and supporting local developments. This is intended to be carried out while maintaining the core neoliberal economic structure already implemented (Craig \& Porter, 2006; Larner \& Craig, 2005). Craig and Porter (2006) state that as consequence, a complex mix of partnerships, competition, free markets and community was created, which has produced a mix of outcomes and a corresponding range of critiques.

Larner and Craig (2005) argue the use of partnerships came as a response to the fragmentation of services produced by the neoliberal policy shifts of the late 1980s and early 1990s. The authors add that the use of partnerships could be seen as a compensatory measure for the deficiencies and limitations of a strong market oriented approach (Larner \& Craig, 2005). Aimers and Walker (2016) highlight that the partnerships approach became an appropriate way to 
breakdown some of the power imbalances and hierarchies between state and non-state actors. Partnerships were also seen a pathway to generate increased "community capacity" (Aimers \& Walker, 2016, p. 340) through fostering community networks and relationships. However, Aimers and Walker (2016) note that the pursuit of such partnerships failed to acknowledge issues surrounding inequality and power as a result of the underlying intention of neoliberalism's focus on capital.

\subsection{Neoliberalism's link with partnerships and conservation in Aotearoa New Zealand}

The influence of businesses and market-based principles has fostered the increase of competition within society (Harvey, 2005; Jones, 2012). Büscher et al. (2012) and Harvey (2005) state that competition is a fundamental component of neoliberal ideology and is commonly linked with the pursuit of generating efficient use of resources. When applied to the conservation sector, this increase in competition can have broader negative impacts for other organisations. A prominent outcome of increasing competition in the conservation domain was previously highlighted by Participant 3 with conservations competing with DOC for external funding and support (see section 4.3.1). However, other impacts are concentrated on the management of the commercial partnerships and the potential outcomes this may produce.

One of the notable productions highlighted by Larner and Butler (2005) of the emphasis of partnerships is the "unnatural groupings" (p. 81) of participants. Larner and Butler (2005) state that for these groupings to succeed, considerable efforts are needed often requiring designated personal or teams to make the collaboration happen. This situation of unnatural groupings is represented by DOC's partnerships with business and supporting involvement from NGOs (Participant 3). Potentially providing further challenges is the relationship between corporate business and conservation which has typically been represented as combative and mutually exclusive. In addition, Larner and Butler (2005) also raise questions around the effectiveness of allocating significant 
amounts of resources to maintaining the unnatural groupings of the partners. The priority placed on creating partnership can oversimplify and obscure the realities of the historical relationships between the partners, specifically between community groups and government. This point is enhanced by a lasting scepticism around the actual intention of the partnerships model - as queried by interview representatives from environmental NGOs (Participants 3 and 4; see also Larner \& Butler, 2005).

Further questions are prompted on how partnerships can continually produce desirable and equitable outcomes in such a structured relationship, formalised by contractual arrangements (Aimers \& Walker, 2016; Larner \& Butler, 2005; Craig \& Porter, 2006). Larner and Butler (2005) question whether the genuine, organic outcomes of the partnerships can be realised with the inherently formalised process that occurs. The authors outline that as a result, government departments must allocate valuable time and resources to the cause. The partnerships within DOC's commercial partnerships do carry some of these concerns. The individual connections between the Department and the respective partners are different in each relationship. For example, the likes of Air New Zealand and Genesis Energy have long standing relationships that evolved over time into formal partnerships (Participant 2 and 5). Others, such as Fulton Hogan, are more recent alliances that have grown out of the partnerships strategy (Participant 7). Creating potential further challenge is the range of projects and goals between partners, with Toyota New Zealand championing an education-oriented program to other partners working with endangered species (Participant 5, 6 and 7).

With shifting priorities, direction and the role of different parts of society, DOC must continue to balance the realisation of conservation goals with maintaining public support (Aimers \& Walker, 2016). As Participant 2 states, "we've got to be really clear, we are public servants. So, our role, here, is to serve the public". This is where the balancing act that Harvey (2005) highlights comes into play for DOC. Harvey (2005) expresses concern that this can have significant consequences for democracy within the state. By chasing the allure of commercial partnerships, involvement cannot be to the detriment of providing 
and protecting social good. With an increasingly blended line between corporate business and the state, Harvey (2005) adds that with corporate business on board with the partnerships model, states often look to provide security for the partners by repressing and resisting dissent of such practices. However, this could work to marginalise communities and parts of society that are not part of formal partnership programs (Aimers \& Walker, 2016).

\subsection{Commodification, commercialisation, marketisation and privatisation}

The encroachment of neoliberalism into environmental conservation has been characterised by four components; commercialisation, commodification, marketisation and privatisation (Bakker, 2007; Castree, 2003; McAfee, 1999). The following sections expand on each of these components and uses them in turn to examine DOC's commercial partnerships.

\subsubsection{Commodification}

Commodification can be defined as the creation of an economic good, or commodity, able to be sold at market determined price (Bakker, 2007; Castree, 2003; McAfee, 1999). This 'good' can be in the form of a service or object that becomes standardised and able to be incorporated into economic markets (Bakker, 2007). The commodity's previous status, category or value is replaced by an assigned worth, while simultaneously establishing the commodity as having a fixed identity. In addition, commodification is inherently about renaming or reassigning an object, idea, human or other entity to become a commodity (Castree, 2003). According to Büscher et al. (2012), commodification also constitutes the process of, or a major contributor to, the deconstruction of holistic features or processes into smaller, more marketable pieces. This is particularly poignant when applied to ecosystems, which become separated and disconnected leading exaggerated degradation and obscuring other negative ecological consequences (Büscher et al., 2012). 
Castree outlines the characteristics of commodification that are particularly relevant to the environment. The first characteristics identified is 'individuation' (Castree, 2003 p. 280). Individuation is an essential practice of the commodification where areas or objects in focus are removed from their surrounding context. This action of defining boundaries around features is in preparation to buy, sell or trade them. In application to environmental conservation, this disconnects the feature or object from its original role in an ecosystem. Consequently, this can reduce or ignore its previous significance within the system (Castree, 2003). Individuation can be identified within the commercial partnerships in the specific focus on native birds from Genesis Energy who are aligned with the whio and Fulton Hogan's support of the takahe. Another important characteristic of commodification highlighted by Castree, (2003, p. 281) is 'valuation'. The assignment of value is fundamental to the feature becoming a commodity, which as Castree emphasises, dilutes other types of value it previously held. For example, ethical or intrinsic value. Instead, with the impression of neoliberalism and a background of capitalist markets, value is largely reserved for measurement in terms of labour or monetary value (Castree, 2003; Miller, et al. 2014).

One of the most pronounced examples of commodification is the production of representations that show the environment in a specific way. Referred to as the "spectacle of nature" (Büscher et al., 2012, p. 16; Jones, 2012, p 256) this production works to shape human relationships with the environment. The core mechanism of these representations is the "production, distribution and consumption" of images (Büscher et al., 2012, p. 17). However, as Büscher et al. (2012) adds, the spectacle of nature is more than just the presentation of a single or a small number of images. Rather, it is a series of representations that work to mediate and commodify people's relationships with the environment. This mediation is done through the promotion and obstruction of certain features working to generate specific relationships between society and the environment while detaching them from the original context (Brockington \& Duffy, 2010; Jones, 2012). 
As society consumes the representations, it transforms how people see a place in terms of what its represents, what is in focus, and what it is constructed of. These representations can also drastically shape how people relate and connect to an area (Jones, 2012). For example, environmental NGOs and organisations have developed and circulated particular images of the environment in support of their view point (Brockington et al., 2008). This is often through the selective production of images showing the negative effects of capitalism on the environment (Büscher et al., 2012). This also can involve the production of images of environments absent of human presence or modification which promote a distinct discourse that ecosystems work best in isolation from human involvement (Jones, 2012). These representations reinforce the Western scientific paradigm of the separation of humans and the natural environment, as discussed in section 2.1.1.

In contrast, neoliberal conservation efforts are also using the spectacle of nature to influence conservation discourse. Jones (2012) states that it is becoming increasingly popular for businesses to support environmental issues by selling the idea of consumers contributing to conservation through purchasing their products. This, as Büscher et al. (2012) highlight, can create a number of issues relating to the idea that society can just consume its way to providing conservation outcomes. For example, Igoe et al. (2010) assert that the use of specific representations presents a target audience with appealing incentives for the consumption of specific products. This is frequently through the presentation of the environment as an object of necessity, desire and indulgence, which can only be obtained through consumption. In addition, the representations showcase that it is only through consuming those particular products that conservation goals can be realised (Büscher, 2010).

The spectacle of nature can be found throughout the commercial partnerships. As previously mentioned in section. 4.2.1, the significant advantages of the partnerships model are the use of the expertise and resources for marketing. For instance, the respective partnerships have designated websites (for example; Whio Forever and Toyota New Zealand's Kiwi Guardians) which show people actively involved with conservation projects or activities. Through these 
examples of individual business marketing campaigns, the increase in individual company involvement in turn leads to the increased visibility of the partnerships model (DOC Partnership team, 2016). This build-up of images depicting business supporting conservation efforts, reinforced by a discourse that wider participation is needed, presents conservation as human-orientated and reliant for its success. This supports Büscher et al. (2012) and Igoe, Neves and Brockington (2010) that the production and consumption of such spectacles of nature shifts away from people seeing the conservation estate as an isolated, human-free domain.

The representations of the relationship between conservation and businesses is also attempting to break down ingrained negative attitudes in relation to how these areas interact with each other. This is carried out through the delivery of positive media stories about conservation produced by DOC. As Participant 3 explains "there are a lot of good news stories, despite the fact there's also a lot of bad news, but DOC only tends to pump it out in one direction". Participant 3 adds by stating, "New Zealander's love conservation and a lot of them are doing it" indicating that businesses would have the opportunity to support this social activity. As noted in the Business: A Partnership Strategy (DOC Partnership team, 2016), the intention goes the other way too, with DOC attempting to change how businesses see their place within the conservation domain. As the Business: A Partnership Strategy outlines, this strategy "is helping to reassure businesses that they are not being put in the 'bad' camp" (p. 4). This was also highlighted by participants from the commercial partners $(5,6$ and 7$)$ who had noticed that DOC was making a real effort to change its appearance to business in being more business savvy and friendly. These examples demonstrate that DOC is attempting to make conservation more integrated with the business sector.

\subsubsection{Commercialisation}

In recognition of the conservation challenges that DOC is facing, Participant 7 queries "I think they're being forced to consider more commercially about their, certainly about their assets". Ewen, Adams and Renwick (2013) argue that DOC 
has implemented three major policy changes. The first is to increase efficiencies of the Department's use of resources by broadening the range of target groups to capture wider ecological functions. Second is the use of optimisation tools to allocate conservation resources at a national level. The third policy is to seek wider community engagement in conservation while implementing the first two policy directives (Ewen et al., 2013). Participant 3, representing Forest and Bird, states that these policy changes are a result of a current "Government that has very much a commercial view on the world". Consequently, "there is a worry around the commercialisation of public conservation land, [it] is a concern" (Participant 3). In order to assess Participant 3's concerns, how commercialisation is defined and represented must be outlined.

Commercialisation is the introduction of commercial principles, for instance, the pursuit of efficiency within an organisation or process. Commercialisation also includes methods and practices, commonly exemplified in the form of costbenefit assessments, alongside commercial objectives, such as the pursuit of profit (McAfee, 1999: Sullivan, 2013). As described by Bakker (2007), commercialisation signifies the institutional change of social norms, customs and rules. Explicit examples of commercialisation can be found in the form of "efficiency", "cost-benefit assessments" and "profit maximisation" (Bakker, 2007, p. 103). Jones (2012) asserts that conservationist organisations are increasingly using "market mechanisms and business principles" (p. 251) to achieve conservation goals. Importantly, representations of commercialisation are able to located within the New Zealand conservation domain.

Language indicating the influence of commercialisation can be found throughout the data and supporting documents released by DOC. For instance, the Department's 2016 Statement of Intent explicitly outlines the intention to "improve both the efficiency and effectiveness of its work programmes" (DOC, 2016a, p. 14). Further illustrating the commercial language used, "we [DOC] have engaged with stakeholders to look at the value obtained from existing programmes, and to prioritise our activities on a value for money basis" (DOC, 2016a, p. 21). This is then reinforced by Participant 1 who states "I guess it's taking a large corporate model and very loosely saying, well sure, you've [the 
partners] actually got a business relationship with us on public conservation land". The commercial interest in DOC's work is also represented by Participant 6 from Toyota New Zealand, who states that "if we're not able to leverage it or we're not feeling like it's really offering the benefit it's supposed to then we may not renew it". This language explicitly demonstrates the growing commercialisation that the conservation estate is experiencing.

In addition to the language of commercialisation, there was a commonly repeated idea from DOC representatives that the partnerships model is an "investment" (Participants 1 and 2). This was demonstrated by Participant 1 who states, "We consider it an investment in conservation", which was supported by similar language throughout supporting DOC documents. For example; the 2016 Statement of Intent asserts "conservation is seen as an essential investment in New Zealand's wellbeing and brand" (DOC, 2016a, p. 19). Following suit, the 2016 Annual Report has performance indicators monitoring the level of investment, specifically the "Change in the level of investment in conservation from the commercial sector" and "Improvement in level of return on investment for key DOC products and services" (DOC, 2016a, p. 73-74) However, the approach in moving towards an investment mentality is not strictly proposed in monetary sense, for either input or output. As highlighted by Participant 1; "You could say it's a return on investment, but not in a financial term". This links back to the stated intention of the commercial partnerships model to create wider social engagement with conservation.

Bakker argues that commercialisation is also changing the language when referring to people or external groups. A notable example is the change in referring to these actors from 'citizens', to 'customers' (Bakker, 2007). This changes society's place and involvement in debates, policy discussions and conservation itself (Bakker, 2007). Society is positioned strictly as consumers which can exclude those who cannot or are unwilling to afford access, or for those people who engage with the environment outside of commercial processes (McAfee, 1999). This use of new language is clearly articulated by DOC who have prioritised marketing to new customers. The 2016 Annual Report outlines how DOC must take a "customer-focused approach" (p. 24) when 
working with its partners, organisations and "thousands of New Zealanders and international tourists" who use and interact with the conservation estate in some way (DOC, 2016a, p. 24). With this customer framework in mind, "this means telling the conservation story with them in mind, putting them at the centre of what we do, and ensuring our engagement with them is high quality" (DOC, 2016a, p. 24). Drakeford (1997) cautions that the position of society as a 'customer' can have repercussions for the quality of product that is delivered as consumption can override the pursuit of conservation goals (see also Hashim, Haque, \& Hasim, 2015).

\subsubsection{Marketisation}

Marketisation can be defined as "a change in transactions, through the introduction or intensification of price-based competition" (Krachler \& Greer, 2015, p. 216). As elaborated on by Ek, Ideland, Jönsson and Malmberg (2013), "above all, the changes mean that business ideals in organising, managing and measuring the results of the activity will increasingly influence the organisation" (p. 1306). Krachler and Greer (2015) continue by stating that common examples include the assignment of pricing mechanisms, the standardisations of goods being sold and the sanctioning of new players in a market. Market influence and solutions are not new to environment mitigation policies with attempts to curb climate change and pollution drawing numerous strategies, for example; carbon taxes (Pearse, 2010). Pearse (2010) highlights that influential factors that have led to the increase of market-based solutions being proposed, tested and implemented, specifically, the global increase of neoliberal policies. This influence has filtered into many areas of conservation, which is demonstrated by Participant 3 who argues the presence, and apparent preference by DOC, of NGOs with more business acumen and market focus. For example, Participant 3 highlights that are DOC seen to be, from Forest and Bird's perspective, favouring the large international environmental NGO, Nature Conservancy, which has a history of employing market-oriented methods to achieve conservation goals (Büscher, 2013). 
The expansion of market influence does bring notable criticisms. As Dunlap and Fairhead (2014) elaborate, marketisation "places the markets between people and nature" (p. 948). This increase of market influence reinforces the priority of economic value and favours profit motivated actions over economic systems, for instance sustainable logic (Sullivan, 2013). In addition, marketisation can invoke more regulatory control, for instance, through the use of performance indicator evaluations - which was illustrated in section 5.3.2 (Ek et al., 2015). These practices construct the environment, as well as conservation, as quantifiable and tradable. This, as Sullivan (2013) argues, is not positioning the market as "selling nature to save it", but also, "saving it to trade it" (p. 200). These critiques of marketisation demonstrate that such processes encourage the commercialisation and, specifically, commodification of the environment.

\subsubsection{Privatisation}

The fourth process outlined by the literature examined is that of privatisation. As defined by Bakker (2007), privatisation describes a change of ownership or management from public to private sector. Harvey (2005) argues privatisation is a central feature of neoliberalism. This is illustrated by the argument that issues such as the tragedy of the commons and overexploitation could be solved through the allocation and protection of property rights (Harvey, 2005). Privatisation was not a significant feature found in the data collected with only one participant (Participant 3 from Forest and Bird) having any reservations on future changes to access or private ownership. As pointed out by Participant 3, capitalist involvement could become a pathway to privatisation, "it's the beginning of it, you can see a logic going working its way through". Participant 3 elaborates his concerns on potential privatisation of parts of the conservation estate by stating "who knows, and at the moment, if someone was to front up to the government and do that, I suspect they'd get a reasonable hearing". However, Participant 3 clarifies by stating that with "the current commercial partnerships we're talking about, I don't see any of them restricting access to the conservation estate... It's usually quite narrowly focused. That is certainly the case at the moment". 
Despite this elaboration by Participant 3, the prospect of privatising parts of the conservation estate has recently entered the public debate. This has been prompted by discussions encompassing the potential privatisation or stronger use of pricing mechanisms for the users of the Great Walks manged by DOC (Graham, 2016). Proponents draw on the current presence of private business working on the conservation estate, typically in the form of concessions (see also Dinica, 2016). However, concerns were raised that the money collected from potential higher prices to access parts of the conservation estate would end up funding more tourism facilities and related needs, rather than being used for conservation purposes (Graham, 2016). This demonstrates the conjecture and possible challenges that DOC would face if such options were taken.

\subsection{The future of neoliberal ideology and conservation}

When considering future possible trends of New Zealand conservation, Brenner and Theodore (2002) make two notable points about neoliberalism that are particularly salient. First is that neoliberalism is inextricably linked to the specific context and history of the region, as well as the legacies of regulatory structures formerly in place. These historical features imprint pathways have led to the current, and future, market oriented policies in place found in different locations (Brenner \& Theodore, 2002). Linking this to the research area, the current political, social and economic climate in New Zealand is the product of successive governments voluntarily implementing neoliberal structures since the 1980s. The legacy of this has been a situation of ongoing reform and adjustments with prominent features of de-regulation, privatisation and market oriented policies which continue to be modified and remodelled (Larner, 2000; McIntyre et al., 2001). The second point highlighted by Brenner and Theodore (2002) is that neoliberalism produces path-dependent outcomes from the historical context to which is it imposed. That is to say that with each different context, for example, the New Zealand context, the outcomes of the institutional reorganisation end up reflecting the historical legacies of earlier regulations (Brenner and Theodore, 2002). 
A significant outcome of this path-dependent quality of neoliberalisation is that it filters into wider social attitudes. For example, Büscher and Dressler (2012) argue that neoliberalism shifts dominant ideas about the environment towards functional, commodity-driven ways of valuing nature. Castree (2003) states that positioning the environment, or features of it, as a commodity can generate "physical and ethical consequences" (p. 283) that are socially not desirable. Furthermore, Harvey (2005) argues that neoliberal processes continue to prioritise a business and investment friendly environment to enable future capitalist endeavours. Consequently, the marketisation of the environment may override the value placed on resources by local communities, such as social or cultural value. The consequence of this priority is that labour and the environment are treated as commodities which can lead to the marginalisation of citizens and the continued degradation of the environment (Harvey, 2005). With strong national identity links to the environment, the potential consequences of the ongoing commodification of conservation may produce numerous undesired outcomes for the New Zealand society (Ginn, 2008).

\subsection{Contradictions of neoliberal conservation}

A fundamental critique of business involvement with conservation is the contradictory relationship that capitalism inherently has with the environment. As described by Büscher et al. (2012, p 13), capitalism fails to recreate the conditions to continue its own reproduction. This occurs where profit maximisation is the main objective of the relationship between society and the environment. Büscher et al. (2012) argues that profit will typically win when placed against the pursuit of environmental and social outcomes. Fletcher (2010) adds that negotiating this challenge is particularly problematic where the value of extraction and consumption is higher than leaving a resource insitu. The author adds that when environmental conservation approaches incorporate economic market influence, profit maximisation will remain the first priority (Fletcher, 2010; see also Christensen, 2004). Büscher et al. (2012) argues that neoliberalism further exaggerates these capitalist contradictions by exacerbating the forces behind them. As stated in section 5.1.1, neoliberalism 
contradictorily places economic growth as the prerequisite for the expansion and achievement environmental conservation.

Demonstrating further additional contradictions of neoliberalism, Büscher and Dressler (2012) state that neoliberal theory indicates that through commodification, competition and subsequent resource consumption, individuals are incentivised to increase efficiencies with the resources they have. This reinforces the inherent contradiction of neoliberal conservation where it claims to remedy the issues through the same processes that created them (Brockington et al., 2008; Klein, 2007; Büscher et al., 2012). The contradiction is outlined by Harvey (2005) who states that neoliberal policies work under the presumption that consumers have all the required information. Rather intuitively, Harvey (2005) points out that this is not the reality in almost every example of consumption. This links back to the spectacle of nature where selected representations are crafted to shape the desired the relationships, while obscuring parts that might challenge such outcomes.

There is also concern that businesses are able gain opportunities to leverage benefits but have little genuine regard for conservation outcomes (Kareiva, 2012). As Participant 3 states:

They're [the partners] not doing it because they think conservation is a good thing to do. Individually, they might think that. But as corporates they are making hard nose decisions about is it good for their brand. Is it going to benefit us [the company]?

This point follows the argument made by Büscher et al. (2012) that even where companies might think it's the "right thing to do" (Participant 3), the pursuit of profits will tend to outweigh, or out-muscle, the need for social and environmental measures in the end. This is derived from O'Connor's identification of the contradictions of capitalism.

The way that the combined power of capitalist production relations and productive forces self-destruct by impairing or destroying rather than reproducing the conditions necessary to their own reproduction. (O'Connor, 1998, p. 165 as cited in Büscher et al., 2012, p. 13) 
In response, Marvier and Kareiva (2014) acknowledge that businesses getting involved has considerable risks associated, highlighting that the actual success of this approach is one of them. As revealed in the case study, DOC conducts a robust discussion with all of their partners before formalising any relationship (Participants 1, 2, 5, 6 and 7). However, there are concerns that future shifts from these respective businesses may lead to these risks being realised and the partnership falling over (Participant 5). "There's risks around the partner not delivering. Or taking a stance that that's totally at odds with our values", which may come from "...a change of Chief Exec or something” (Participant 1). These tensions exhibit the balancing act the DOC has to perform complicated by the wide range or stakeholders and participants involved.

Furthermore, Harvey (2005) outlines that with the implementation of publicprivate partnerships, it is frequently the state that assumes most, if not all, of the risk. This is in contrast to the private sector party, which commonly stands to gain the most, specifically profit, from the partnerships. There are some indicators that the assertions made by Harvey are supported by the case study in the way which the participants responded to the questions on risk. A leading trend was that participants from DOC acknowledged and elaborated on the risks they had to manage. However, this was not reciprocated by the business partners (Participants 5, 6 and 7) to nearly the same extent, indicating that their assessment of the risks was much lower than that of the state departments.

Because of such strong competition for public attention, representations (as discussed in section 5.3.1) of the environment are created that highlight the favourable, and frequently investment-accessible, parts of conservation (Igoe et al., 2010). An outcome of creating appealing images of business involvement with conservation is the ability for them to "transcend capitalist contradictions" (Büscher et al., 2012, p. 17) avoiding such issues as ecological degradation or social equity consequences. However, where contradictions remain too strong or obvious to negate, the representations portray them to be manageable, or able to be overcome if such neoliberal policies are employed more comprehensively (Büscher et al., 2012). Büscher et al. (2012) argues that this is produced from "eliminating information" (p. 14) which may suggest that 
economic growth is linked to negative outcomes for the environment or social conditions.

Jones (2012) states these images are captured in temporal settings and detach the contextual location that produced them. As a result, they are able to obscure outcomes that can result from the circulation of such images. For instance, the partnership DOC keeps with Air New Zealand involves the promotion of the Great Walks in the conservation estate (McIntyre e al., 2001). Following the intention of the promotion, the visitor numbers to the walks have increased by $12.4 \%$ in the past year (Graham, 2016). This can lead to the erosion of the very attraction of that draws people to the walks, specifically the promise of experiencing pristine and empty nature (McIntyre et al., 2001). Furthermore, Graham (2016) adds that on that some of the more popular tracks, walkers from New Zealand are making up around only $25 \%$ of total users. This creates tensions on the private benefits that, for example Air New Zealand, can gain at the expense of New Zealanders and the free access to the conservation estate they are entitled to. As Dinica (2016) states, this demonstrates the balancing act that DOC has to carry out with the increasing tourism considerations alongside the challenge of a finding enough resources to manage and protect the conservation estate.

The long-term product of the commercial partnerships is that DOC's role may change over time. However, DOC has built up a strong and well-recognised brand, which has broadened the type of power it holds. Instead of exclusively government-legislated power (SSC, 1995), DOC has also created a department which companies want to be associated with. This power is grounded in DOC's brand and image which creates tensions around the consistent public scrutiny and ongoing challenges the national conservation estate faces (Participant 1). With DOC also employing the discourse that conservation is failing, the environmental degradation has the potential to undermine the Department's power entrenched in its brand. While there are some "great spots of success" (Participant 1), the overall trend is not a great reflection on the Department. Strengthened by the legislative authority, the sheer size of the estate and, compared to other conservation organisations, a large budget, DOC retains 
significant influence within the conservation domain. However, the promotion of neoliberal strategies that could lead to further environmental degradation may see the Department have to juggle conservation against consumption and the importance of its brand.

Following the notion that neoliberalisation is a process, the continued influence and adaption of neoliberalism has produced significant outcomes on the partnerships model (Larner \& Craig, 2005). The product is a distinct blend of features that are typically seen as mutually exclusive or incompatible. As Craig and Porter (2006) state, "the result is a strange new hybrid of... partnership and competitive contracts, inclusion and sharp discipline, free markets and community" (p. 219, emphasis in original). This hybrid approach was also seen as a blurring of the lines between community, the voluntary sector, business and government. This was done in way to generate more community and social capital in order to reduce socially unacceptable outcomes (Aimers \& Walker, 2016). Unfortunately, this also produced a series of unintended outcomes and oversights, from a naivety and oversimplification of the power imbalances found in the relationships, to a dysfunctional distribution of multilevel accountabilities (Aimers \& Walker, 2016). Larner and Butler (2005) further argue that the partnerships model has also increased the governmentalisation in the social sector. The authors highlight that the processes that filter out of the managing of the partnerships represent new and established political mechanisms used to govern such practices. Larner and Butler (2005) provide insight into these governance mechanisms highlighting that a range of techniques that help to maintain and form areas and subjects able to be controlled by governmental bodies. However, the partnerships model has also been applied within the social sector, which feeds back to produce significant implications and create new expectations on the government (Larner \& Butler, 2005). 


\subsection{Chapter summary}

This chapter identifies the attributes of neoliberalism represented in the commercial partnerships. Specifically, neoliberal conservation is prominently represented by the increasing commercialisation of the conservation as demonstrated with the encroachment of profit maximisation and competition. Commodification is identified through representations of the environment and conservation. The temporal and singular nature of these representation work to simultaneously promote certain aspects of the wider context, leading to the impression that neoliberal conservation can transcend inherent capitalist contradictions. Representations are used to demonstrate that the presence of humans and business in conservation, moving away from traditional presentations of human-free environments. However, these representations have been criticised for concealing the destructive consequences of such economic motivated strategies. Highlighting Büscher et al.'s (2012) argument, profit maximisation will frequently override the ability for conservation gains when both cannot be achieved completely. These concerns are sought be navigated by DOC by ensuring the conservation is always the winner in these relationships. The ability to further negotiate the undesirable features of neoliberalism, the use win-win strategies are explored in the next chapter. 


\section{Chapter Six - Presentations and perceptions}

\subsection{Introduction}

This next chapter addresses the proposition of win-win strategies which have made their way into conservation approaches. This chapter will initially outline how win-win strategies can be identified and how the use of 'success' is interpreted. The use of win-win strategies are showcased in the case study of the commercial partnerships. This chapter demonstrates how win-win strategies are used to sell business involvement in conservation to the public. It will then outline how win-win strategies are employed to sell the idea of getting involved with conservation to businesses. Following this, the contradictions of win-win strategies will be outlined.

\subsection{Win-win strategies}

Changing social and individual behaviour is now recognised to be an effective strategy to achieve conservation outcomes (Nilsson et al., 2016; Steg \& Vlek, 2009; Walker \& Redmond, 2015). As Thomas (2015) states, strategies that focus on the negative consequences of resource use can be good for raising awareness of particular issues. However, Thomas (2015) adds that solely providing information to the public has little effect in changing behaviours. Targeting people's attitudes and beliefs, values, social norms, and self-interest is now recognised to be a very effective way of achieving conservation goals (McDonald, Fielding, \& Louis, 2014; Thomas, 2015). Win-win strategies are being used to fulfil this course of action, which can cater to a wider range of attitudes, values and circumstances among individuals (Chaigneau \& Brown, 2016; Phelps, Friess, \& Webb, 2012). By generating a wide base of support, winwin strategies are intended to become established as common sense and social norms (McDonald et al, 2014). With such appealing advantages and producing a seemingly intuitive way forward, win-win strategies have been widely used. 
Providing a brief description of how the approaches work, Maddux (1995) states that win-win strategies are used to achieve positive outcomes, usually for parties involved who are seeking different outcomes. Maddux (1995) argues that successful strategies are achieved where the parties involved enter into negotiations to achieve the most desired result for all involved. This, as the author adds, indicates that process of win-win negotiations should not be based on strictly ethical values. Instead, win-win strategies are just "good business" (Maddux, 1995, p. 13). The end product for a respective party may not be the best immediate outcome as wanted, however, the result is still a win of some measure. An important point here is that when applied to conservation, it could mean that the best result may not be achievable.

The use of win-win strategies have become very prevalent in global conservation discourses. Chaigneau and Brown (2016) and McShane et al. (2011) argue that the attraction of win-win strategies is that, in keeping with neoliberal promises, they frequently claim to be able to achieve development goals alongside wider conservation goals. Under this premise, win-win strategies have proved to be an easy sell with NGOs, government authorities, conservation and community groups all willing to implement such schemes (Chaigneau \& Brown, 2016). A major selling point of using win-win rhetoric is that it implies the strategy proposed has considered and evaluated the environmental and developmental outcomes and consequences. This can lead to the appearance of a sustainable and ethical intervention (Chaigneau \& Brown, 2016; McShane et al., 2011). However, this is not always the case in reality.

The discourse of win-win strategies can be represented by DOC's commercial partnerships strategy and the wider economic objectives. For instance, Participant 1 states DOC's vision “is a partnership that results in a win-win for business and conservation". The explicit intention of creating and promoting win-win scenarios is also reinforced in Business: A Partnership Strategy. It states "by consciously positioning our nature as the foundation for our economic, cultural and social success, we present a win/win outcome for businesses and our nature" (DOC Partnership team, 2016, p. 4, emphasis in original). Win-win strategies are also found indirectly referred to through the presentation of 
benefits that can be simultaneously obtained. This is illustrated in the government report outlining projected areas where New Zealand can economically progress; the 2015 Business Growth Agenda; Building Natural Resources (MBIE, 2015). This report outlines that through investing in conservation, both DOC and the partners can receive value from it. It adds that the partnerships "demonstrate the symbiotic nature of conservation and business and how investment in conservation actively benefits business" (MBIE, 2015, p. 6). In further support of a win-win agenda, variations of the following quote are repeated throughout the chapter summary that the Business Growth Agenda is "focused on practical initiatives to improve land productivity and increase incomes while improving environmental outcomes" (MBIE, 2015, p. 6). However, win-win strategies can, and frequently do, fail to meet expectations in practice.

Win-win strategies have attracted strong criticism for not fulfilling its promises. As McShane et al. (2011) highlight, the amount of win-win initiatives that equally achieve the intended benefits for conservation as well as social development is very few. This is supported by Phelps et al. (2012) who state there is a growing recognition that conservation outcomes suffer, particularly where trade-off decision are required to made. Conversely, Benjaminsen and Svarstad (2010) argue that often where win-win strategies are implemented by powerful conservation players, such as NGOs or through government policy, the expected economic or development benefits often remain modest. In addition, where benefits are made, win-win strategies have been criticised for regularly distributing benefits to the more powerful players in society (Benjaminsen \& Svarstad, 2010). Parallel to the contentions made in section 2.2.3, these points of critique show the tensions within the complex and often misleading discourse surrounding new conservation.

Revealing further considerations of the presence of business in win-win strategies, McIntyre et al. (2001) argue that safeguarding community and NGOs may prove to be difficult in the face of business pressures. Phelps et al. (2012) state that a major component of win-win strategies is the acknowledgement that compromises will be needed to achieve the intended goals. However, the equity 
of these compromises is regularly hard to manage (Phelps et al., 2012). For example, where there is contention around a specific resource, the protection of conservation or community interests over economic pursuits could potentially be difficult to govern for a monitoring authority - in this case, DOC (Christensen, 2004; McIntyre et al., 2001). The product of such inequality is that community groups and NGOs face a growing pressure to compensate the economic focus. Participant 3 states "the community groups which you are loading with more and more responsibility on because you're [DOC] backing off stuff that is your statutory responsibility to do". This encapsulates Chaigneau and Brown's (2016) argument that employing such discourses shows a willingness to accept the underlying assumptions of win-win strategies - particularly that outcomes are equally distributed.

\subsubsection{Win-win strategies in the commercial partnerships}

The prospect of business increasing its involvement with conservation cannot simply be implemented without risking a public backlash. DOC have the challenge of navigating a strong historical tradition of the Aotearoa New Zealand conservation estate being managed by central government agencies (Dinica, 2016; Craig et al., 2013). As Büscher (2014) states, the act of 'selling' business involvement to the public is the major component of getting this approach up and running. To do this, an incentive or a 'win' must be identified. The intended broader 'win' is that more conservation work can be carried out. As Participant 2 explains, "so, our goal is to get more conservation done, so this [business involvement] will help us achieve that goal”. As illustrated in the 2016 Annual Report the use of the commercial partnerships is help fulfil DOC's intention of "connecting New Zealanders to conservation and its social, cultural, economic and environmental values and benefits" and "shifting our society towards taking personal responsibility for conservation and contributing towards it" (DOC, 2016a, p. 71). The realisation of wider conservation benefits represents the win that the commercial partners will be experienced by the New Zealand public. 
In alignment of broader conservation goals, DOC is also targeting wins that will assist the Department more directly. A significant part of what the Department gains from the commercial partnerships is extra funding and resources. As introduced by Participant 4, "I think it's trying to get resources to supplement its government resourcing, to do more". This is also acknowledged by Participant 1 representing DOC who states, "So, funding is one component of that [partnership]". Similarly, recognising that there are other components or reasons for the partnerships, Participant 7 states, "I think a consideration is that them [DOC] partnering with industry... [is that] it gives them some financial robustness potentially, or an element, or perception of more savvy and engaged with industry". Participant 6 adds "they get exposure to more of a corporate environment, and how corporates function and operate". Participant 6 continues, "I sense what they're trying to do is be more relevant, more approachable, more open, from this kind of closed away, hidden department". The attainment of resources and increased business acumen and presence the Department itself can increase its ability and capacity to carry conservation.

Correspondingly, the commercial partnerships will assist DOC to increase its public presentation, or brand. As Participant 7 states "I see the second part of that question [about what DOC gets out of the commercial partnerships] is resources and brand recognition". Participant 6 adds that the intention of DOC's alignment with big, well-known companies can help promote the DOC brand. "I think if they get some really good brands on board it kind of builds the DOC brand" (Participant 6). Participant 6 adds "they've got some really good brands that are reputable in New Zealand partnering with them. So, that kind of adds to that brand awareness and how people might think about the DOC brand... away just from the green and gold signs". As the 2016 Annual Report outlines, "This also offers DOC an opportunity to profile its own products and services" (DOC, 2016a, p. 72). By enhancing its brand recognition and awareness, DOC get the opportunity to expand their conservation plans.

DOC is also able to redeem the benefits of the partners influence and leadership in the national business sector. As explained by Participant 1, the process of having a "well-heeled" brand telling DOC's story is "priceless". This is notable 
through the perception that as a business leader in New Zealand, the respective partners can show other business that it's possible and desirable to develop conservation-minded approaches to business. This support gives a level of legitimacy to DOC who have managed to gain the support of large, successful and well-known businesses to align with their new approach. This is aimed at showing other business operators that conservation is worth getting involved with, and a general presentation to the public that New Zealand businesses are willing to support the cause (Craig et al., 2013).

To maximise the potential of this strategy, DOC is using large, easily recognised businesses (Participants 1 and 2). The partners are considered to be leaders in New Zealand business or within their respective sectors, Participant 1 states "so we've got a family of around eight very large partners". An important characteristic for the use of these businesses is the reach of their customer base and range of audiences between the partners for DOC to utilise. Furthermore, and specifically, from DOC's perspective, it provides “increased reach into the new audiences" (Participant 1, also noted by Participants 2 and 5). To achieve this, Büscher (2014) states that accompanying reports of win-win projects and discourse are intentionally positive with the aim of presenting the strategy as working-out-as-planned and producing the desired results. This is exemplified by Participant 2 in respect to the partnership with Air New Zealand who states "it's been successful, so therefore you talk about your successes". Furthermore, Christensen (2004) argues that commonly used strategies for projects described as win-win is that it's "not OK to report failures" (p. 35). As a result, Büscher (2014) adds that the promotion of the 'successes' then encourages more business involvement in conservation.

\subsubsection{How success is found and promoted}

Selling the idea of a new approach requires successful narratives and stories to be highlighted and circulated. However, Blaikie (2006) states "success, in turn, is defined in ways that will allow it to be found" (p. 1954). Blaikie builds on this by stating success is often crafted from neglecting complete, or parts of, 
interventions that do not support the push for similar methods. This allows what is considered a success to be changeable and simultaneously found in multiple places (Blaikie, 2006). However, in mainstream conservation, what is deemed successful typically falls back to a Western, scientific interpretation (Blaikie, 2006; Kellert, 1995; Willems-Braun, 1997). This is demonstrated in DOC's 2015 and 2016 annual reports where success is illustrated by performance indicators measured against nominated targets. The range of these indicators extends from pest control efforts to maintenance carried out on historical buildings to partnerships engaged (DOC, 2015; DOC 2016a). Additionally, the indicators are carefully selected to establish the direction of what the promoter desires conservation to involve and represent (Blaikie, 2006).

The accumulation of success stories, as argued by Büscher (2014), can act as capital. The strength of this capital then influences how discourses and ideas can hold their position across space and time (Büscher, 2014). By continuing to use and strengthen the discourse of business and conservation compatibility, it can then establish itself as common sense and a logical part for the nation's conservation strategy. This, simultaneously, deconstructs previous discourses that established conservation and certain type of business involvement as incompatible (Parker, 1992). The results can be new social norms through accepting the position of business in conservation targets and practices (McDonald et al., 2014). This connects to Participant 1's anticipation of a multiplier effect that will see the public expectation of these projects produce consequential action from New Zealand businesses. Chen et al. (2009) support this intention by stating that with more businesses contributing to conservation, businesses, individuals and groups that pose stronger reluctance follow suit to avoid negative publicity or reputation effects (Chen, et al., 2009).

With the association of business alongside nationally significant conservation projects run by DOC, business can become positioned as essential to the species success. As Fletcher (2010) notes, the lines between roles of the respective parties can become blurred. For instance, the position of business involvement can then become a condition for conservation success. This, following the work 
of Büscher et al. (2012), is deliberate in attempts to create a sense of compatibility between conservation and business. It also can position the partnerships as a key constituent in the success of conservation. Where the discourse of a wider approach to conservation is established, businesses become a central pillar of it. Partnerships are then normalised and seen as common sense alongside more-traditional forms of conservation, for instance; pest control efforts and species regeneration (Soulé \& Lease, 1995).

\subsection{Selling conservation to business}

The foundation of DOC's commercial partnership's model is having the ability to create support and buy-in from businesses. DOC has clearly had success in this area, evidenced by partners it has already got on board. While there are mix of reasons why these particular businesses have become involved with this strategy, to continue to expand business involvement with conservation and retain the current partners, incentives must be created. To produce wider business involvement, conservation strategies are starting to move away from traditional tactics, which emphasise ethical and altruistic motivations (Craig et al., 2013). While these motivations remain important and appeal to some areas of society, additional incentives must be available to encourage others.

Reflecting the benefits of brand alignment that DOC gains, this also represents a 'win' for those businesses involved in the partnerships. As Participant 6 states, “it's a really good synergy, people are responding really well to the brand alignment" This is where Participant 1's proposal of using the conservation estate for "business leverage" reappears (see section 4.2). As stated in the 2016 Annual report "DOC has a very strong brand" (DOC, 2016a, p. 72), consistently placing high in annual brand rankings. The report goes on to state "this good standing provides a connection with people, an incentive for businesses to partner with DOC and align their messaging" (p. 72). Partners are able to gain leverage off the association with DOC with the aim at improving their social standing and customer catchment. 
Along with the brand association, businesses are also able to use images to present positive links between business and conservation. Fitting alongside DOC's work is the use of the conservation estate itself and its respective features in imagery and promotion. DOC have presented these images and business association through the avenues that the Department has available, for example; websites, reports and press releases (DOC, 2016a). However, a number of the partners are also marketing their relationship with DOC and the conservation estate. As highlighted by Participant 3, many of DOC's commercial partners are associated with prominent features of the conservation estate. For instance; Air New Zealand regularly promote their conservation work alongside the Great Walks campaign and Meridian also link their work with the kākāpō in their respective advertising campaigns (Cumming, 2016; DOC, 2016a).

In conjunction with conservation, these businesses involved in the partnerships model are also able to align with socially positive causes. As Participant 1 states "that increasingly businesses are wanting to align themselves with a really good cause". This is demonstrated by Participant 6 who states "so a lot of brands are wanting to be seen as doing the right thing, or partnering with partners that are doing the right thing". However, linking back to the use of win-win strategies, while these partnerships have altruistic or socially constructive intentions linked to them, they are still geared to provide benefits to the company in some way. This is illustrated by Toyota New Zealand who have a criteria with how they decide to engage with for external relationships. As Participant 6 explains:

whenever we look at a partnership or a sponsorship... we look at a certain type of criteria. And generally, that criteria revolves around three things; does it benefit New Zealand, does it benefit Toyota, and does it benefit our customers and our staff and our dealers? And certainly, when you look at the DOC partnership it ticks all three of those boxes.

\subsection{Contradictions of win-win and consumption-based strategies}

Win-win strategies, like neoliberal conservation, produces a number of contradictions and tensions. In fact, many of the contradictions follow those of 
neoliberal contradiction as outlined in section 5.5. The popularity of win-win strategies, Christensen (2004) states, is due to the appealing intention to combine and pursue environmental conservation with social development. However, such policies are frequently based on "weak assumptions and little evidence" (Christensen, 2004, p. 38). Christensen (2004) argues that in many cases, evidence actually points to the opposite of what win-win strategies claim will happen. For example, there is little evidence directly showing that improving social conditions of communities that surround PAs produces additional conservation benefits. Contrastingly, Christensen (2004) claims that there is also evidence demonstrating that increasing incomes can accelerate environmental degradation. This follows the work of Redford and Sanderson (1992, as cited in Christensen, 2004) who states that win-win strategies are a "deadly combination of wishful thinking, quickly contrived policy poultices, and poor information" (p. 35). This produces the appearance that win-win strategies are successful, while in reality they are "rotting in the middle" from previously unforeseen outcomes.

McAfee (1999) highlights two challenges for relying on consumption-based solutions in win-win strategies. First, by encouraging the consumption of products in order to assist conservation efforts, this approach relies on technological solutions rather than changing social structure or behaviours. This does not align with the work of Nilsson et al. (2016), Steg and Vlek (2009) and Walker and Redmond (2015), who instead argue that behavioural change will be needed to make the biggest conservation gains. In addition, McAfee (1999) argues that win-win strategies will struggle to produce socially equitable outcome when assigning value to a product in locations where people may not be able to afford them, or do not see a monetary-based value on the product. These characteristics reinforce the Western-centric idea of how to remedy environmental issues. Furthermore, this may also exaggerate already pronounced social inequalities specifically where "biodiversity benefits" (p. 139) for health and wellbeing can only be obtained through monetary-based consumption (McAfee, 1999). 


\subsubsection{Perceptions of greenwashing}

This increase of business participation is matched with a growing public awareness that conservation funding is inadequate for the scale of the issues and the size of the estate that DOC oversees (McIntyre et al., 2001; Participants 3 and 4). The budget inadequacies are also supported by Dinica (2016) who states that this has directed the Department to scout new areas of accessing potential resources. As Participant 1 acknowledges, negotiating the risk that partnership team may end up looking like they are just "fundraising" for the Department, reinforced the need for DOC to foster wider community group backing and networks. Such negative public perceptions could heavily undermine the commercial partnership model and the wider social change it will, or has the potential to create (McDonald et al., 2014).

The use of imagery and representations to present business or economic relationships is often matched by calls of greenwashing, which was represented in the responses from Participants 3 and 4 (Büscher et al., 2012). Büscher et al. (2012) use the example of companies advertising how their efforts contribute to environmental issues while in fact concealing the destructive actions they also carry out. This is supported by Participant 3 representing Forest and Bird, who cites the historical relationship between DOC and Solid Energy as the prime example of greenwashing in attempts to obscure the significant environmental damage the company was carrying out. "Solid Energy was in there [working with DOC]... it was very much a greenwash, given its job is digging big great holes and putting out carbon into the atmosphere" (Participant 3). However, Participant 4 from the Environmental Defence Society adds:

It depends on your perspective on business. If you see business as partners, or potential partner in conservation and you see people stepping up to the plate, then you're going to see it as a positive thing. If you are deeply cynical about market forces and the motivation of business, then you're going to see it as cynical manipulation of public sentiment for greenwashed purposes.

This summary by Participant 4 neatly captures how different perspectives and attitudes in society can judge the involvement of business in conservation 
differently. This, subsequently illustrates the challenges that DOC face in fostering support for relationships between conservation and business.

From the assessment of Participant 1, the perception of greenwashing is one of the biggest risks that the Department faces. Interestingly, the partners interviewed did not reciprocate the same degree of concern as strongly as Participant 1, representing DOC. Using Toyota New Zealand as an example, the company's representative (Participant 6) acknowledged potential perceptions that aligning with conservation projects may bring. However, Participant (Participant 6) asserts that Toyota Zealand is careful not to be exploitive in their sponsorship and partnership relationships. In response to a question about greenwashing concern, Participant 6 replies:

No. And I think for us we're always very careful not to be seen to be exploitative. So, whether we're partnering with an organisation like DOC or whether we're partnering with an ambassador... we're very careful to not seen to be exploiting those organisations or individuals. So, I don't have any current reservations or risk, no.

Representing Fulton Hogan, Participant 7 also mirrored the lesser degree of concern of greenwashing:

There was no real consequence in terms of a down side for us, you know you've got to be cognisant as a company that you're not just doing it for the sake of greenwashing, and given our drivers are not around marketing and advertising, that wasn't a concern for us.

It is important to reaffirm here that Participant 7 outlined that Fulton Hogan see the commercial partnership as a social responsibility, or the "right thing to do" (Participant 7; see also 4.2.1). Correspondingly, there is notably a lesser amount of an online presence for the Fulton Hogan partnership than with some of the other partnerships. While this research did not investigate why this is the case, it may, intentionally or otherwise, work to avoid such criticisms of greenwashing.

The Department appears to recognise that there are many complexities and considerations for the win-win approach. As Participant 1 asserts in response to perceived risks about the approach, "I mean every day feels like it's quite 
risky". Supporting her colleague from DOC, Participant 2 elaborates "yeah there are risks, there are things we've got to be watchful for. So where do we fit, what is our role? DOC's role within the conservation landscape". However, Participant 2 rationalises, “I guess from our [DOC's] point of view, in terms of doing our business, basically the opportunity so outweighs the risk, that it's just a no brainer".

\subsection{Chapter summary}

To incentivise external participation in conservation and the public support for it, DOC have promoted a win-win strategy. This strategy follows the traditional method found in the literature of aligning social or economic development and conservation objectives. The fundamental characteristic of these strategies is that wins can be obtained in both areas, for business and conservation. The wins intended for DOC is the provision of funding and resources for conservation, as well as the exposure of conservation to new areas of society. Alternatively, the wins for business are realised through the alignment with DOC and conservation. Here, the partners are able to gain business leverage through the association with a publicly strong brand. This chapter also demonstrated how DOC finds success within the Western scientific paradigm through the presentation of key performance indicators. In doing so, these successes support the apparent compatibility of conservation and business. However, as Christensen (2004) critiques, there is little evidence to support that win-win strategies fulfil their potential. Further criticisms from some of the interview participants indicated that the perception of 'greenwashing' would be a prominent risk for those involved in the partnership. While, DOC acknowledged that there was some risk of this, these concerns were not reciprocated by the partner representatives. 


\section{Chapter Seven - Conclusion, limitations and further research}

\subsection{Conclusion of Findings}

This research thesis examined how the involvement of private business's in conservation is influencing the approaches, practices and appearance of the movement. Recent research has shown a shift away from strictly traditional protectionist and community based conservation approaches to include a broader range of alternative strategies. Specifically, the focus on increasing more social engagement and participation through the use of businesses has become popular. As demonstrated, this shift has subsequently also filtered into conservation discourse and efforts in Aotearoa New Zealand. The case study examining DOC's commercial partnership model revealed three central themes, with supporting discourses, related to the shift away from traditional conservation. This chapter will summarise these themes.

The first theme, examined in Chapter Four, was the need for a new, wider approach to environmental conservation. This theme corresponded to the first research question as to why DOC sought to increase private business involvement with conservation. Within this theme, there was a strong discourse of failure that current conservation efforts are unable to achieve their goals, both globally, and in Aotearoa New Zealand. In response, a more humanoriented approach has been promoted. By expanding the range of people exposed to conservation, and by increasing the relevance of conservation to them, a proliferation of social participation and engagement is intended to take place. This research demonstrated that a central method of this approach is to involve private businesses. The case study revealed that this is intended to enable better access to resources that respective business can provide, for example, additional funding and marketing expertise. In addition, some participants hoped that involving businesses and broadening participation in conservation would make conservation mainstream. As revealed by responses from interview participants, emphasis on DOC expanding commercial 
partnerships has been meet with both support and critique, with notable concerns on increased competition in the conservation domain between respective organisations. However, a transcending attitude amongst participants is that in order to counter perceived failure, conservation must become more of a priority for all parts of society in Aotearoa New Zealand.

Chapter Five addresses the second research question of how DOC has encouraged private business to become involved in conservation. This question also led to the examination of the impact of increasing business involvement, specifically focusing on the increasing influence of neoliberal ideology in the conservation domain. Through identifying neoliberal conservation and its application in New Zealand, the research located how neoliberal attributes are evident in DOC's commercial partnership model. Using Bakker (2007), Castree (2003) and McAfee's (1999) typology of neoliberal processes that shape the environment, I analysed the case study for processes of commodification, commercialisation, marketisation and privatisation. The research found that commercialisation, and in particular, commodification, are particularly evident within the partnerships. Commodification was demonstrated by the 'spectacle of nature' where specific representation of the environment and conservation are produced, distributed and consumed, as illustrated by the images used by the partners. In response to the third research question, such processes also indicate how the public's relationship with conservation might change with increased involvement of private businesses. This chapter additionally identified how neoliberalism is an evolving process that is influenced by historical and geographical contexts and frequently complimented by associated economic and social reregulation.

Chapter Six examines the theme of win-win strategies and the way the win-win discourse has been used to gain support for partnerships to navigate the critiques of neoliberalism. I examined how the explicit use of the strategy is found in the commercial partnership through the involvement of business in conservation and how it is sold to the public. Here, the deliberate success stories are used to show the compatibly between the two of domains, while additionally incentivising involvement in partnerships. The second central example of win- 
win strategies is how involvement in conservation is sold to businesses. In this strategy, businesses are able to use DOC's brand and the relationship that the public has with conservation to their own benefit. However, the main risk taken from the case study is how the new approach is subsequently perceived by the public. Linking to the final research question, DOC must negotiate the concerns of greenwashing and perceptions that the partnerships are primarily used for supplementing the Department's budget. There are also other risks identified in associated literature that indicate introducing neoliberal logics, such as commercialisation and commodification, can have the potential to contradict any conservation gains, or even accelerate environmental degradation.

\subsection{Limitations of the research}

The size of the case study presented the biggest limitation to the research. The case study was fundamentally restricted by the length of the Master's Thesis and the availability of time to move through the process of gathering data and analysing it.

While the number of commercial partners DOC has is limited, there were a number of partners who did not want to participate for a variety of reasons. This, evidently, further reduced the sample size of available participants. In addition, by going through DOC to get access to those partners that did participate, there was always a danger of the partners being deliberately selected that would show the approach in a positive light. Despite this limitation, the information that was gathered was detailed and rich, and the selection of two environmental NGOs to be interviewed as well, I could access critical perspectives.

\subsection{Further Research}

Future research could usefully monitor how the current commercial partnerships approach is progressing, and more specifically, examine whether partnerships do indeed broaden participation in conservation. Additionally, 
future research could examine the partnerships model from the perspective of the public and for example; who the public expects to maintain the conservation estate, who is allowed access the estate and how that is managed, or what level of conservation is desired.

With the commercial partnerships model continuing to be employed and the dynamic nature of private business interests, ongoing or revisiting research would be beneficial to show how the process is unfolding. In particular, more detailed information about the length of partnerships, reasons for withdrawing, and the effects of changing relationships could be examined.

Furthermore, neoliberalism in Aotearoa New Zealand conservation is becoming increasingly apparent, for example in large initiatives like Predator Free NZ. Investigating how these processes develop and what their implications mean for approaches to conservation will be important. In addition, there is scope to examine how conservation may be affected by broader social and political attitudes to neoliberal ideology and ultimately, if these approaches provide actual benefit to the conservation estate.

\subsection{Summary}

This research has examined the commercial partnerships model of conservation in Aotearoa New Zealand. By examining the strategy employed by DOC, this research was able to provide an analysis of why such approaches are being used. In addition, the research has provided a foundation for future study of DOC's contemporary conservation strategies by outlining the main components of it and the underlying practices used. With ongoing pressures and challenges facing the conservation estate, research examining the use of business involvement strategies is increasingly relevant. In addition, the potential expansion of business relationships with conservation in Aotearoa New Zealand further increases the application of this research in this area.

The unique nature of the commercial businesses working directly with a government agency restricted that relevancy of respective literature. This limitation in the research illustrated the gap in the literature that this thesis was 
concerned with. In order to carry out a critical analysis of the data, comparisons to literature with similar characteristic and situations were made. In addition, the limited volume of other related literature situated in the New Zealand context also restricted the level of analysis. Ideally, comparisons to other localised case studies would have benefited the robustness of the research. This research provides a platform in this respect for future research on business involvement in conservation.

Furthermore, this research contributes to an emerging body of international literature in two ways. Firstly, by studying an empirical example, and by adopting a constructivist approach, I identified key discourses and themes. These discourses and themes demonstrated how neoliberalisation in conservation takes place, namely through a powerful discourse of conservation failure contrasted by the promise of "win-win" in new conservation. As argued earlier, how neoliberalism takes form is context specific and so empirical case studies as essential for making sense of changing discourses in conservation. 


\section{Reference List}

Adams, R. T. (2015). Neoliberal Environmentality among Elites: Becoming "Responsible Producers" in Santarém, Brazil. Culture, Agriculture, Food and Environment, 37(2), 84-95. https://doi.org/10.1111/cuag.12055

Aimers, J., \& Walker, P. (2016). Can community development practice survive neoliberalism in Aotearoa New Zealand? Community Development Journal, 51(3), 332-349. https://doi.org/10.1093/cdj/bsv042

Auditor-General. (2012). Department of Conservation: Prioritising and partnering to manage biodiversity. Office of the Auditor-General New Zealand. Retrieved from http://oag.govt.nz/2012/biodiversity

Auerbach, N. (2006). The meanings of neoliberalism. In R. K. Roy, A. Denzau, \& T. D. Willett, Neoliberalism: national and regional experiments with global ideas. (pp. 26-50). London; New York: Routledge.

Ayres, L. (2008). Semi-Structured Interview. In L. Given, The SAGE Encyclopedia of Qualitative Research Methods. 2455 Teller Road, Thousand Oaks California 91320 United States: SAGE Publications, Inc. Retrieved from http://sk.sagepub.com/reference/research/n420.xml

Bakker, K. (2007). Neoliberalising Nature? Market environmentalism in water supply in England and Wales. In N. Heynen, J. McCarthy, S. Prudham, \& P. Robbins (Eds.), Neoliberal environments: false promises and unnatural consequences. (pp. 101-113). London; New York: Routledge.

Barriball, K. L. (1994). Collecting Data using a semi-structured interview: a discussion paper. Journal of Advanced Nursing, 19(2), 328.

https://doi.org/10.1111/j.1365-2648.1994.tb01088.x

Baxter, J. (2010). Qualitative Research Design and Rigour. In I. Hay, Qualitative research methods in human geography. (3rd ed.., pp. 81-97). Oxford; New York: Oxford University Press.

Baxter, P., \& Jack, S. (2008). Qualitative case study methodology: study design and implementation for novice researchers. The Qualitative Report, 13(4), 544-559.

Beehive.govt.nz. (2016, May 19). \$4.5 million DOC Community Fund opens. Retrieved July 8, 2016, from http://www.beehive.govt.nz/release/45-milliondoc-community-fund-opens

Benjaminsen, T., \& Svarstad, H. (2010). The Death of an Elephant: Conservation Discourses Versus Practices in Africa. Forum for Development Studies, 37(3), 385-408. https://doi.org/10.1080/08039410.2010.516406 
Berkes, F. (2004). Rethinking Community-Based Conservation, Repensando la Conservación Basada en Comunidades. Conservation Biology, 18(3), 621-630. https://doi.org/10.1111/j.1523-1739.2004.00077.x

Blaikie, P. (2006). Is Small Really Beautiful? Community-based Natural Resource Management in Malawi and Botswana. World Development, 34(11), 19421957. https://doi.org/10.1016/j.worlddev.2005.11.023

Borgmann, A. (1995). The reality of nature and nature of reality. In M. E. Soule \& G. Lease, Reinventing nature? Responses to postmodern deconstruction. (pp. 3164). Washington, D.C.: Island Press.

Bradshaw, M., \& Stratford, E. (2010). Qualitative Research Design and Rigour. In I. Hay, Qualitative research methods in human geography. (3rd ed.., pp. 69-80). Oxford; New York: Oxford University Press.

Braun, B., \& Wainwright, J. (2001). Nature, Poststructualism and Politics. In B. Braun \& N. Castree (Eds.), Social nature: theory, practice, and politics. (pp. 4163). Malden, MA: Blackwell Publishers.

Brechin, S. R., Murray, G., \& Mogelgaard, K. (2010). Conceptual and Practical Issues in Defining Protected Area Success: The Political, Social, and Ecological in an Organized World. Journal of Sustainable Forestry, 29(2-4), 362-389. https://doi.org/10.1080/10549810903550811

Brockington, D., \& Duffy, R. (2010). Capitalism and Conservation: The Production and Reproduction of Biodiversity Conservation. Antipode, 42(3), 469-484. https://doi.org/10.1111/j.1467-8330.2010.00760.x

Brockington, D., Duffy, R., \& Igoe, J. (2008). Nature unbound: conservation, capitalism and the future of protected areas. London; Sterling, VA: Earthscan.

Büscher, B. (2010). Derivative Nature: interrogating the value of conservation in "Boundless Southern Africa." Third World Quarterly, 31(2), 259-276. https://doi.org/10.1080/01436591003711983

Büscher, B. (2013). Nature 2.0. Geoforum, 44, 1-3. https://doi.org/10.1016/j.geoforum.2012.08.004

Büscher, B. (2014). Selling Success: Constructing Value in Conservation and Development. World Development, 57, 79-90.

Büscher, B., \& Dressler, W. (2012). Commodity conservation: The restructuring of community conservation in South Africa and the Philippines. Geoforum, 43(3), 367-376. https://doi.org/10.1016/j.geoforum.2010.06.010

Büscher, B., Dressler, W., \& Fletcher, R. (2014). Nature Inc.: environmental conservation in the neoliberal age. Tuczon, Arizona: University of Arizona Press. Retrieved from http://site.ebrary.com/lib/vuw/Doc?id=10857859 
Büscher, B., Sullivan, S., Neves, K., Igoe, J., \& Brockington, D. (2012). Towards a Synthesized Critique of Neoliberal Biodiversity Conservation. Capitalism Nature Socialism, 23(2), 4-30.

https://doi.org/10.1080/10455752.2012.674149

Butler, G., \& Richardson, S. (2015). Barriers to visiting South Africa's national parks in the post-apartheid era: black South African perspectives from Soweto. Journal of Sustainable Tourism, 23(1), 146-166. https://doi.org/10.1080/09669582.2014.940045

Cachelin, A., Rose, J., \& Paisley, K. (2015). Disrupting Neoliberal Discourse in Critical Sustainability Education: A Qualitative Analysis of Intentional Language Framing. Environmental Education Research, 21(8), 1127-1142. https://doi.org/10.1080/13504622.2014.974023

Castree, N. (2003). Commodifying what nature? Progress in Human Geography, 27(3), 273-297. https://doi.org/10.1191/0309132503ph428oa

Chaigneau, T., \& Brown, K. (2016). Challenging the win-win discourse on conservation and development: analyzing support for marine protected areas. Ecology and Society, 21(1). https://doi.org/10.5751/ES-08204-210136

Charmaz, K. (2011). Grounded theory methods in social justice research. In N. K. Denzin \& Y. S. Lincoln, The SAGE Handbook of Qualitative Research (4th ed., pp. 359-380). SAGE.

Charmaz, K. (2014). Constructing grounded theory. (2nd ed.). London: SAGE.

Cheek, J. (2008). Foucauldian Discourse Analysis. In L. Given, The SAGE Encyclopedia of Qualitative Research Methods. 2455 Teller Road, Thousand Oaks California 91320 United States: SAGE Publications, Inc. Retrieved from http://sk.sagepub.com/reference/research/n180.xml

Chen, X., Lupi, F., He, G., \& Liu, J. (2009). Linking social norms to efficient conservation investment in payments for ecosystem services. Proceedings of the National Academy of Sciences of the United States of America, 106(28), 11812-11817.

Chiswell, H. M., \& Wheeler, R. (2016). “As long as you're easy on the eye': reflecting on issues of positionality and researcher safety during farmer interviews. Area, 48(2), 229-235. https://doi.org/10.1111/area.12257

Christensen, J. (2004). Win win illusions. Conservation in Practice, 14(2), 34-41.

Collard, R.-C., Dempsey, J., \& Rowe, J. (2016). Re-regulating socioecologies under neoliberalism. In S. Springer, K. Birch, \& J. MacLeavy, The handbook of neoliberalism. (pp. 469-479). New York, NY: Routledge.

Connelly, L. M. (2016). Trustworthiness in qualitative research. MedSurg Nursing, 25(6), 435. 
Cope, D. G. (2014). Methods and meanings: credibility and trustworthiness of qualitative research, 41(1), 89.

Cousin, G. (2005). Case Study Research. Journal of Geography in Higher Education, 29(3), 421-427. https://doi.org/10.1080/03098260500290967

Craig, D., \& Porter, D. (2006). Development beyond neoliberalism? governance, poverty reduction and political economy. London: New York; Routledge. Retrieved from http://helicon.vuw.ac.nz/login?url=http://www.VUW.eblib.com/EBLWeb/pat ron/?target=patron\&extendedid=P_274413_0

Craig, J., Anderson, S., Clout, M., Creese, B., Mitchell, N., Ogden, J., ... Ussher, G. (2000). Conservations Issues in New Zealand. Annual Review of Ecology and Systematics, 31(1), 61-78. https://doi.org/10.1146/annurev.ecolsys.31.1.61

Craig, J., Moller, H., Norton, D., Saunders, D., \& Williams, M. (2013). Enhancing our heritage: Conservation for 21st Century New Zealanders: Ways forward from the Tahi group of concerned scientists. Pacific Conservation Biology, 19(3), 256-269.

Cumming, G. (2016, April 13). Under new management. NZ Herald (online). Retrieved April 13, 2016, from http://m.nzherald.co.nz/nz/news/article.cfm?c_id=1\&objectid=10882902

Czech, B. (2007). The Foundation of a New Conservation Movement: Professional Society Positions on Economic Growth. BioScience, 57(1), 6-7. https://doi.org/10.1641/B570102

Dinica, V. (2016). Tourism concessions in National Parks: neo-liberal governance experiments for a Conservation Economy in New Zealand. Journal of Sustainable Tourism, 0(0), 1-19. https://doi.org/10.1080/09669582.2015.1115512

Doak, D. F., Bakker, V. J., Goldstein, B. E., \& Hale, B. (2014). What is the future of conservation? Trends in Ecology \& Evolution, 29(2), 77-81. https://doi.org/10.1016/j.tree.2013.10.013

Department of Conservation (DOC). (2017). Māori: DOC's role. Retrieved March 5, 2017, from http://www.doc.govt.nz/about-us/our-partners/maori/

Department of Conservation (DOC). (2007). A short history of the Department of Conservation 1987-2007: Vision, role, overview and statutory mandate. Retrieved July 4, 2016, from http://www.doc.govt.nz/about-us/our-role/ourhistory/a-short-history-of-doc/

Department of Conservation (DOC). (2015). Annual Report for year ended 30 June 2015: Corporate publications. Wellington, New Zealand. Retrieved from http://www.doc.govt.nz/about-us/our-role/corporate-publications/annualreports-archive/annual-report-for-year-ended-30-june-2015/ 
Department of Conservation (DOC). (2016a). Annual Report for year ended 30 June 2016: Corporate publications. Wellington, New Zealand. Retrieved from http://www.doc.govt.nz/about-us/our-role/corporate-publications/annualreports-archive/annual-report-for-year-ended-30-june-2016/

Department of Conservation (DOC). (2014). Briefing to the incoming Minister of Conservation 2014. Retrieved April 6, 2016, from http://www.doc.govt.nz/about-us/our-role/corporate-publications/briefingsto-new-ministers-archive/briefing-to-the-incoming-minister-of-conservation2014/

Department of Conservation (DOC). (2016b). Our national partners: Our partners. Retrieved November 12, 2016, from http://www.doc.govt.nz/about-us/ourpartners/our-national-partners/

DOC Partnership team. (2016, August 2). Business: A Partnership Strategy. DOC Partnership team document.

Drakeford, M. (1997). The poverty of privatization: Poorest customers of the privatized gas, water and electricity industries. Critical Social Policy, 17(51), 115-132. https://doi.org/10.1177/026101839701705106

Dunlap, A., \& Fairhead, J. (2014). The Militarisation and Marketisation of Nature: An Alternative Lens to "Climate-Conflict." Geopolitics, 1-25. https://doi.org/10.1080/14650045.2014.964864

Dunn, K. (2010). Interviewing. In I. Hay, Qualitative research methods in human geography. (3rd ed., pp. 102-138). Oxford; New York: Oxford University Press.

Ek, A-C., Ideland, M., Jönsson, S., \& Malmberg, C. (2013). The tension between marketisation and academisation in higher education. Studies in Higher Education, 38(9), 1305-1318. https://doi.org/10.1080/03075079.2011.619656

Ellermann, A. (1998). Can discourse analysis enable reflective social work practice? Social Work Education, 17(1), 35-44. https://doi.org/10.1080/02615479811220041

Elman, C., Gerring, J., \& Mahoney, J. (2016). Case Study Research: Putting the Quant Into the Qual. Sociological Methods \& Research, 45(3), 375-391. https://doi.org/10.1177/0049124116644273

England, K., \& Ward, K. (2010). Theorizing Neoliberalism. In M. B. Steger \& R. K. Roy, Neoliberalism a very short introduction. (pp. 50-60). Oxford; New York: Oxford University Press. Retrieved from http://site.ebrary.com/lib/vuw/Doc?id=10362194

Escobar, A. (1996). Construction nature: Elements for a post-structuralist political ecology. Futures, 28(4), 325-343. 
Ewen, J. G., Adams, L., \& Renwick, R. (2013). New Zealand Species Recovery Groups and their role in evidence-based conservation. Journal of Applied Ecology, 50(2), 281-285. https://doi.org/10.1111/1365-2664.12062

Ferguson, J., \& Lohmann, L. (1994). The anti-politics machine: "development" and bureaucratic power in Lesotho. The Ecologist, 24(5), 176.

Fletcher, R. (2010). Neoliberal environmentality: Towards a poststructuralist political ecology of the conservation debate. Conservation and Society, 8(3), 171-181. https://doi.org/10.4103/0972-4923.73806

Fletcher, R. (2012). Using the Master's Tools? Neoliberal Conservation and the Evasion of Inequality. Development and Change, 43(1), 295-317. https://doi.org/10.1111/j.1467-7660.2011.01751.x

Fletcher, R. (2014). Taking the chocolate laxative: Why neoliberal conservation "falls forward". In W. Dressler, R. Fletcher, \& B. Büscher, Nature Inc.: environmental conservation in the neoliberal age. (pp. 87-107). Tuczon, Arizona: University of Arizona Press. Retrieved from http://site.ebrary.com/lib/vuw/Doc?id=10857859

Flick. (2007). Designing Qualitative Research. London, England, United Kingdom: SAGE Publications, Ltd. Retrieved from http://srmo.sagepub.com/view/designing-qualitative-research/SAGE.xml

Flowerdew, R. (2005). Fining previous work on the topic. In R. Flowerdew \& D. Martin, Methods in human geography: a guide for students doing a research project. (2nd ed.., pp. 48-56). Harlow, England; New York: Prentice Hall.

Fox, N. J. (2008). Induction. In L. Given, The SAGE Encyclopedia of Qualitative Research Methods. 2455 Teller Road, Thousand Oaks, California 91320, United States: SAGE Publications, Inc. Retrieved from http://sk.sagepub.com/reference/research/n212.xml

Freyfogle, E. T. (2006). Why conservation is failing and how it can regain ground. New Haven: Yale University Press. Retrieved from http://site.ebrary.com/lib/vuw/Doc?id=10167895

Galletta, A. (2013). Mastering the semi-structured interview and beyond from research design to analysis and publication. New York: New York University Press. Retrieved from http://helicon.vuw.ac.nz/login?url=http://www.jstor.org/stable/10.2307/j.ct t9qgh5x

Glaser, B. G., Strauss, A. L., \& Strutzel, E. (1968). The Discovery of Grounded Theory; Strategies for Qualitative Research. Nursing Research, 17(4), 364.

Gogus, D. A. (2012). Constructivist Learning. In P. D. N. M. Seel (Ed.), Encyclopedia of the Sciences of Learning (pp. 783-786). Springer US. https://doi.org/10.1007/978-1-4419-1428-6_142 
Graham, T. (2016, December 12). Should NZ's Great Walks be privately-run?

Retrieved January 9, 2017, from

http://www.radionz.co.nz/news/national/320211/should-nz's-great-walksbe-privately-run

Gudsell, K. (2016, May 30). DoC funding cut by \$40m - independent expert.

Retrieved January 10, 2017, from

http://www.radionz.co.nz/news/national/305139/doc-funding-cut-by-\$40mindependent-expert

Hajer, M. A. (1997). The Politics of Environmental Discourse. Ecological

Modernization and the Policy Process. Oxford: Oxford University Press.

Retrieved from

http://helicon.vuw.ac.nz/login?url=http://dx.doi.org/10.1093/019829333X.0 01.0001

Hammersley, M., \& Atkinson, P. (2007). Ethnography principles in practice. (3rd ed.). London; New York: Routledge. Retrieved from http://helicon.vuw.ac.nz/login?url=http://www.VUW.eblib.com/EBLWeb/pat ron/?target=patron\&extendedid=P_308687_0

Harris, P. (2001). Towards a critical post-structuralism. Social Work Education, 20(3), 335-350. https://doi.org/10.1080/02615470120057424

Harvey, D. (2005). A brief history of neoliberalism. Oxford; New York: Oxford University Press. Retrieved from http://site.ebrary.com/lib/vuw/Doc?id=10180656

Hershberg, R. M. (2014). Constructivism. In D. Coghlan \& M. Brydon-Miller, The SAGE Encyclopedia of Action Research. 1 Oliver's Yard, 55 City Road, London EC1Y 1SP, United Kingdom: SAGE Publications Ltd. Retrieved from http://srmo.sagepub.com/view/enyclopedia-of-action-research/n73.xml

Hodgson, D., \& Watkins, S. C. (1997). Feminists and neo-Malthusians: past and present alliances. Population and Development Review, 23(3), 469.

Igoe, J., Neves, K., \& Brockington, D. (2010). A spectacular eco-tour around the historic bloc: Theorising the convergence of biodiversity conservation and capitalist expansion. Antipode, 42(3), 486-512. https://doi.org/10.1111/j.1467-8330.2010.00761.x

Jones, C. (2012). Ecophilanthropy, Neoliberal Conservation, and the Transformation of Chilean Patagonia's Chacabuco Valley. Oceania, 82(3), 250-263. https://doi.org/10.1002/j.1834-4461.2012.tb00132.x

Jones, S. (2002). Social constructionism and the environment: through the quagmire. Global Environmental Change, 12(4), 247-251. https://doi.org/10.1016/S0959-3780(02)00062-6 
Kareiva, P. M. (2014). New Conservation: Setting the Record Straight and Finding Common Ground. Conservation Biology, 28(3), 634-636. https://doi.org/10.1111/cobi.12295

Kareiva, P. M. (2012). QnAs with Peter M. Kareiva. Proceedings of the National Academy of Sciences of the United States of America, 109(26), 10127. https://doi.org/10.1073/pnas.1207920109

Kareiva, P. M, \& Marvier, M. (2012). What Is Conservation Science? BioScience, 62(11), 962-969. https://doi.org/10.1525/bio.2012.62.11.5

Kellert, S. (1995). Concepts of Nature East and West. In M. E. Soule \& G. Lease, Reinventing nature? Responses to postmodern deconstruction. (pp. 103-121). Washington, D.C.: Island Press.

Khoja-Moolji, S. (2014). Constructionist and Poststructuralist Theories. In L. Ganong (eds.), M. Coleman, \& G. Golson (Eds.), The Social History of the American Family. SAGE publications. Retrieved from http://www.academia.edu/4209541/Constructionist_and_Poststructuralist_T heories

Kirby, K. R. (2014). "New Conservation" as a Moral Imperative. Conservation Biology, 28(3), 639-640. https://doi.org/10.1111/cobi.12294

Klooster, D. (2010). Standardizing sustainable development? The Forest Stewardship Council's plantation policy review process as neoliberal environmental governance. Geoforum, 41(1), 117-129. https://doi.org/10.1016/j.geoforum.2009.02.006

Krachler, N., \& Greer, I. (2015). When does marketisation lead to privatisation? Profit-making in English health services after the 2012 Health and Social Care Act. Social Science \& Medicine, 124, 215-223. https://doi.org/10.1016/j.socscimed.2014.11.045

Kurian, P., \& Munshi, D. (2012). Denial and Distancing in Discourses of Development: shadow of the "Third World" in New Zealand. Third World Quarterly, 33(6), 981-999. https://doi.org/10.1080/01436597.2012.681495

Lalasz, R., Kareiva, P. M., \& Marvier, M. (2011). Conservation in the Anthropocene Beyond Solitude and Fragility. Breakthrough Journal 2, 1-6.

Laker, J. A. (2016). What's a nice, straight, white guy doing in an essay like this?!!! Privilege, oppression and the binary politics of positionality. Social Alternatives, 35(3), 57-60.

Larner, W. (2000). Neo-liberalism: policy, ideology, governmentality. Studies in Political Economy, (63), 5-25. 
Larner, W., \& Butler, M. (2005). Governmentalities of Local Partnerships; The Rise of a "Partnering" State in New Zealand. Studies in Political Economy, (75), 79102.

Larner, W., \& Craig, D. (2005). After Neoliberalism? Community Activism and Local Partnerships in Aotearoa New Zealand. Antipode, 37(3), 402-424. https://doi.org/10.1111/j.0066-4812.2005.00504.x

Macnaghten, P., \& Urry, J. (1998). Contested natures (Vol. 54). London: Sage Publications. Retrieved from http://site.ebrary.com/lib/vuw/Doc?id=10566997

Maddux, R. B. (1995). Successful negotiation effective "win-win" strategies and tactics (3rd ed..). Menlo Park, Calif.: Crisp. Retrieved from http://site.ebrary.com/lib/vuw/Doc?id=10058864

Martínez Pérez, G., Mubanga, M., Aznar, C. T., \& Bagnol, B. (2015). Grounded Theory, 14(4). https://doi.org/10.1177/1609406915618324

Marvier, M. (2014). New Conservation Is True Conservation. Conservation Biology, 28(1), 1-3. https://doi.org/10.1111/cobi.12206

Marvier, M., \& Kareiva, P. (2014). The evidence and values underlying "new conservation." Trends in Ecology \& Evolution, 29(3), 131-132. https://doi.org/10.1016/j.tree.2014.01.005

Mauthner, N. S., \& Doucet, A. (2003). Reflexive Accounts and Accounts of Reflexivity in Qualitative Data Analysis. Sociology, 37(3), 413-431.

May, T. (2011). Social Research: issues, methods and process / Tim May. (4th ed..). Maidenhead, England: Open Unive rsity Press.

MBIE; New Zealand Government. (2015). Business Growth Agenda: 2015. Wellington, New Zealand Government. Retrieved November 15, 2016, from http://www.mbie.govt.nz/info-services/business/business-growthagenda/towards-2025

MBIE; New Zealand Government. (2014). The Business Growth Agenda: Future Direction 2014. Wellington, New Zealand Government. Retrieved November 15, 2016, from http://www.mbie.govt.nz/info-services/business/businessgrowth-agenda/pdf-and-imagelibrary/2014/Business\%20Growth\%20Agenda\%20Future\%20Direction\%20 2014.pdf

McAfee, K. (1999). Selling Nature to save It? Biodiversity and Green Developmentalism. Environment and Planning D: Society and Space, 17(2), 133-154. https://doi.org/10.1068/d170133 
McDonald, R. I., Fielding, K. S., \& Louis, W. R. (2014). Conflicting social norms and community conservation compliance. Journal for Nature Conservation, 22(3), 212-216. https://doi.org/10.1016/j.jnc.2013.11.005

McIntyre, N., Jenkins, J., \& Booth, K. (2001). Global Influences on Access: The Changing Face of Access to Public Conservation Lands in New Zealand. Journal of Sustainable Tourism, 9(5), 434-450. https://doi.org/10.1080/09669580108667413

McShane, T. O., Hirsch, P. D., Trung, T. C., Songorwa, A. N., Kinzig, A., Monteferri, B., ... O'Connor, S. (2011). Hard choices: Making trade-offs between biodiversity conservation and human well-being. Biological Conservation, 144(3), 966-972. https://doi.org/10.1016/j.biocon.2010.04.038

Meffe, G. K. (2001). Crisis in a Crisis Discipline. Conservation Biology, 15(2), 303304. https://doi.org/10.1046/j.1523-1739.2001.015002303.x

Merlingen, M. (2013). Is Poststructuralism a Useful IR Theory? What About Its Relationship to Historical Materialism? Retrieved from http://www.eir.info/2013/05/08/is-poststructuralism-a-useful-ir-theory-and-what-aboutits-relationship-to-historical-materialism/

Miller, B., Soulé, M. E., \& Terborgh, J. (2014). “New conservation” or surrender to development? Animal Conservation, 17(6), 509-515. https://doi.org/10.1111/acv.12127

Milner, H. R. (2007). Race, Culture, and Researcher Positionality: Working through Dangers Seen, Unseen, and Unforeseen. Educational Researcher, 36(7), 388400.

New Strategist Publications, Inc., \& New Strategist Publications. (2012). The Millennials Americans Born 1977 to 1994 (5th ed..). Ithaca: New Strategist Publications, Inc.

New Zealand Tourism Board. (2016, August 23). Welcome to New Zealand. The Official Site for New Zealand Tourism. Retrieved August 23, 2016, from http://www.newzealand.com/int/

Nilsson, D., Baxter, G., Butler, J. R. A., \& Mcalpine, C. A. (2016). How do communitybased conservation programs in developing countries change human behaviour? A realist synthesis. Biological Conservation, 200, 93-103. https://doi.org/10.1016/j.biocon.2016.05.020

Parker, I. (1992). Discourse dynamics: critical analysis for social and individual psychology. London; New York: Routledge.

Pearse, R. (2010). Making a market? Contestation and climate change. (Special Issue: Climate Challenge). Journal of Australian Political Economy, (66), 166. 
Perry, B. (2011). Case Study Research. In T. May (Ed.), Social Research: issues, methods and process. (4th ed.). Maidenhead, England: Open University Press.

Peters, M., Hamilton, D., \& Eames, C. (2015). Action on the ground: A review of community environmental groups' restoration objectives, activities and partnerships in New Zealand. New Zealand Journal of Ecology, 39(2), 179-189.

Petriello, M., \& Wallen, K. (2015). Integrative reflections on the new conservation science debate. Biodiversity and Conservation, 24(6), 1549-1551. https://doi.org/10.1007/s10531-015-0874-z

Phelan, S. (2014). Neoliberalism, media and the political. Basingstoke, Palgrave Macmillan. Retrieved from http://www.palgraveconnect.com/doifinder/10.1057/9781137308368

Phelps, J., Friess, D. A., \& Webb, E. L. (2012). Win-win REDD+ approaches belie carbon-biodiversity trade-offs. Biological Conservation, 154, 53-60. https://doi.org/10.1016/j.biocon.2011.12.031

Phillips, N., Lawrence, T. B., \& Hardy, C. (2004). Discourse and Institutions. The Academy of Management Review, 29(4), 635-652. https://doi.org/10.2307/20159075

Punch, K. (2005). Introduction to social research: quantitative and qualitative approaches. (2nd ed..). London; Thousand Oaks, California: SAGE.

Punch, K. (2014). Introduction to social research: quantitative \& qualitative approaches. (3rd ed.). Los Angeles, California: SAGE.

Rajvanshi, A. (2015). Biodiversity Offsets: Incentivizing Conservation for Managing Business Impacts. Emerging Economy Studies, 1(1), 22-36. https://doi.org/10.1177/2394901514565011

Redclift, M., \& Woodgate, G. (1998). From a Sociology of Nature to Environmental Sociology: Beyond Social Construction. Environmental Values, 7(1), 3-24.

Redford, K. H., \& Sanderson, S. E. (1992). The Brief, Barren Marriage of Biodiversity and Sustainability? Bulletin of the Ecological Society of America, 73(1), 36-39.

Roberts, P. (2003). Sustainable Development and Social Justice: Spatial Priorities and Mechanisms for Delivery. Sociological Inquiry, 73(2), 228-244. https://doi.org/10.1111/1475-682X.00054

Roxburgh, T. (2016, October 28). Doc boss suggests Great Walks charges. Retrieved January 25, 2017, from https://www.odt.co.nz/regions/queenstown/docboss-suggests-great-walks-charges

Russell, J. C., Innes, J. G., Brown, P. H., \& Byrom, A. E. (2015). Predator-Free New Zealand: Conservation Country. BioScience, 65(5), 520-525. https://doi.org/10.1093/biosci/biv012 
Segal, D., L., Coolidge, F., L., O’Riley, A., \& Heinz, B., A. (2006). Structured and semistructured interviews. Clinician's Handbook of Adult Behavioral Assessment, 121-144.

Shank, G. (2008). Deduction. In L. Given, The SAGE Encyclopedia of Qualitative Research Methods. 2455 Teller Road, Thousand Oaks, California 91320, United States: SAGE Publications, Inc. Retrieved from http://sk.sagepub.com/reference/research/n105.xml

Simon, M. (1996). Beyond inductive and deductive reasoning: The search for a sense of knowing. Educational Studies in Mathematics, 30(2), 197. https://doi.org/10.1007/BF00302630

Soulé, M. (2013). The “New Conservation." Conservation Biology, 27(5), 895-897. https://doi.org/10.1111/cobi.12147

Soulé, M. E. (1985). What Is Conservation Biology? BioScience, 35(11), 727-734. https://doi.org/10.2307/1310054

Soulé, M. E., \& Lease, G. (1995). Reinventing nature? Responses to postmodern deconstruction. Washington, D.C.: Island Press.

Springer, S., Birch, K., \& MacLeavy, J. (Eds.). (2016). The handbook of neoliberalism. New York, NY: Routledge.

State Services Commission. (1995). Review of the Department of Conservation. Retrieved from http://www.doc.govt.nz/Documents/aboutdoc/news/issues/Review-of-the-Department-of-Conservation-(Post-CaveCreek).pdf

State Services Commission, the Treasury, \& Department for the Prime Minister and Cabinet. (2014, July). Review of the Department of Conservation (DOC). Retrieved March 16, 2016, from http://www.ssc.govt.nz/sites/all/files/pifreview-doc-july14.PDF

Steg, L., \& Vlek, C. (2009). Encouraging pro-environmental behaviour: An integrative review and research agenda. Journal of Environmental Psychology, 29(3), 309-317. https://doi.org/10.1016/j.jenvp.2008.10.004

Stewart, D. L. (2010). Researcher as Instrument: Understanding "Shifting" Findings in Constructivist Research. Journal of Student Affairs Research and Practice, 47(3), 291-306. https://doi.org/10.2202/1949-6605.6130

Sullivan, S. (2013). Banking Nature? The Spectacular Financialisation of Environmental Conservation. (Report). Antipode, 45, 198.

Sultana, F. (2007). Reflexivity, Positionality and Participatory Ethics: Negotiating Fieldwork Dilemmas in International Research. ACME: An International EJournal for Critical Geographies, 6(3), 374-385. 
Taiepa, T., Lyver, P., Horsley, P., Davis, J., Bragg, M., \& Moller, H. (1997). Comanagement of New-Zealand's conservation estate by Maori and Pakeha: a review. Environmental Conservation, 24(3), 236-250. https://doi.org/10.1017/S0376892997000325

Tallis, H., \& Lubchenco, J. (2014). A call for inclusive conservation: Heather Tallis, Jane Lubchenco and 238 co-signatories petition for an end to the infighting that is stalling progress in protecting the planet. Nature, 515(7525), 27.

Thomas, R. (2015). Informing conservation practice through environmental education: The "What", "How" and "Why". In R. Roth \& N. Bennett (Eds.), The conservation social sciences: What? how? and why?: A report for conservation organizations, foundations, practitioners, agencies and researchers (pp. 40-43). Retrieved from https://dspace.library.uvic.ca//handle/1828/5786

Toyota New Zealand. (2016, March 1). New DOC/Toyota programme gets families into nature. Retrieved March 2, 2017, from https://www.toyota.co.nz/abouttoyota/toyota-news/2016/march/new-doctoyota-programme-gets-familiesinto-nature/

Valentine, G. (2005). Tell me about...: using interviews as a research methodology. In R. Flowerdew \& D. J. 18- Martin, Methods in human geography: a guide for students doing a research project. (2nd ed.., pp. 110-127). Harlow, England; New York: Prentice Hall.

Van Huijstee, M. M., Francken, M., \& Leroy, P. (2007). Partnerships for sustainable development: a review of current literature. Environmental Sciences, 4(2), 7589. https://doi.org/10.1080/15693430701526336

Vanner, C. (2015). Positionality at the Center: Constructing an Epistemological and Methodological Approach for a Western Feminist Doctoral Candidate Conducting Research in the Postcolonial. International Journal of Qualitative Methods, 14(4), 1-12. https://doi.org/10.1177/1609406915618094

Waitt, G. (2010). Doing Foucauldian Discourse Analysis- Revealing Social Realities. In I. Hay, Qualitative research methods in human geography. (3rd ed.., pp. 218240). Oxford; New York: Oxford University Press.

Walker, B., \& Redmond, J. (2015). Changing the Environmental Behaviour of Small Business Owners: The Business Case. Australian Journal of Environmental Education, 30(2), 254-268. https://doi.org/10.1017/aee.2015.6

West, P., Igoe, J., \& Brockington, D. (2006). Parks and Peoples: The Social Impact of Protected Areas. Annual Review of Anthropology, 35, 251.

Western, D. (2000). Conservation in a Human-Dominated World. Issues in Science and Technology, 16(3), 53-60. 
Willems-Braun, B. (1997). Buried epistemologies: the politics of nature in (post)colonial British Columbia. Annals of the Association of American Geographers, 87(1), 3-31.

Willems-Braun, Bruce. (1997). Buried Epistemologies: The Politics of Nature in (Post)colonial British Columbia. Annals of the Association of American Geographers, 87(1), 3-31. https://doi.org/10.1111/0004-5608.00039

Yanos, P. T., \& Hopper, K. (2008). On “False, Collusive Objectification": Becoming Attuned to Self-Censorship, Performance and Interviewer Biases in Qualitative Interviewing. International Journal of Social Research Methodology, 11(3), 229237. https://doi.org/10.1080/13645570701605756

Yin, R. K. (1994). Case study research: design and methods. (2nd edition, Vol. 5). Thousand Oaks, Calif: Sage Publications.

Young, R. (1981). Post-Structualism; An Introduction. In R. Young (Ed.), Untying the text: a post-structuralist reader. (pp. 1-28). Boston: Routledge \& Kegan Paul. 


\title{
Appendices
}

\section{Appendix 1 - Ethic's Forms}

\author{
TE WHARE WANANGA O TE OPOKO O TE IKA A MAUI \\ INFORMATION SHEET FOR PARTICIPANTS \\ A New Approach to Conservation \\ Ben Stantiall, Candidate for a Master's in Environmental Studies \\ School of Geography, Environment and Earth Sciences
}

Thank you for your interest in this project. Please read this information before deciding whether or not to take part. If you decide to participate, thank you. If you decide not to take part, thank you for considering my request.

\section{What is the aim of the project?}

This interview will be used as part of a case study to assess the ways in which partnerships between commercial enterprises and the Department of Conservation (DOC) are shaping conservation policy and future projects in New Zealand. This work will be aimed at identifying how these partnerships shape conservation and who participates in conservation as a result. I am inviting representatives of DOC, commercial enterprises engaged in partnerships with DOC and environmental NGOs to participate in this study.

This research has been approved by the Victoria University of Wellington Human Ethics Committee, application number: 0000022932.

\section{How can you help?}

If you agree to take part, I will interview you in an appropriate area of convenience which can be a public place (for example; a café). I will ask you questions about conservation and commercial partnerships and your organisation's perspective of it. The interview will take between 30 minutes to an hour. I will record the interview and transcribe it later.

You can stop the interview at any time, without giving a reason. You can withdraw from the study up to four weeks after the interview. If you withdraw, the information you provided will be destroyed and there will be no negative consequences for you or your organisation.

\section{What will happen to the information you give?}

You will not be named in the final report or any outputs from this research. However, in order to clearly discuss commercial partnerships for conservation, your organisation will be named (on the proviso that you have the authority to agree to this on behalf of the organisation). Your job title will not be used either - unless you expressly wish it to be. Only 
my supervisors and I will read the notes or transcript of the interview. The interview transcripts, summaries and any recordings will be kept securely and destroyed 3 years after the research ends.

All research participants will be treated with respect and the knowledge they share will be greatly appreciated.

\section{What will the project produce?}

The information from my research will be used in my Master's thesis. I may also use the results of my research for university conference presentations, academic reports and articles for the public through other media.

\section{If you accept this invitation, what are your rights as a research participant?}

You do not have to accept this invitation if you don't want to. If you do decide to participate, you have the right to:

- $\quad$ choose not to answer any or selected questions;

- $\quad$ ask for the recorder to be turned off at any time during the interview;

- $\quad$ withdraw from the study up until four weeks after your interview;

- $\quad$ ask any questions about the study at any time;

- $\quad$ receive a copy of your interview recording (if it is recorded);

- $\quad$ read over and comment on a transcript of your interview (once typed up);

- $\quad$ agree on another name for me to use rather than your real name (otherwise I will assign you a code name);

- $\quad$ be able to read any reports of this research by emailing the researcher to request a copy.

If you have any questions or problems, who can you contact?

If you have any questions, either now or in the future, please feel free to contact either:

Student:

Name: Ben Stantiall

benstantiall@hotmail.com

\section{Human Ethics Committee information}

\section{Supervisor:}

Name: Dr Amanda Thomas

Role: Lecturer

School: Geography, Environment and Earth

Sciences (SGEES)

Phone: 044636117

Amanda.Thomas@vuw.ac.nz

If you have any concerns about the ethical conduct of the research you may contact the Victoria University HEC Convener: Associate Professor Susan Corbett. Email susan.corbett@vuw.ac.nz or telephone+64-4-4635480.

Your participation is greatly appreciated.

Ben Stantiall 


\section{Totom VICTORIA \\ * $\because 20$ University of Wellington}

CONSENT TO INTERVIEW

\section{A New Approach to Conservation}

\section{Ben Stantiall, Candidate for a Master's in Environmental Studies School of Geography, Environment and Earth Sciences}

This consent form will be held for 3 years.

Researcher: Ben Stantiall (benstantiall@hotmail.com)

- I have read the Information Sheet and the project has been explained to me. My questions have been answered to my satisfaction. I understand that I can ask further questions at any time.

- I agree to take part in an audio recorded interview.

I understand that:

- I may withdraw from this study up to four weeks after the interview, and any information that I have provided will be destroyed.

- $\quad$ The information I have provided will be destroyed 3 years after the research is finished.

- I understand that the results will be used for a Masters thesis and a summary of the results may be used in academic reports and/or presented at conference presentations, in academic reports and articles for the public through other media.

- $\quad$ My name and job title will not be used in reports, but the name of my organisation will be.

- I would like a copy of the transcript of my interview:

Yes

I would like to receive a copy of the final thesis and have added my email address below.

Signature of participant:

Name of participant:

Date:

Contact details: 
Human Ethic's Approval Form

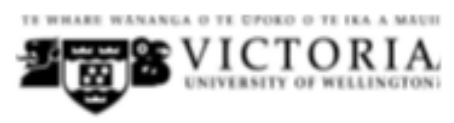

\section{MEMORANDUM}

\begin{tabular}{|l|l|}
\hline TO & Ben stantiall \\
\hline COPY TO & \\
\hline FROM & Dr Stephen Marshall, Acting Convener, Human Ethics Committee \\
\hline
\end{tabular}

\begin{tabular}{|l|l|}
\hline DATE & 27 May 2016 \\
\hline PAGES & 1 \\
\hline
\end{tabular}

\begin{tabular}{|l|l|}
\hline SUBJECT & $\begin{array}{l}\text { Ethics Approval: 22932 } \\
\text { DoC's corporate approach to conservation }\end{array}$ \\
\hline
\end{tabular}

Thank you for your application for ethical approval, which has now been considered by the Standing Committee of the Human Ethics Committee.

Your application has been approved from the above date and this approval continues until 8 March 2017. If your data collection is not completed by this date you should apply to the Human Ethics Committee for an extension to this approval.

Best wishes with the research

Stephen Marshall,

Acting Convener, Victoria University Human Ethics Committee 


\section{Appendix 2 - Question schedule}

\section{DOC's questions}

DOC has made recent shift to actively pursue partnerships with commercial business, why has DOC made this shift?

- $\quad$ Is there any reason why the term 'partnerships' is used?

Why has DOC made this shift?

- What does DOC get from this?

What do the commercial partners get from these partnerships?

Is there a criteria for who DOC works with?

- $\quad$ Or what type of businesses are sought?

"DoC has been focusing on changing how this (commercial) sector thinks about and interacts with conservation." $\wedge$

- Can you explain how DoC is changing how the commercial sector thinks and interacts with conservation?

Do you think the partnerships model will/has changed the public perception about how conservation is managed?

- $\quad$ Or how it is carried out?

Will it, or has it changed the public's perception on what conservation represents?

- $\quad$ Expected to have wider public interaction?

What has the response been from other conservation players towards the shift? (Iwi, NGO, community groups)

A concern raised by the SSC in a review of DOC is how to balance commercial business and conservation - do you think they are compatible? $\wedge \wedge$

- $\quad$ Are commercial partnerships universally the way forward or only in specific roles?

Is the involvement of the private sector intended to spread into other parts of DoC's work? (ie; education, advocacy)

Do you see future conservation having an increased partnerships presence?

- $\quad$ Bigger involvement of partnerships in DOCs work?

Are there risks involved with increasing commercial partnerships and reducing barriers ${ }^{\wedge}$ for further involvement in conservation?

- $\quad$ Impact on DOC'S duties (advocacy)

Do you think that there is consideration that commercial partnerships could impact (negatively or positively) certain groups accessing the conservation estate?

- $\quad$ Or being involved (community groups?)

${ }^{\wedge}$ pg 68 - Department of Conservation Annual Report for the year ended 30 June 2014

${ }^{\wedge}$ Pg 22 - A concern raised by the State Services Commission Review of the DoC (2014) 


\section{Partner Questions}

Can you please explain your organisation's relationship with DOC?

Why DOC specifically (as oppose to other NGOs or organisations)?

What do you (as an organisation) get out of partnering with DOC? - the main reason for this relationship?

What is appealing about the partnerships model as appose to more traditional sponsorship models?

Why do you think DOC is pursuing the partnerships model with commercial businesses?

- What does DOC get out of it?

- Is this about resources or brand recognition?

"DOC has been focusing on changing how... (the commercial) sector thinks about and interacts with conservation." ^

- $\quad$ From your perspective/experience, how has DOC gone about this?

Do you think the commercial partnerships approach will change the wider relationship of conservation and private business interaction? - have wider impacts?

- Increased business participation in general, or is it restricted to certain types of business (good brand recognition, big etc)?

Has commercial business involvement in conservation become more acceptable or desirable?

Will it, or has it changed the public's perception on what conservation represents? - Or how conservation is carried out?

- (Expectations around public interaction?)

A concern raised by the SSC in a review of DOC is how to balance commercial business and conservation ${ }^{\wedge}$

- Do you think there are limits to the compatibility between conservation and business?

Do you (as a company) have any reservations, or considered risks with your alignment with DOC?

Do you see any general risks involved with increasing commercial partnerships and reducing barriers for further involvement in conservation?

- $\quad$ Could it impact on DOC'S duties (advocacy)?

- Biodiversity outcomes?

Do you see any changes in access to certain groups in regards to the conservation estate? - Or being involved with?

- For example; community groups, tourists, local communities, NGOs, other businesses?

- $\quad$ (Positive or negative)

${ }^{\wedge} \mathrm{Pg} 42$ - Department of Conservation Annual Report for the year ended 30 June 2015

${ }^{\wedge} \wedge \mathrm{Pg} 22$ - A concern raised by the State Services Commission Review of the DoC (2014) 


\section{NGO Questions}

Can you please explain your organisation's relationship with DOC?

What are your views on DOC's commercial partnership model?

- Why do this think this model has developed?

What do you think DOC aims to get out of these commercial partnerships?

- Is this about brand recognition /or resources?

What do you think the official partners get out of this partnership?

- $\quad$ Image/brands promotion or a genuine desire to do good?

What are your views on commercial business involvement in conservation in general?

- $\quad$ Is this the way forward?

- Has this impacted your relationship with DoC?

Will DOC's commercial partnerships change the relationship of conservation and private business interaction?

What has been the response from other conservation players towards the shift? (ie; Iwi, NGO, community groups)

Do you think the partnerships model will/has changed the public perception about how conservation is managed?

- $\quad$ Or how it is carried out?

Will it, or has it changed the public's perception on what conservation represents?

- $\quad$ Expected to have wider public interaction?

A concern raised by the SSC in a review of DOC is how to balance commercial business and conservation - do you think they are compatible? ${ }^{\wedge}$

- $\quad$ Are commercial partnerships universally the way forward or only in specific roles?

Do you think the partnerships model will impact the level (or type) of conservation able to be carried out?

- Expand or reduce current efforts?

- Further specialise DOC's role?

Are there risks involved with increasing commercial partnerships and reducing barriers for further involvement in conservation?

- $\quad$ Impact on DOC'S duties (advocacy)

Do you think that there is consideration that commercial partnerships could impact (negatively or positively) certain groups accessing the conservation estate?

- $\quad$ Or being involved (community groups?)

${ }^{\wedge} \mathrm{Pg} 22$ - A concern raised by the State Services Commission Review of the DoC (2014) 